\title{
Die Untersuchungen der Biologischen Anstalt über die Okologie der Heringsbrut in der südlichen Nordsee
}

\author{
Von A. Bückmann \\ unter Benutzung der Vorarbeiten von W. Mielck und A. Koтthaus \\ Mit 22 Zahlentafeln und 7 Abbildungen.
}

II. Teil.

\section{Inhalt.}

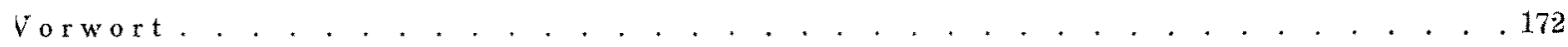

A. Das Auftreten der Heringslarven an den Küsten der inneren Deutschen

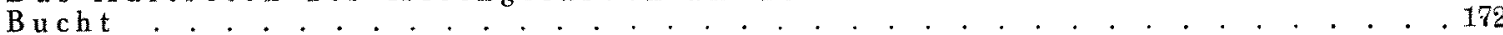

I. Das Material und seine Bearbeitung . . . . . . . . . . . . . . . . . . . . . . . . 172

II. Fangmengen und Tiefenverteilung . . . . . . . . . . . . . . . . . . . . . . . . . 173

a) Gebiet Helgoland . . . . . . . . . . . . . . . . . . . . . . . . . . . . . . . . 173

b) Die Mittelstationen . . . . . . . . . . . . . . . . . . . . . . . . . . . . . 175

c) Die Innenstationen . . . . . . . . . . . . . . . . . . . . . . . . . . . . . 176

III. Die Größenzusammenseţung der Heringslarven . . . . . . . . . . . . . . . . . . . . . 176

IV. Folgerungen aus den Untersuchungen über das Aufłreten der Heringslarven an den Küsten der inneren

Deutschen Bucht. . . . . . . . . . . . . . . . . . . . . . . . . . 178

V. Heringslarven und Jungheringe . . . . . . . . . . . . . . . . . . . . . . . . . 180

B. Untersuchungen über die Wirbelzahl der Heringslarven . . . . . . . . . . 181

I. Material und Methoden . . . . . . . . . . . . . . . . . . . . . . . . . 181

a) Das Material . . . . . . . . . . . . . . . . . . . . . . . . . . . . . . 181

b) Die Methoden der Untersuchungen . . . . . . . . . . . . . . . . . . . . . . . 181

II. Ober Vorkommen und Bedeutung der Komplexbildungen an der Wirbelsäule des Herings . . . . . 182

a) Frühere Untersuchungen . . . . . . . . . . . . . . . . . . . . . . . . . . . . . . . . . . 182

b) Die Häufigkeit der Komplexbildungen bei den Heringslarven. . . . . . . . . . . . . . 182

c) Die Formen der Komplexbildungen . . . . . . . . . . . . . . . . . . . . . . . 183

d) Die Längenverhältnisse der letgten Wirbel . . . . . . . . . . . . . . . . . . . . . 185

e) Beobachtungen über die Entwicklung des Schwanzskeletts . . . . . . . . . . . . . . . . . 186

f) Die Wirbelzahl der Heringslarven mit und ohne Komplexbildung . . . . . . . . . . . 191

III. Die Variation der Zahl der Wirbelkörper . . . . . . . . . . . . . . . . . . . . . 193

IV. Die Ursachen der Unterschiede in der Wirbelzabl der Jahrgänge . . . . . . . . . . . . . 200

.. Zus a mmenfassung . . . . . . . . . . . . . . . . . . . . . . . . . . . . . . . . . . . 202

Schriftenverzeichnis . . . . . . . . . . . . . . . . . . . . . . . . . . . . 205

Die Untersuchungen auf See wurden mit Mitteln der Deutschen wissenschaftlichen Kommission für Meeresforschung durchgeführt. 


\section{Vorwort.}

Der erste Teil dieser Untersuchungen (dieser Band S. 1-57) ist bereits April 1942 als Sonderdruck erschienen. Dort findet sich eine eingehende Darlegung der Bedeutung, die die Erforschung der Ökologie der Heringsbrut für Fragen der Fischereiwissenschaft beansprucht. Außerdem enthält der erste Teil die Befunde über die Lage und Bedeutung der Laichplätze, den Transport der Heringslarven durch die Meeresströmungen sowie die aktiven Wanderungen der Heringslarven auf der offenen See und endlich über das Wachstum der Heringslarven. Diese Ergebnisse dürfen hier als bekannt vorausgesetzt werden.

Der vorliegende zweite Teil beschäftigt sich mit den Untersuchungen an Heringslarven im inneren Teil der Deutschen Bucht, in dem Gebiet zwischen Helgoland, Eider-, Elbe-, Weser- und Jademündung.

Das Manuskript ist 1942 abgeschlossen-worden, konnte aber bisher nicht veröffentlicht werden. Leider ist das zugrundeliegende Material in Helgoland vernichtet worden. Es war daher nicht möglich, die Ergebnisse im Lichte neuerer Veröffentlichungen noch einmal zu überarbeiten oder modernere statistische Methoden für den Vergleich der verschiedenen Fänge heranzuziehen.

Diese Arbeiten wurden von Mrelck zu dem Zweck aufgenommen, das Eintreffen der Heringslarven an den Küsten vor ihrer Metamorphose zu verfolgen. Dies geschah etwa in der Erwartung, noch an der Küste die Wellen der Heringslarven unterscheiden zu können, die von den Hauptlaichgebieten der mittleren Nordsee und der flämischen Bucht herangeführt werden. Die Küstenuntersuchungen sind zum großen Teil ausgeführt worden, ehe die Seeuntersuchungen vorgenommen oder doch wenigstens im Zusammenhang ausgewertet waren. Es ist inzwischen festgestellt worden, daß schon auf der offenen See zu Ende des Winters die Rückführung der jeweils angetroffenen Bevölkerung von Heringslarven auf bestimmte Laichakte große Schwierigkeiten macht. - Diese Schwierigkeiten müssen im Küstengebiet, wo sich die Larven vor der Metamorphose ansammeln, noch wesentlich größer sein.

Weiter bestand zunächst die Hoffnung, die Scheidung der Larven nach ihrer Herkunft wenigstens bis zu einem gewissen Grad durchführen zu können durch die Untersuchung der Wirbelzahl der Larven. Es bestand die Wahrscheinlichkeit, daß die vom Kanal herstammenden Larven sich durch größere Wirbelzahl von denen der mittleren Nordsee unterscheiden würden, weil die durchschnittliche Wirbelzahl des Kanalherings etwas höher ist als die des Doggerbankherings. Es wird im folgenden gezeigt werden, daß sich auch diese Erwartung nicht erfüllt hat.

Schließlich wurde an die Untersuchung die Erwartung geknüpft, daß sie ein Urteil über die Menge der Heringslarven, die in den einzelnen Jahren die deutsche Küste erreichen. ermöglichen würde. Beziehungen zum Ausfall der Jahrgänge konnten sich hierbei ergeben und auch die Bedingungen, die zu einer mehr oder weniger reichen Larvenversorgung der inneren Deutschen Bucht führen, konnte man zu erkennen hoffen. Indessen erwies es sich als außerordentlich schwierig, in dem sehr vielgestaltigen, stark wechselnde Bedingungen aufweisenden Küstengebiet brauchbare Bestimmungen der Häufigkeit der Larven zu erhalten. Die Ergebnisse der Fänge waren sehr wechselnd - das mag mit der Neigung der älteren Larven zur Schwarmbildung zusammenhängen - , und bei einer ins einzelne gehenden Analyse des Materials gewinnt man daher nicht den Eindrud, daß man zu bestimmten und verläßlichen Schlußfolgerungen gelangen kann.

So ist das Ergebnis der Küstenuntersuchungen bescheiden und jedenfalls nicht das ursprünglich erwartete. Die Bearbeitung ist unter den verschiedensten Gesichtspunkten erfolgt, die sich aber zum größten Teil nicht als fruchtbar erwiesen. Unter diesen Umständen wird die Darstellung in möglichst zusammengefaßter Form gegeben. Es schien vor allem nicht angezeigt. die beschränkten und vielfach negativen Ergebnisse nun mit umfangreichem Tabellen- oder Abbildungsmaterial zu belegen.

Was die Wirbelzählungen betrifft, so hatten diese, wie erwähnt, zwar nicht das erwartete Ergebnis, doch gelangte der Verfasser zu andersartigen Befunden und Schlußfolgerungen, die doch zweifellos ein gewisses Interesse beanspruchen können.

\section{A. Das Auftreten der Heringslarven an den Küsten der inneren Deutschen Bucht.}

\section{Das Material und seine Bearbeitung.}

Ein erhebliches Material von Knüppelnetzfängen wurde in den Herbst- und Wintermonaten (November-April) der Jahre 1925-1934 in dem Gebiet zwischen Helgoland, der Jade, der Elbe- und Eidermündung gesammelt. Bei Helgoland wurden ziemlich regelmäßig 
an folgenden Orten Fänge gemacht: bei Leuchttonne Sellebrunnen, $2 \mathrm{Sm}$ W von Helgoland Leuchttonne, bei Tonne 1 in der Südeinfahrt und bei Tonne Düne $\mathrm{O} 2$. Nach der Elbmündung $\mathrm{zu}$ wurden meist die folgenden Stationen befischt: $7 \frac{1}{2} \mathrm{Sm}$ SO von Helgoland, bei den ElbeFeuerschiffen I, II, III und IV und querab von Neufeld oberhalb Cuxhaven. In Richtung auf die Jade lagen die Stationen: $8 \mathrm{Sm} \mathrm{S} 1 / 2 \mathrm{O}$ von Helgoland, bei Nordergründe Tonne, bei Außenjade Feuerschiff, bei Minsener Sand Feuerschiff, querab Schillig Hörn und bei Genius-Bank.

Die Untersuchungen bei Helgoland und in der Elbmündung wurden nach Möglichkeit zweimal im Monat ausgeführt, die Untersuchungen im Jadegebiet hin und wieder eingeschoben. In einzelnen Fällen wurden außer den oben angeführten noch einige zusätgliche Stationen $(z . B$. westlich von Helgoland und vor der Eidermündung) untersucht. Von 1930 an wurde an jedern Fangort, wie bereits erwähnt, ein Oberflächen- und ein Tiefenzug gemacht. Im ganzen liegen nicht weniger als 888 Fänge von je 10 Minuten Dauer vor, die insgesamt über 47000 Heringslarven enthalten. Diese Larven wurden zum allergrößten Teil gemessen. Nur bei einigen Massenfängen wurde die Zusammensetzung der gezählten Gesamtmenge nach der einer repräsentativen Probe errechnet.

Auf die einzelnen Jahre verteilen sich die Fänge und Ausbeuten wie folgt:

$\begin{array}{lccccccccc}\text { Winter: } & 1925 / 26 & 1926 / 27 & 1927 / 28 & 1928 / 29 & 1929 / 30 & 1930 / 31 & 1931 / 32 & 1932 / 33 & 1933 / 34 \\ \text { Fänge: } & 9 & 37 & 66 & 56 & 228 & 162 & 117 & 119 & 104 \\ \text { Larven: } & 129 & 784 & 2801 & 929 & 16561 & 14231 & 3963 & 6626 & 1356\end{array}$

Es fällt sogleich auf, daß nicht nur die Zahl, sondern auch die Ergiebigkeit der Fänge sehr verschieden sein muß. Doch kann man nicht ohne weiteres schließen, daß ein Winter larvenreich, ein anderer arm gewesen sei. Die Fänge sind örtlich und zeitlich nicht völlig gleichmäßig verteilt - das war schon des Wetters wegen für das kleine Dienstfahrzeug der Anstalt nicht möglich. - Bei der großen Verschiedenheit der Fangergebnisse nach Jahreszeit, Wassertiefe und Fangort aber kann ein Unterschied in der Materialansammlung großen Einfluß auf die errechnete durchschnittliche Ergiebigkeit der Fänge haben.

Um eine Zusammenfassung des Materials zu ermöglichen und dabei den Einfluß ungleichmäßiger Materialsammlung tunlichst auszuschalten, wurde es in folgender Weise aufbereitet:

Drei Teilgebiete des untersuchten Raumes wurden unterschieden, nämlich (a) das Gebiet um Helgoland einschließlich der in etwas größerem Abstand westlich davon liegenden Stationen, die in den ersten Wintern untersucht worden sind; (b) das Gebiet der Küste und der äußeren Teile des Wattenmeeres, hier "Mittelstationen" genannt; und (c) die "Innenstationen" im Bereich der eigentlichen Mündungen von Elbe und Jade: Oberhalb des Feuerschiffs Elbe IV und von Schillig Hörn. Diese Einteilung entspricht nicht allein den Unterschieden in den ökologischen Verhältnissen, sondern ergibt sich vor allem auch natürlich aus den Unterschieden in Dichte und Zusammensetgung der Larvenbevölkerung.

Zeitlich ist das Material, dem Plane der Sammlung entsprechend, in Halbmonatsabschnitte geteilt. Der Zeitpunkt der Probenentnahme liegt aber nicht immer in der Mitte des Halbmonats. So wurden z. B. die ersten Märzuntersuchungen 1931 am 15./16., die zweiten am 26. und 31. gemacht. 1934 erfolgten die zweiten Februar-Untersuchungen am 28. Februar und 1. März, die zweiten April-Untersuchungen endeten erst am 4. Mai. Teilweise wurden die beiden Serien eines Monats wieder zu Monatsmitteln zusammengefaßt.

Für jedes Gebiet und jeden Termin wurde der Fang je 30 Minuten berechnet, und zwar für die Winter 1925/26-1928/29 nur für die Tiefenfänge, für die Winter 1929/30 bis 1933/34 einmal für die Tiefenfänge und einmal für die Oberflächenfänge. Man kann daher für die ganze Beobachtungszeit die halbstündigen 'Tiefenfänge vergleichen, für die leţten fünf Winter außerdem die Stundenfänge (Oberfläche und Tiefe), und man kann die Ergiebigkeit der Oberflächen- und Tiefenfänge vergleichen. Zusammenfassungen und Mittelberechnungen beruhen auf den in der oben angegebenen Weise ermittelten 30-Minuten-Fängen.

Die Messungsreihen sind gleichfalls auf die 30-Minuten-Fänge umgerechnet und durch Zusammenfassung von je 2-mm-Intervallen geglättet worden.

\section{Fangmengen und Tiefenverteilung.}

a) Gebiet Helgoland.

Die Zahlentafel 1 gibt Auskunft über den Gehalt des 30-Minuten-Tiefenfanges im Durchschnitt für die Stationen des Gebietes Helgoland, und zwar für die ganzen Monate berechnet. 


$$
\begin{aligned}
& \text { Zahlentafel } 1 . \\
& \text { Gebiet Helgoland. } \\
& \text { Heringslarven in je } 30 \text { Minuten Knüppelnetzfang. } \\
& \text { (Tiefe) }
\end{aligned}
$$

\begin{tabular}{lccccccccc} 
Jahr: & $1925 / 26$ & $1926 / 27$ & $1927 / 28$ & $1928 / 29$ & $1929 / 30$ & $1930 / 31$ & $1931 / 32$ & $1939 / 33$ & $1933 / 34$ \\
\hline November & - & - & - & - & 0 & - & - & 0 & - \\
Dezember & - & - & 0 & - & $\overline{3}$ & 0 & 0 & - & - \\
Januar & 13 & 9 & 13 & 35 & 52 & 1 & 3 & 3 & 0 \\
Februar & 58 & 60 & 78 & 92 & 58 & 118 & 9 & 61 & 0 \\
März & - & 32 & 147 & 60 & 178 & 124 & 1 & 92 & 0 \\
April & - & - & 137 & - & 147 & 50 & - & - & 5 \\
\hline
\end{tabular}

In den Monaten November und Dezember sind, soweit Untersuchungen gemacht worden sind, keine Larven gefangen worden. Im Januar ist die Zahl zunächst gering, sie erreicht im Februar oder März ihren Höhepunkt und geht im April wieder zurück. Darin macht nur das Jahr 1933/34 eine Ausnahme, in dem vor April überhaupt keine Larven gefangen sind.

Das Gebiet Helgoland bildet einen Teil der Area, in dem die im ersten Teil dieser Arbeit unter $\mathrm{C}$ geschilderten weiträumigeren Seeuntersuchungen vorgenommen sind. Der Befund der Zahlentafel 1 stimmt völlig mit den Ergebnissen des Abschnitts $\mathrm{G}$ überein, nach dem die Deutsche Bucht, von einigen Vorläufern abgesehen, erst im Februar von Heringslarven erfüllt wird, die von der Doggerbank und der Flämischen Bucht herkommen, und daß die Abwanderung dieser Larven nach der Küste im April beginnt.

Sehr auffällig ist der Unterschied in der Ergiebigkeit der Fänge in den einzelnen Jahren: 1927/28 und 1929/30 weisen die höchsten Zahlen auf: 1930/31 bleibt etwas hinter diesen Jahren zurück, mehr noch 1928/29, 1932/33, 1926/27 und 1925/26. Vor allem sind aber die Fänge der Jahre 1931/32 und 1933/34 ausnehmend gering. rücksichtigt.

Dieser Befund wird auch in Zahlentafel 2 bestätigt, die die Oberflächenfänge mit be-

Zahlentafel 2

\begin{tabular}{|c|c|c|c|c|c|c|c|c|c|c|c|c|c|c|c|}
\hline & \multicolumn{3}{|c|}{$1929 / 30$} & \multicolumn{3}{|c|}{$1930 / 31$} & \multicolumn{3}{|c|}{$1931 / 32$} & \multicolumn{3}{|c|}{$1932 / 33$} & \multicolumn{3}{|c|}{$1933 / 34$} \\
\hline & 0. & $\mathrm{~T}$ & Zus. & O. & $\mathrm{T}$ & Zus. & O. & $\mathrm{T}$. & Zus. & O. & $\mathrm{T}$ & Zus. & O. & $\mathrm{T}$ & Zus. \\
\hline November & 0 & 0 & $\mathbf{0}$ & - & - & - & - & - & - & 0 & 0 & 0 & - & - & - \\
\hline Januar & 23 & 52 & 75 & 5 & 1 & 6 & 69 & 3 & 72 & 0 & 3 & 3 & 9 & 0 & 9 \\
\hline Februar & 427 & 68 & 495 & 47 & 114 & 161 & 33 & 9 & 42 & 6 & 61 & 67 & 0 & 0 & 0 \\
\hline März & 397 & 112 & 509 & 415 & 124 & 539 & 16 & 2 & 18 & 1 & 92 & 93 & 1 & 0 & 1 \\
\hline April & 31 & 147 & 178 & 32 & 50 & 82 & - & - & - & - & - & - & 1 & 5 & 6 \\
\hline
\end{tabular}

Gebiet Helgoland.

Heringslarven in je einstündigen Knüppelnetzfängen.

(Oberfläche und Tiefe)

Die Tafel zeigt ferner, daß die Oberllächenfänge im Durchschnitt erheblich reicher sind als die Tiefenfänge. Jene enthielten mehr als doppelt soviel Larven wie diese. Allerdings gibt es eine ganze Reihe von Fällen, in denen die Tiefenfänge größer sind ( 8 von den 17 positiven Eintragungen der Tafel), aber in diesen Fällen ist dann die absolute Fangmenge nicht groß. Bei den großen Fängen war immer die Oberfläche reicher.

Eine Erklärungsmöglichkeit sowohl für diese Verhältnisse wie für die großen Unterschiede der Larvenmenge in den einzelnen Jahren liegt nahe und muß auf ihre Stichhaltigkeit geprüft werden.

Nach ZoRell wechselt die Lage der Konvergenzlinie zwischen dem von W und NW herandringenden Nordseewasser und dem durch den Ausfluß der Elbe im Salzgehalt herabgesetzten Küstenwasser in der Deutschen Bucht. Helgoland kann im Bereich des Nordseewassers liegen und hat dann mehr oder weniger hohe Salzgehalte von der Oberfläche bis zum Boden. Es kann aber auch im Bereich der Konvergenz liegen. Dann ist eine Deckschicht schwachsalzigen Wassers über einer stärkersalzigen Tiefenschicht entwickelt. Da nun die Heringslarven von See her herankommen und mindestens erst sekundär im Küstenwasser erscheinen, so wäre zu vermuten, daß in dem homohalinen Nordseewasser die großen Oberflächenfänge gemacht worden seien, während bei Schichtung die Oberflächenfänge im salzarmen Küstenwasser geringer wären als in der Tiefe. Zugleich wäre bei hohem Salzgehalt in der ganzen Wassersäule, insonderheit aber bei starkem Einfluß atlantischen Wassers, wie er 1930 herrschte, die Bedingung für be- 
sonders große Larvenfänge gegeben. Die Prüfung zeigt indessen, daß diese Vermutung sich nicht bestätigt. In Zahlentafel 3 sind die von GoEDECKE (1939 a) graphisch dargestellten Monatsmittel des Oberflächensalzgehalts von Helgoland Reede mit der Ergiebigkeit der halbstündigen Tiefenfänge verglichen. Man sieht, daß keine Kovariation besteht: Dem recht hohen Salzgehalt der Jahre 1933 und 1934 stehen ausnehmend kleine Larvenfänge gegenüber. Bemerkt werden muß noch, daß die angegebenen Oberflächensalzgehalte, wie ein Vergleich mit den Tiefenbeobachtungen zeigen würde, die hydrographischen Verhältnisse des Gebiets recht gut kennzeichnen.

Zahlentafel 3 .

Monatsmittel des Salzgehalts

des Oberflächenwassers von Helgoland Reedeund Ergiebigkeit der Larvenfänge im Gebiet Helgoland.

\begin{tabular}{|c|c|c|c|c|c|c|c|c|c|c|}
\hline \multirow[t]{2}{*}{ Monat } & \multicolumn{2}{|c|}{ Dezember } & \multicolumn{2}{|c|}{ Januar } & \multicolumn{2}{|c|}{ Februar } & \multicolumn{2}{|c|}{ März } & \multicolumn{2}{|c|}{ April } \\
\hline & $S \%$ & Stück & $S \%$ & Stück & $\mathrm{S} \%$ & Stück & $\mathrm{S} \%$ & Stück & $S \%$ & Stück \\
\hline $1926 / 27$ & - & - & 31.9 & 9 & 32.8 & 60 & 32.8 & 32 & 31.2 & - \\
\hline $1927 / 28$ & 33.4 & 0 & - & 13 & - & 78 & - & 147 & 33.6 & 137 \\
\hline $1928 / 29$ & 32.2 & - & 32.7 & 35 & 一 & 92 & 33.5 & 60 & 31.3 & - \\
\hline $1929 / 30$ & 33.4 & - & 33.5 & 52 & 33.3 & 68 & 33.8 & 178 & 33.9 & 147 \\
\hline $193 n / 31$ & 32.6 & 0 & 32.1 & 1 & 32.3 & 114 & 31.4 & 124 & 31.0 & 50 \\
\hline $1931 / 32$ & 31.8 & 0 & 32.1 & 3 & 30.6 & 9 & 31.5 & 1 & 32.4 & 一 \\
\hline $1932 / 33$ & 33.3 & - & 33.6 & 3 & 32.9 & 61 & 33.3 & 92 & 31.0 & - \\
\hline $1933 / 34$ & 33.0 & - & 33.3 & 0 & 32.6 & 0 & 32.8 & 0 & 33.4 & 5 \\
\hline
\end{tabular}

Auch findet sich bei genauer Analyse der einzelnen Beobachtungen keine Beziehung zwischen dem Auftreten oder Fehlen von Schichtung und der Tiefenverteilung der Heringslarven. An solchen Tagen, an denen keine Schichtung des Wassers an den Helgoländer Stationen zu beobachten war und die ganze Wassersäule einen mehr oder weniger hohen Salzgehait hatte, waren in 6 Fällen die Oberflächenfänge größer als die Tiefenfänge (1116:383 Stück); $11 \mathrm{mal}$ waren die Tiefenfänge größer $(102: 551$ Stück). An Tagen mit ausgesprochener Schichtung und relativ salzarmem Oberflächenwasser waren $7 \mathrm{mal}$ die Oberflächenfänge größer (2386 : 315 Stück) und 8mal die Tiefenfänge (119:369 Stück). Durch tageszeitliche Vertikalwanderungen der Larven können diese Verschiedenheiten auch nicht bedingt sein. Die Fänge sind fast alle bei Tageslicht gemacht worden. Auch ein jahreszeitlicher Unterschied in dieser Beziehung ist nicht zu erkennen. Man kann nur das folgende feststellen: Im Gebiet von Helgoland neigen die Heringslarven dazu, die Oberflächenschichten zu bevorzugen. Besonders tun sie dies, wenn sie in dichten Schwärmen auftreten.

b) Die Mittelstationen.

Das gleiche gilt, wie Zahlentafel 4 zeigt, in verstärktem Maße von den Mittelstationen. Die in der Tafel verzeichneten Durchschnittswerte sind - mit Ausnahme von Januar 1934, wo nur eine Larve im Stundenfang war, sämtlich für die Oberflächenfänge viel höher.

Zahlentafel 4 .

Mittelstationen.

Heringslarven in je 30 Minuten Knüppelnetzfang (Tiefe).

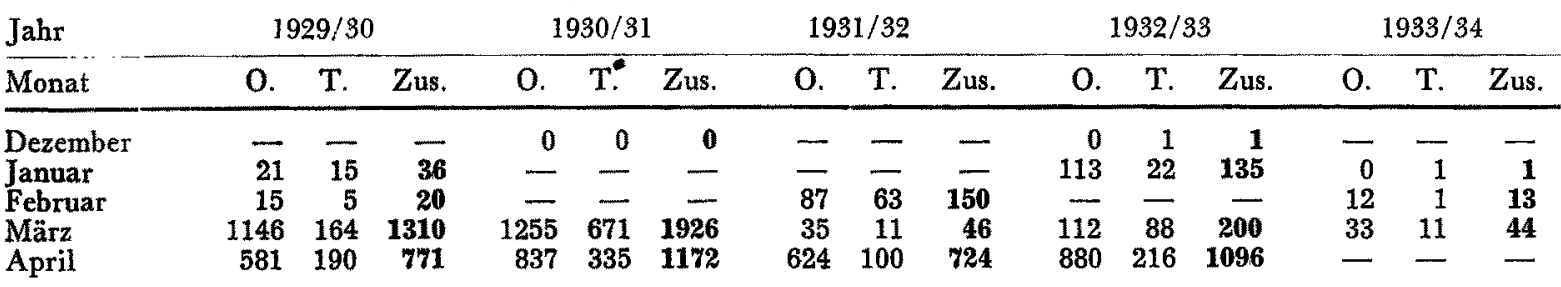

Zahlentafel 5 .

Mittelstationen.

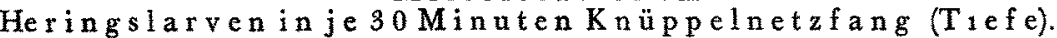

\begin{tabular}{|c|c|c|c|c|c|c|c|c|c|}
\hline Jahr & $1925 / 26$ & $1926 / 27$ & $1927 / 28$ & $1928 / 29$ & $1929 / 30$ & $1930 / 31$ & $1931 / 32$ & $1932 / 33$ & $1933 / 34$ \\
\hline November & 一 & - & - & 4 & - & - & 一 & 1 & - \\
\hline Dezember & - & - & - & - & - & 0 & - & - & - \\
\hline Januar & - & - & - & 52 & 15 & - & - & 22 & 1 \\
\hline Februar & 37 & - & 286 & 8 & 5 & - & 63 & - & 1 \\
\hline März & - & 61 & 220 & - & 164 & 671 & 11 & 88 & 11 \\
\hline April & - & - & 50 & 153 & 190 & 335 & 100 & 216 & - \\
\hline
\end{tabular}


Das Material umfaßt allerdings auch Einzelfänge, bei denen der Tiefenfang ergiebiger war. Insbesondere war das in der Nähe von Feuerschiff Elbe I am Südrand der Stromrinne zumeist der Fall. (Fänge bei Bake Scharhörn Nord.) Am Nordrand der Stromrinne dagegen, bei Groß-Vogelsand, waren zumeist die Oberflächenfänge größer. Da nun das ablaufende, salzärmere „Oberwasser" sich vornehmlich am Nordrand hält, so bedeutet das gleichzeitig, daß in den 9 Fällen, in denen die Oberflächenfänge größer waren, der Salzgehalt der Oberfläche geringer war als in den 14 Fällen, wo die Tiefenfänge größer waren. Weiter oberhalb, bei den Feuerschiffen II und III, sind die Oberflächenfänge dann fast ausnahmslos reicher als die Tiefenfänge. Die Larven meiden hiernach das salzarme Wasser nicht, sondern suchen es auf und sammeln sich darin an. Infolgedessen ist bei Elbe I das salzarme Oberwasser reicher an Larven als das mit der Flut aufsteigende salzigere Wasser.

Die Zahlentafeln 4 und 5 (diese für die Tiefenfänge seit 1926) zeigen, daß schon im Spätherbst einzelne Larven im Bereich der Mittelstationen auftreten können. Für den November 1928 war dies schon im ersten Teil dieser Arbeit erwähnt worden. Auch 1932 wurde eine Larve gefangen, nicht aber im Dezember 19.30. Weiterhin sind die Fänge im Januar und im Februar noch mäßig. (Nur im Februar 1928 ist eine für den Tiefenfang sehr große Fangmenge zu verzeichnen.) Der Höhepunkt wird mit Massenfängen im März (1930, 1931) oder im April (1932, 1933) erreicht.

Versucht man, sich ein Bild von der Häufigkeit der Larven in den einzelnen Jahren zu machen, so fällt besonders auf, daß die Winter 1927/28, 1929/30 und 1930/31 sich ebenso wie bei Helgoland als larvenreich erweisen. Allerdings ist 1930/31 hier unstreitig das reichste Jahr, während es bei Helgoland gegen 1929/30 zurückstand. - In den Jahren 1931/32 und 1932/33 sind zwar im April auch große Fänge gemacht worđen, doch gleichen diese die geringere Zahl im März nicht aus. 1933/34 ist wiederum bei weitem das ärmste Jahr.

\section{c) Die Innenstationen.}

Auf den Innenstationen sind, wie Zahlentafel 6 ausweist, die Tiefenfänge im Durchschnitt größer als die Oberflächenfänge. Bei einer großen Zahl von Einzelfängen aber ist es anders. Es kommen hier Heringslarven auch in Wasser von weniger als $10 \%$ Salzgehalt vor. Die Heringslarven ertragen also ohne weiteres Brackwasser und meiden es nicht. Doch kann bei Ebbe das an der Oberfläche ablaufende Flußwasser natürlich zunächst keine Larven mit sich führen, und dies dürfte die durchschnittlich geringere Ergiebigkeit der Oberflächenfänge bedingen.

In den Herbstmonaten sind fast keine Fänge in diesem Gebiet gemacht worden. Zwei Tiefenfänge im November 1928 (Jade) waren ergebnislos. Erst im März und April werden die Fangmengen auf den Innenstationen groß und erreichen dann mehrere 1000 Stück je Stunde. Die höchste Zahl - 5211 - ist für den April des Jahres 1933 verzeichnet, das sich auf den Mittelstationen und bei Helgoland nur als mäßig reich erwies. Allerdings beruht diese Zahl auf einer einzigen Station. Die Ergiebigkeit der Fänge im Flußgebiet kann sehr schnell wechseln, weil die Larven hier mit Herannahen der Metamorphose zur Schwarmbildung übergehen. Man darf daher wohl auf die Unterschiede zwischen den einzelnen Jahren, die die Zahlentafel 6 erkennen läßt, kein großes Gewicht legen. Allerdings ist 1934 auch hier larvenarm. - Aus den Jahren vor 1930 liegen nur vereinzelte Angaben vor, die hier ohne Interesse sind.

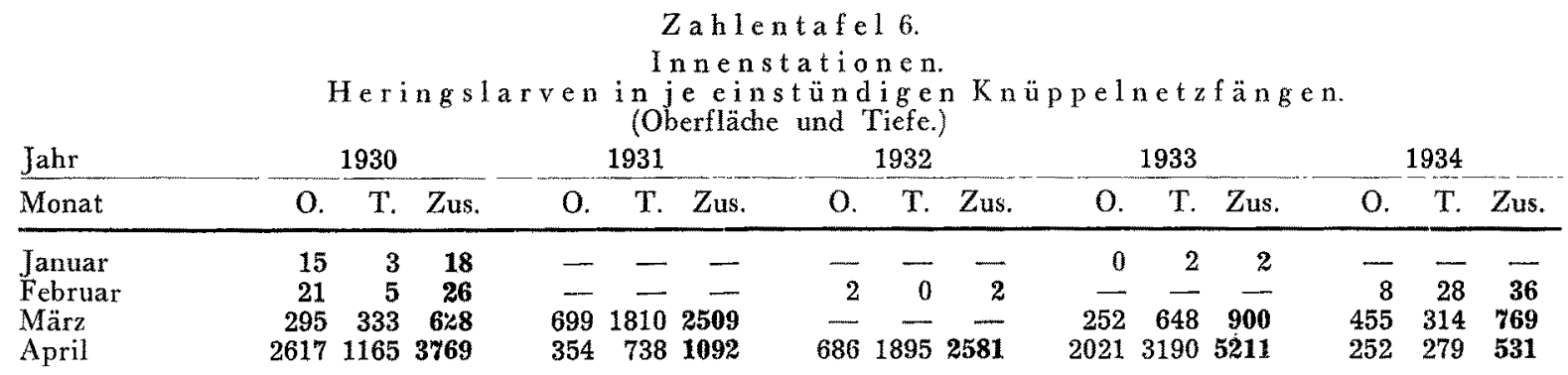

\section{Die Größenzusammensetzung der Heringslarven.}

Die Untersuchung der Größenzusammensetjung wurde vornehmlich mit dem Ziele vorgenommen, das Wachstum der Heringslarven in den letgten Monaten vor der Metamorphose näher zu verfolgen und zu prüfen, in welchem Mengenverhältnis die bei den Seeuntersuchungen 
unterschiedenen Gruppen der Doggerbank- und Downslarven in den einzelnen Jahren an der deutschen Küste erscheinen. Es wurde schon darauf hingewiesen, daß dies sich als unmöglich erweist.

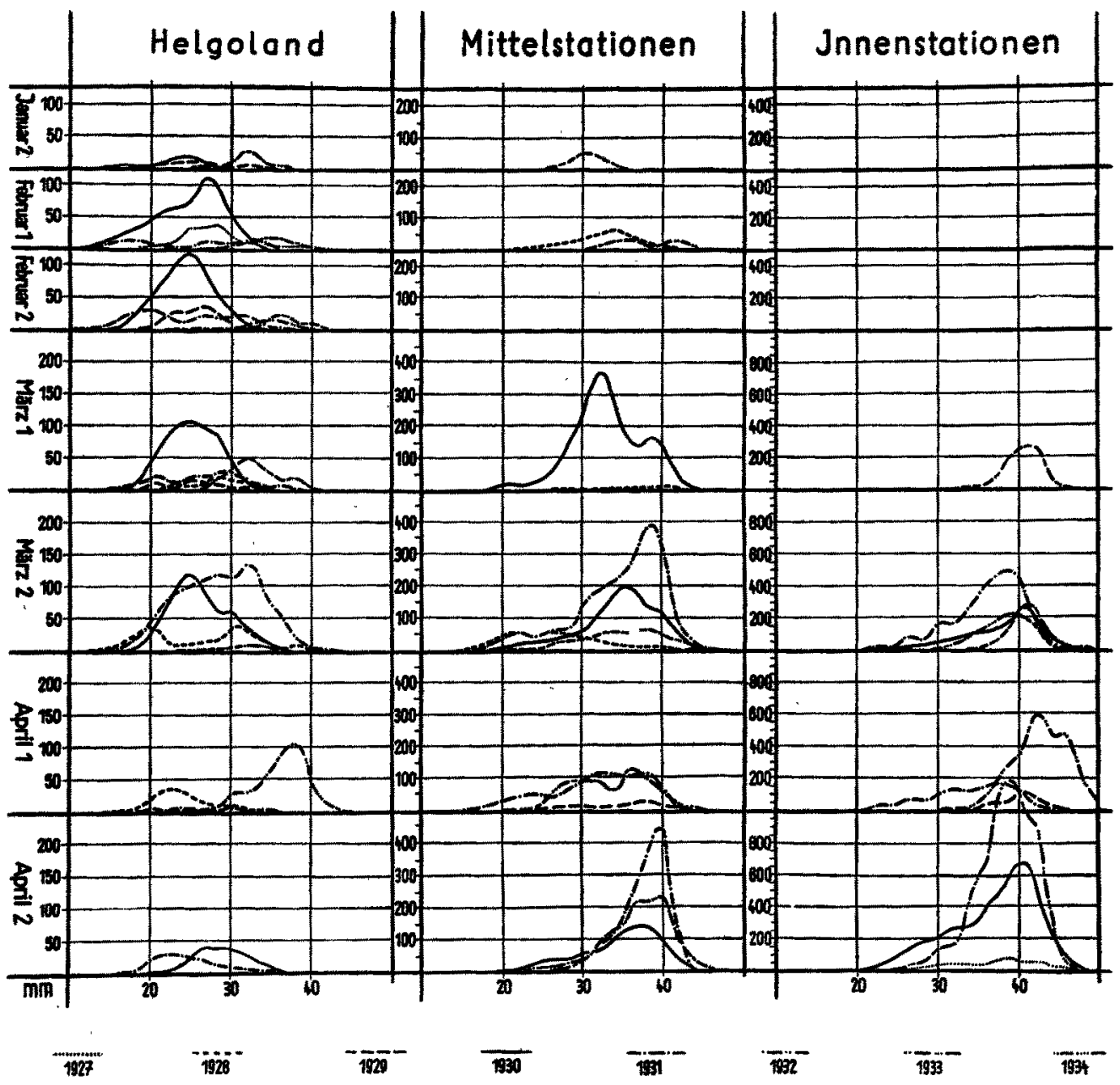

Abb. 1. Größe und Häufigkeit der Heringslarven in der inneren Deutschen Bucht 1927-1934.

Abb. 1 enthält die auf $2 \mathrm{~mm}$ geglätteten Längenkurven für die drei Gebiete und die einzelnen Halbmonate. Zugrunde gelegt ist wiederum die Fangmenge in Stundenfang (Oberfläche und Tiefe) für die Jahre 1930-1934, die Fangmenge im halbstündigen Tiefenfang für die Jahre 1926-1929. Eingezeichnet sind die Kurven für alle Jahre, in denen Untersuchungen vorgenommen und der Fang groß genug war, um in dem gewählten Maßstab in Erscheinung zu treten. Zur Raumersparnis ist der Maßstab für die Mittelstationen doppelt so groß wie für die Innenstationen, für die Helgoländer Stationen doppelt so groß wie für die Mittelstationen und viermal so groß wie für die Innenstationen gewählt worden. Die Kurvenlinien der einzelnen Jahre sind durch Kennungen unterschieden.

Die Betrachtung dieser Abbildung lehrt, daß die Größenverhältnisse der Heringslarven in diesem Küstengebiet aus sich se'bst keinen Aufschluß über das Wachstum der Gruppen abgeben. Die Kurven für das Helgoländer Gebiet von 1930 z. B. (ausgezogene Linien) zeigen von Januar bis zweite Hälfte Märrz immer etwa die gleiche Lage der Gipfel zwischen 20 und $30 \mathrm{~mm}$. Es ist zu vermuten, daß jeweils kleinere Larven den Bestand bei Helgoland auffüllen, während die größeren nach den Mittelstationen zu abwandern. Man kann nun vielleicht den Gipfel im Gebiet Helgoland bei $27 \mathrm{~mm}$ in der ersten Februarhälfte mit dem Gipfel bei $32 \mathrm{~mm}$ auf den Mittelstationen in der ersten Märzhälfte, bei $36 \mathrm{~mm}$ in der zweiten Märzhälfte und bei $40 \mathrm{~mm}$ auf den Innenstationen in der zweiten Aprilhälfte in Verbindung bringen, jedoch ist die Richtigkeit dieser Kombinationen nicht zu erweisen. Andere Möglichkeiten sind nicht auszuschließen. Man muß also wohl auf die genauere Analyse des Wachstums verzichten. Dagegen macht sich die Abwanderung der größeren Individuen in Richtung auf die Küste in den allgemeinen Größenverhältnissen der Larven in den 3 Gebieten geltend. Allgemein genommen und ohne Rücksicht auf einzelne Ausnahmen ist festzustellen, daß bei Helgoland die Längen zwischen 20 und $30 \mathrm{~mm}$ während des ganzen Winters am häufigsten sind, auf den 
Mittelstationen solche zwischen 30 und 40, während auf den Innenstationen die Kurvengipfel bei oder über $40 \mathrm{~mm}$ liegen. In Zah'entafel 7 sind zur Ergänzung die Durchschnittslängen dex Heringslarven in den drei Teilgebieten für jeden Halbmonat angegeben. Für Helgoland liegen die Durchschnittswerte zwischen 25 und $28 \mathrm{~mm}$, nur einmal bei $32 \mathrm{~mm}$, ohne im Laufe des Jahres ein durch Wachstum verursachtes Ansteigen zu zeigen. Das Entsprechende gilt für d e Mittelstationen, wo die Werte bei (30) $33-36 \mathrm{~mm}$ liegen, und für die Innenstationen mit (34) $38-40 \mathrm{~mm}$. Da die Durchschnittslängen in der Zeit nur unregelmäßige Schwankungen, nicht aber einen Anstieg zeigen, ist es zulässig, für jedes Gebiet einen Gesamtdurchschnitt zu berechnen. Er liegt für Helgoland bei 27,2, für die Mittelstationen bei 34,4, für die Innenstationen bei $38.6 \mathrm{~mm}$.

Zahlentafel 7 .

Durchschnittslänge der in den drei Teilgebietengefangenen Heringslarven im $L$ a uf e der Jahreszeit (alle Jahre zusammen).

Zeitabschnitt Jan. 2. Februar 1. Februar 2. März 1. März 2. April 1. April 2. Zus.

$\begin{array}{lllllllll}\text { a) Helgoland } & 27.8 & 25.8 & 25.2 & 25.8 & 27.6 & 32.4 & 27.4 & 27.2 \\ \text { b) Mittelstationen } & 30.2 & 34.0 & 36.4 & 33.2 & 34.0 & 33.0 & 364 & 34.4\end{array}$

$\begin{array}{lllllllll}\text { c) Innenstationen } & 34.7 & 40.8 & 38.7 & 40.0 & 37.6 & 40.0 & \left.38.4^{*}\right) & 38.6\end{array}$

") Nicht eingerechnet eine kleine Zahl von Larven des Frühjahrsherings von $11-14 \mathrm{~mm}$.

Bezeichnend ist es auch, daß die Mehrzahl der in Abb. 1 wiedergegebenen Kurven von links mehr oder weniger sanft anste:gt und dann voin Höhepunkt nach rechts weit steiler wieder abfällt. Das ist eine bei Fischmessungen im allgemeinen ungewöhnliche Form, und ein Vergleich mit den in Abschnitt $\mathrm{C}$ des ersten Teiles dieser Arbeit gegebene Kurve zeigt, daß sie auch für Heringslarven ungewöhnlich ist, daß sie allerdings im Küstengebiet bei großen Larven regelmäßig erscheint. Sie ist so zu erklären, daß jeweils die größten Individuen aus der Larvenbevölkerung ausscheiden, teils durch Abwanderung tiefer ins Küstengebiet hine n, teils durch Eintritt der Verwandlung zum Junghering. Die Jungheringe werden mit dem Knüppelnets nur noch zufällig gefangen. Sie erscheinen daher im allgemeinen in unseren Fängen nicht, und daraus erklärt sich der steile Abfall aller Kurven bei etwa $40 \mathrm{~mm}$. Gelegentlich allerdings wird ein Schwarm von Metamorphosestadien gefangen. Das war zum Beispiel in der ersten Aprilhälfte 1932 der Fall, und daraus erklärt sich die weit nach rechts ausladende Kurve für die Innenstationen.

Die Größenzusammensetzung der Larven in den einzelnen Jahren schwankt beträcht lich. Bei Helgoland sind die Larven von 1931:32 und auch 1932/33 viel größer als sonst. Auf den Mittelstationen zeichnet sich das Jahr 192:/28 durch besonders geringe Durchschnittslänge aus. Auf den Innenstationen sind die Larven 1932 viel größer als in den anderen Jahren. Versucht man einen Gesamtdurchschnitt zu bilden, indem man die Durchschnittswerte für die drei Teilgebiete gleich bewertet, so kommt man zu folgenden Durchschnittslängen der Herings larven:

\begin{tabular}{ccccccc}
\hline $1927 / 28$ & $1928 / 29$ & $1929 / 30$ & $1930 / 31$ & $1931 / 32$ & $1932 / 33$ & $1933 / 34$ \\
30.9 & 32.8 & 32.2 & 32.6 & 37.4 & 36.2 & 34.1 \\
\hline
\end{tabular}

\section{Folgerungen aus den Untersuchungen über das Auftreten der Heringslarven an den Küsten der inneren Deutschen Bucht.} gering.

Troty des umfangreichen Materials sind die Ergebnisse der Untersuchungen enttäuschend

Wie im vorigen Abschnitt gezeigt worden war, können einzelne Heringslarven schon im November an den Küsten der Deutschen Bucht erscheinen. Im allgemeinen aber ist ihre Menge bis Ende Januar ziemlich bedeutungslos. Im Februar dagegen erscheinen sie in größerer Zahl bei Helgoland. Das eigentliche Küstengebiet ist immer noch spärlich bevölkert. Hier erscheinen sie erst von Anfang März, in den inneren Teilen des Wattenmeeres und der Elbmündung erst von Ende März an in Massen. Bei Helgoland ist Ende April schon wieder die Abnahme der Zahl zu erkennen, während die Innenstationen jegt am reichsten sind. 
Die Zuwanderung an die Küste beginnt also im Februar, wenn die Deutsche Bucht, wie früher gezeigt wurde, sich mit einem Gemisch von Doggerbank- und Downslarven erfüllt hat, die sich in der Länge um diese Zeit noch deutlich unterscheiden lassen, wenn auch Ubberschneidungen vorkommen. Außerdem sind beide Larvengruppen nach Größe gestaffe 't. Die der Küste am nächsten befindlichen sind jeweils die größten. Wenn dies auch nur darauf beruhen sollte, daß die Larven näher an der Küstc günstigere Ernährungsverhältnisse finden, so würden doch in weiterem Verlauf die größeren Larven auf Grund ihrer größeren Bewegungsenergie die Küste zuerst erreichen. Wahrscheinlich aber ist die Größenstaffelung bereits eine Folge davon, daß bei den Plusvarianten des $\mathrm{W}$ achstums der Trieb zur aktiven Wanderung nach den Metamorphosegebieten am frühesten einsetzt.

Diese Verhältnisse haben es zur Folge, daß wir es im Küstengebiet nicht mehr mit Größengruppen zu tun haben, die das unmittelbare Ergebnis des Wachstums und seiner individuellen Variation sind. Aus der Bevö'kerung, die bei Helgoland vorhanden ist, wandern beispielsweise jeweils die größten weiter an die Küste. Kleinere erscheinen von See her, wie Strömung und Wanderung sie heranführen, und ersetzen sie, bis auch für sie der Zeitpunkt gekommen ist, die Küste aufzusuchen. So ist es nicht mehr möglich, die Gruppen der Doggerbankund Downslarven zu unterscheiden, wenn auch zweifellos die später erscheinenden Larven vorwiegend Downslarven sein werden. Eine Grenze zwischen beiden ist nicht zu ziehen, ihre anteilmäßige Bedeutung für die Larvenbevölkerung der Deutschen Bucht kann auf diese Weise nicht mehr bestimmt werden.

Während aus dem Helgoländer Gebiet die größten Individuen zur Küste abwandern, verschwinden die größten Individuen aus der Larvenbevölkerung der Küste durch die Metamorphose. Die Jungheringe halten sich in stark beweglichen Schwärmen und werden vom Knüppelnetz nicht mehr repräsentativ gefangen (vergl. Clark 1933). Diese Verhältnisse bedingen, daß die Längenmessungen meist nach rechts steil abfallende "Auslesekurven“ liefern, während der Anstieg der Kurven im linken Ast infolge der allmählichen Zuwanderung stets sanft ansteigt.

Während der mehr planktonischen Lebensphase der Heringslarven wurde wiederholt eine klare Beziehung der Verbreitung zu den hydrographischen Verhältnissen festgestellt. Jegt in der Periode der aktiven Bewegung verschwinden diese Beziehungen. Bei ihrer Wanderung an die Küste lassen sich die Larven durch die Grenzen der Wasserkörper (Nordsee- und Küstenwasser) offenbar nicht beeinflussen. Sie dringen weit ins Brackwasser vor und ertragen eine Salinität von weniger als $10 \%$. Bei ihrer Wanderung zeigen sie zunehmende Tendenz, die Oberflächenschichten zu bevorzugen. Bei Helgoland und bei Elbe I sind die Tiefenfänge in einem wesentlichen Teil der Fälle die größeren. Wenn aber Heringslarven in großen Mengen auftreten, so tun sie das auch hier vorzugsweise an der Oberfläche. In den inneren Teilen des Wattenmeeres sind die Oberflächenfängə praktisch immer die größeren. Wenn schließlich an den innersten Stationen des Elbgebiets die Tiefenfänge wieder reicher sind, so deshalb, weil das an der Oberfläche abströmende Flußbrackwasser zunächst noch larvenleer ist und die Larven erst im Laufe der Zeit in dasselbe einwandern.

Bei Helgoland und auf den Mittelstationen sind die Fänge in den Wintern 1927/28, 1929/30 und 1930/31 reich an Heringslarven. Arm waren die Winter 1931/32 und 1933/34, mittelmäßig die Winter 1928/29 und 1932/33. Eine unmittelbare Beziehung zu den hydrographischen Verhältnissen ist nicht zu erkennen. - Mit dem Larvenreichtum der einzelnen Jahre bei Helgoland und auf den Mittelstationen stimmt die Ergiebigkeit der Fänge auf den Innenstationen nicht überein. Man kann aber nicht erwarten, aus den wenigen Fängen an diesen Stationen repräsentative Mittel für die Larvenhäufigkeit zu erhalten, da die Fangmengen hier - wohl wegen der beginnenden Schwarmbildung - sehr ungleichmäßig sind.

In der Größe der Larven bestanden Unterschiede zwischen den einzelnen Jahren. 1927/28 waren sie besonders klein, 1931/32 und 1932/33 besonders groß. Für das lettgenannte Jahr ist im ersten Teil dieser Arbeit nachgewiesen, daß Doggerbanklarven in der Deutschen Bucht reichlich, Larven aus der Flämischen Bucht dagegen nur auffallend spärlich vertreten waren. Es ist an sich ja sehr wahrscheinlich, daß die Larven im Küstengebiet der Deutschen Bucht umso kleiner sind, je mehr Larven aus der Flämischen Bucht das Gebiet erreichen. Die Befunde über die Größe der Larven sind aber nicht so einheitlich, daß man es wagen dürfte, nun ohne weitere Bestätigung für 1927/28 etwa eine besonders starke, für 1931/32 eine extrem geringe Versorgung mit Larven aus der Flämischen Bucht zu folgern.

Nach den Erfahrungen von 1926-1934 scheint és nicht lohnend, eine Überwachung des Eintreffens der Heringslarven an der deutschen Küste vorzunehmen. Das Küstengebiet ist so ungeheuer vielgestaltig und die Verhältnisse sind so verwickelt, daß man kaum eindeutige Ergebnisse erwarten kann. Es sei daran erinnert, daß wir in der Deutschen Bucht aus dem 
gleichen Grunde die Untersuchungen über die Schollen der ersten beiden Lebensjahre im Wattenmeer aufgeben mußten und durch Untersuchungen über den Jungschollenbestand in der offenen See ersetzten. Ähnlich wird man auch fürs erste die Überwachung der Larvenversorgung der Deutschen Bucht in die offene See verlegen. Der geeignete Monat hierfür ist der Februar. Larven aus der mittleren Nordsee wie aus der Flämischen Bucht haben jegt die Deutsche Bucht erreicht, die kritische Zeit des Einflusses der Strömungen auf den Transport ist, soweit wir bisher sehen können, im wesentlichen vorüber. Im nächsten Monat wird die Küstenwanderung der Doggerbanklarven schon spürbar sein und den Einblick in die Zusammenhänge erschweren. Im Januar aber ist die Entscheidung über die Larvenzufuhr vermutlich noch nicht gefallen. Den besten Aufschluß über das Ergebnis des Larventransports erhalten wir unstreitig durch eine regelmäßige Öbersichtsfahrt im Februar, die das Gebiet zwischen dzr deutschen Küste und der Doggerbank und möglichst viel von der Flämischen Bucht erfassen müßte.

\section{Heringslarven und Jungheringe.}

Es ist eingangs die Frage aufgeworfen worden, ob Beziehungen zwischen der Larvenversorgung der Deutschen Bucht und dem Vorkommen von Jungheringen ein bzw. zwei Jahre später bestehen. Ein Versuch, diese Frage auf Grund des vorliegenden Materials zu klären, ist wenig aussichtsreich. Die periodischen Untersuchungen über das Auftreten der Larven an der Deutschen Küste 1926-1934 geben, wie wir gesehen haben, nur eine unsichere Vergleichsbasis. Was die Jungheringe anbetrifft, so ist jedenfalls der Ertrag des Elbheringsfanges nicht in Ubereinstimmung mit dem zwei Jahre früher beobachteten Larvenreichtum, wie folgende Zusammenstellung zeigt:

\begin{tabular}{|c|c|c|c|c|c|c|c|c|}
\hline $\begin{array}{l}\text { Jahr: } \\
\text { Larvenmenge: }\end{array}$ & $1926 / 27$ & $\begin{array}{c}1927 / 28 \\
+\end{array}$ & $1928 / 29$ & $\begin{array}{c}1929 / 30 \\
+\end{array}$ & $\begin{array}{c}1930 / 31 \\
+\end{array}$ & $1931 / 32$ & $1932 / 33$ & $\begin{array}{c}1938 / 34 \\
-\end{array}$ \\
\hline eringsfang: & 7291 & 4276 & 2147 & 6393 & . 719 & 6249 & 1042 & 20807 \\
\hline Jahr: & 1928,29 & $1929 / 30$ & $1930 / 31$ & $1931 / 32$ & $1932 / 33$ & $1933 / 34$ & $1934 / 35$ & $1935 / 36$ \\
\hline
\end{tabular}

Über die einjährigen Jungheringe gibt die Statistik des Elbheringsfanges keine Auskunft. Dagegen lagen einige Beobachtungen über das Vorkommen von Jungheringen vor. Sie wurden auf ihre Verwendbarkeit geprüft. Zunächst war in den meisten Fällen der Umfang des Materials zu gering, um ein Urteil über die Haufigkeit des Vorkommens der Heringe daraut zu gründen. Doch wäre auch ein Urteil allein übər die Größenzusammensez̧ung der Jungheringe von Interesse gewesen. Es sei darauf hingewiesen, daß Hodgson mehrere verschiedene Modi der Längenvariation einjähriger Jungheringe unterschieden hat und annimmt, daß jeweils die kleineren Fische einer späteren Laichzeit entstammen. Es wäre demnach zu prüfen, ob ein Jahr nach dem Auftreten zahlreicher Downslarven die Gipfellänge der Jungheringe besonders niedrig liegt. Es zeigt sich aher, daß die Fänge, die mit Knüppelnetz und verschiedenen kleinen Fischneţen ausschließlich im Küstengebiet gemacht worden sind, nicht repräsentativ für den Jungheringsbestand sind. Fast während des ganzen Jahres, jedenfalls aber von Juli bis April, lagen die Gipfellängen bei 8 oder $9 \mathrm{~cm}$, als ob während dieser Zeit kein Wachstum erfolge. $Z$ weifellos ist die Erscheinung darauf zurückzuführen, daß kleinere Fische zu den Schwärmen hinzukommen, während die größeren, älteren sich anderen Schwärmen, vermutlich außerhalb des Küstengebiets, anschließen.

Ein repräsentativeres Material liefern die Decksteertneţfänge, die auf den Frühjahrs.. fahrten 1931, 1932 und 1933 in der ganzen Deutschen Bucht gemacht worden sind. Man darf annehmen, daß auf diese Weise die örtliche Sonderung der Fische verschiedener Größe ausgeglichen wird.

Anfang Mai 1931 wurden sehr viele Jungheringe von geringer Länge $(9 \mathrm{~cm})$ gefangen. Das stimmt gut mit der Tatsache überein, daß im Winter 1929/30 sehr viele und sehr kleine Heringslarven beobachtet waren.

Im April 1932 waren die Jungheringstänge viel geringer, die kleinen um $9 \mathrm{~cm}$ fehlten fast völlig, der Gipfel lag bei $11 \mathrm{~cm}$. Im vorhergehenden Winter aber waren auch sehr viele und kleine Heringslarven beobachtet worden, so daß hier von einer Übereinstimmung der Befunde keine Rede sein kann.

Mitte Mai 1933 waren die Jungheringsfänge etwas ergiebiger als 1932. Die Längen gruppierten sich um 2 Gipfel, nämlich $10 \mathrm{~cm}$ an der nordfriesischen Küste und $12 \mathrm{~cm}$ an der ostfriesischen. Der vorhergehende Winter war, nach unseren Fängen zu urteilen, sehr arm an Larven, und es fehlte besonders an kleineren.

Eine Beziehung zwischen dem Vorkommen von Larven und Jungheringen ist also vor der Hand nicht nachzuweisen. Nach Vornahme periodischer, methodisch wohlüberlegter Untersuchungen auf beiden Gebieten wird man diese Frage nach einmal prüfen müssen. 


\section{B. Untersuchungen über die Wirbelzahl der Heringslarven.}

\section{Material und Methoden.}

a) Das Material.

Um zu prüfen, ob unter den Heringslarven der Deutschen Bucht auch Individuen des Kanalheringstyps mit der verhältnismäßig hohen mittleren Wirbelzahl von 56,7 eine Rolle spielen, wurden an einem Teil des Materials Wirbelzählungen vorgenommen. Die Bildung der knöchernen Wirbel ist erst etwa bei einer I änge von $30 \mathrm{~mm}$ abgeschlossen. Nur Larven von dieser Größe an aufwärts wurden zu den Zählungen verwendet. Unter diesen Umständen konnten Larven des Kanaltyps erst von den Frühjahrsmonaten an in den Zählungen hervortreten. Es war mithin zunächst festzustellen, ob die durchschnittliche Wirbelzahl der Larven wenigstens in den einzelnen Jahren gegen Ende der Untersuchungsperioden anstiege.

Mit dieser Fragestellung wurden die Untersuchungen von Kotthaus begonnen. Er konnte bereits zeigen, daß die jüngsten Larven in der Deutschen Bucht keine höhere Wirbelzahl haben als die älteren, früher an den Küsten eingetroffenen. Dagegen fand er erhebliche Verschiedenheiten der mittleren Wirbelzahl in den einzelnen Jahren. Es schien erforderlich, diese interessanten Ergebnisse durch Vermehrung des Materials zu erhärten. Da die Ergänzungen Kotтhaus' Befunde bestätigen, wird im folgenden das ganze Material zusammen behandelt.

Es umfaßt Fänge der "Augusta" zwischen Hzlgoland, Elbe und Jade aus den Monaten Februar bis April der Jahre 1930-1934 sowie Fänge des "Poseidon" aus verschiedenen Teilen der Deutschen Bucht, zutmeist von der Küste, von den Fahrten im Mai 1929, im April 1932 und im März 1935. Es handelt sich insgesamt um 34 Proben, die teils aus einzilnen Fänmen stammen, zum Teil aber, wenn die Larven spärlich waren, mehrere Fänge umfassen. Jede Probe wurde in drei Grö3engruppen aufgeteilt: $30-35 \mathrm{~mm}, 35-40 \mathrm{~mm}$, über $40 \mathrm{~mm}$ Als sich bei der Bearbeitung ein genaueres Eingehen auf das Phänomen der komplexen Wirbel und die Entwidklung des Schwanzskeletts als wünschenswert erwies, wurden noch einige weitere $F$ änge mit teilweise für diesen Zweck histologisch konserviertem Material vom Winter 1937 und 1940 mit herangezogen.

b) Die Methoden der Untersuchungen.

Die für das vorhandene Material geeignete Methode der Wirbelfärbung wurde von KOTTHAUS erprobt. Die Larven waren an Bord mit den ganzen Knü spelneţfängen in Formol von $1-2 \%$ konserviert, später ausgesucht und in Formol gleicher Konzentration aufbewahrt worden. Die Ungleichmäßigkeit der Konservierung, die an Bord nicht ganz zu vermeiden ist. macht sich bei der Färbung oft unangenehm bemerkbar. War die Konzentration zu gering, so blieben die Larven zu weich und zerrissen leicht be1 der Abtragung der Muskulatur vor dem Färben. Bei zu hoher Konzentration anderseits färbte sich das Material schlecht.

Das der Konservierungsflüssigkeit entnommen: Material wurde zunächst $36-48$ Stunden in fließendem Wasser ausgewaschen, dann wurden die Larven gemessen und in $5 \mathrm{~mm}$-Längengruppen aufgeteilt, und anschlicßend wurde die Muskulatur einer - meist der l'nken - Körperseite mit Hilfe einer scharfen Lanzettnadel vorsichtig entfernt. Auch wurde die eine Hälfte des Schädels abgetragen, vor allem das Pleurooccipitale entfernt, um auch den ersten Wirbel völlig frei zu legen.

Als Färbemittel für Knochen wurde Alizarin verwandt. KOTTHAUS machte Versuche mit den von verschiedenen Autoren angegebenen Verfahren (z. B. KANDLER, MARX, ROMEIS). Er erzielte dann aber die besten Ergebnisse bei Verwendung noch schwächerer Konzentrationen als die genannten Autoren. Er stellte zunächst folgende Stammlösung her:

1 Teil konz. Lösung von Alizarin sicc. in Alk. 96\%.

10 Teile Alk. $96 \%$

Von dieser Stammlösung wurde, je nach Zahl und Gößße der zu färbenden Larven, 1 Teil mit $3-5$ Teilen Alk. $96 \%$ oder $70 \%$ verdünnt. Die stärkere Konzentration reicht zur Färbung von etwa 150 , die schwächere für etwa 50 Larven aus. Bei Larven auf den frühesten Verknöcherungsstadien wurden sehr geringe Konzentrationen der Farblösungen gewählt, weil sich sonst Farbe in der Muskulatur ablagert und das Zählen der Wirbel sehr erschwert wird.

Die filetierten und in die drei Größengruppen aufgeteilten Larven wurden aus Aqua dest. unmittelbar in die Farblösung überführt und darin gelassen, bis die Lösung farblos geworden war. Bei größeren Larven von mehr als $35 \mathrm{~mm}$ Länge dauerte die Färbung 6-8 Stunden, bei kleineren Larven länger. etwa 12-24 Stunden. Nach der Färbung waren die knöchernen El.men+e des Skeletts dunkelrot gefärbt, während die Muskulatur nur einen mehr oder weniger schwachen roten $\mathbf{S}$ himm $\times \mathbf{r}$ besaß. Es erwies sich als belanglos für das Ergebnis der Färbung, ob die Alizarinlösung alkalisch, neutral oder schwach sauer war.

Nach dem Färben wurden die Larven unter dem Binokular von den der Wirbelsäule noch anhaftenden Resten der linken Körpermuskulatur befreit. Dann wurden die Wirbel mindestens zweimal gezählt. Ergab dic zweite Zählung eine Abweichung, so wurde noch einmal nachkontrolliert. Die Zählungen hat anfangs Dr. KOTT. HAUS selbst vorgenommen, spä'er wurde sie von den technischen Assistenten I. TƠLKE und M. KOCH ausgeführt und zum allergrößten Teil vom Verfasser noch einmal kontrolliert.

Anfangs wurde versucht, bei den Larven von 25 bis $30 \mathrm{~mm}$ mit noch unvollkommen verknöcherten Wirbeln die Zählung dadurch zu ermöglichen, daß die knorpligen Haemal- und Spinalbögen gefärbt und gezählt wurden. Dieser Versuch wurde aber wegen des häufigen Auftretens komplexer Wirbel (Wirbel mit überzähligen Bögen und Fortsätzen) aufgegeben.

Das bearbeitete Material wurde, da Alkohol das Alizarin auswäscht, in Tetralin aufbewahrt. Die Larven mit überzähligen Bögen und Fortsätzen (Komplexbildungen) wurden hierbei ausgesondert und später noch einmal einer genaueren mikroskopischen Untersuchung unterworfen. Bei einem Teil der Larven erwies șich das allerdings als unmöglich, weil die Färbung zerstört oder die Larven zu hart und spröde geworden waren.

Zur Untersuchung der Entwicklung der Komplexbildungen wurden kleinere Larven nach Knorpelfärbung untersucht. Bei altem Formolmaterial gelang diese Färbung nur schlecht. Daher wurden im Winter 1940 Larven 
in Carnoy, Zenker, Helly, Bouin, Formol-Alkohol konserviert. Eine gute Knorpelfärbung wurde mit Toluidinblau erzielt (Knorpel blauviolett, "Muskulatur grünlich), während KOTTHAUS einer sehr dünnen Lösung von Methylenblau den Vorzug gegeben hatte. Doppelfärbungen mit Alizarin und Toluidinblau gelangen nur selten.

Frontale Längsschnitte und Querschnitte wurden durch die Shwanzregion von Heringslarven gemarht, um die Lagebeziehungen zwischen den knorplig präformierten Bögen und den direkt verknöchernden Wirbelkörpern, sowie zwischen Muskulatur, Blutgefäßen und Fortsätzen zu ermitteln. Eingcbettet wurde über Benzol, gefärbt besonders mit Bleue de Lyon - Mucicarmin. Die Längsschnitte neigten im Bereich der Chorda sehr zum Splittern, selbst wenn vorher entkalkt wurde.

\section{Uber Vorkommen und Bedeutung der Komplexbildungen an der Wirbelsäule des Herings}

a) Frühere Untersuchungen.

Als „komplexe Wirbel“ bezeichnet KändLeR solche Wirbel an dem Ende der Wirbelsäule, deren Körper überzählige obere und untere Bögen und Dornfortsätze tragen. Zumeist zeigt der Körper solcher Wirbel keine Anzeichen dafür, daß er aus zwei ursprünglich getrennten Anlagen verschmolzen sei, wie das an anderen Stellen der Wirbelsäule gelegentlich vorkommt. Indessen hat KäNDLER auch komplexe Wirbel mit Verwachsungsspuren gefunden.

Komplexbildungen kamen regelmäßig und bei einem beträchtlichen Teil der von KäNDLER untersuchten Plattfische vor. Wenig später als KäNDLER beschrieb Ford (1933) sie bei Heringen von Plymouth. In einer späteren Arbeit (1937) wies er sie bei einer großen Zahl von Knochenfischarten nach. Wegen der Regelmäßigkeit und Häufigkeit des Vorkommens kann man, wie KäNDLER betont, die komplexen Wirbel also nicht als Anomalien oder pathologische Bildungen ansehen und als solche aus dem Untersuchungsmaterial ausscheiden.

KäNDLER stellte weiterhin fest, daß die durchschnittliche Wirbelzahl dor Schollen mit komplexen Wirbeln geringer ist als bei solchen mit normalen. Ist der erste Wirbel oder das Urostyl komplex, so beträgt der Unterschied einen ganzen Wirbel, ist der letzte Wirbel vor dem Urostyl komplex, so beträgt er einen halben Wirbel. Die Komplexbildung am ersten Wirbel und am Urostyl sieht er daher als durch Verschmelzung zweier Wirbelanlagen entstanden an, das Auftreten überzähliger Fortsätze am leţten Wirbel aber erklärt er als unvollkommene Abgliederung der letzten Wirbelanlage.

Bei den Heringen fand Ford keine Komplexbildungen am ersten Wirbel und am Urostyl. Er unterschied 6 Typen (1933 Abh. 4): a) zwei miteinander teilweise verschmolzene Spinalfortsätze am lezten Wirbel vor dem Urostvl; b) zwei getrennte Spinalfortsäţe am gleichen Wirbel; c) zwei Spinalfortsäłe am gleichen Wirbel, von denen der vordere nicht fest mit dem Wirbelkörper verwachsen, sondern ,autonom" ist; d) die gleiche Ausbildung der Spinalfortsätze, dazu ein überzähliger Haemalfortsa' $z$ am zweiten Wirbel vor dem Urostyl; e) zwei Spinalfortsätze am zweiten Wirbel vor dem Urostyl und f) zwei Spinal- und zwei Haemalfortsätze am zweiten Wirbel vor dem Urostyl.

Ford sieht in dem komplexen Wirbel die Art, wie der Organismus die Anlage eines Wirbelbruchteils realisiert. Er wirft die Frage auf, warum die Möglichkeit nur bei einigen wenigen Wirbeln innerhalb des Rückgrats verwirklicht wird. In diesem Zusammenhange erwähnt er KyLES Anschauung, daß die Wirbelzahl unter dem gemeinsamen Einfluß der Umweltbedingungen und den Bewegungen des sich entwickelnden Fisches bestimmt wird. Diese Anschauung würde es nach ForD verständlich machen, daß die Variation der Wirbel an den Enden der Wirbelsäule am stärksten ist.

Die eigenen Beobachtungen über die Komplexbildungen bei den Heringslarven förderten eine Reihe von bemerkenswerten Einzelheiten ans Licht, die eine Untersuchung über die Entwicklungsgschichte des Schwanzskeletts nahe legten, wie auch KäNDI.FR sie schon empfohlen hatte. Dabei ergab sich eine Auffassung der Entstehung der Komplexbildungen, die in der Tat in der Funktion des Schwanzskeletts den wichtigsten Faktor zu ihrer Ausbildung sieht.

b) Die Häufigkeit der Komplexbildungen beiden Heringslarven.

Die eigenen Beobachtungen über die Häufigkeit des Vorkommens von Komplexbildungen bei Heringslarven stehen mit Fords Feststellungen in Einklang. Man kann jedoch hier nicht einfach von "komplexen Wirbeln" sprechen, da man, wie sogleich näher dargelegt werden soll, in einer beträchtlichen Anzahl der Fälle nicht entscheiden kann, welcher der boiden in Frage kommenden Wirbel komplex ist. Es werden daher die neutralen Ausdrücke „Komplexbildung" und ,überzähliger Fortsats" verwendst.

Von 8044 daraufhin untersuchten Larven hatten 1607 oder $20.00 \pm 0.45 \%$ überzäh'ige Fortsäze. Bei den einzelnen Größengruppen betrug der Anteil: 


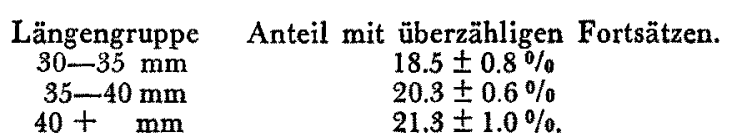

Der etwas geringere Anteil bei den kleinen Larven ist wahrscheinlich dadurch zu erklären, daß hin und wieder noch ganz unverknöcherte und daher ungefärbte überzählige Fortsätge übersehen wurden. Übrigens ist der Unterschied auch nicht statistisch einwandfrei gesichert.

Bei den einzelnen Jahrgängen liegt der Anteil für 1931 mit 16,8\% und für 1934 mit $17,3 \%$ auffällig tief. Bei den anderen Jahrgängen liegt er über $20 \%$, am höchsten für 1929 mit $22,5 \%$. Die extremen Unterschiede sind statistisch gesichert. So beträgt die Differenz 1929 bis $19315.7 \% \pm 1,6 \%$.

c) Die Formender Komplexbildungen.

Die Lage der überzähligen Fortsätze wurde bei einem großen Teil der Individuen (1279 Stück) genauer untersucht. In mehr als vier Fünftel der Fälle war nur dorsal ein überzähliger Fortsats vorhanden, während jeder Wirbel nur einen Haemalfortsaţ trug. Solche Individuen werden als dorsal komplex bezeichnet.

a)

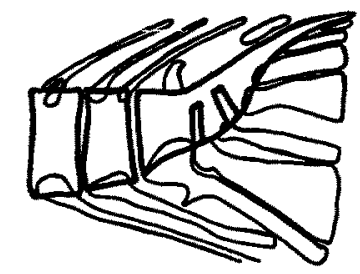

b)

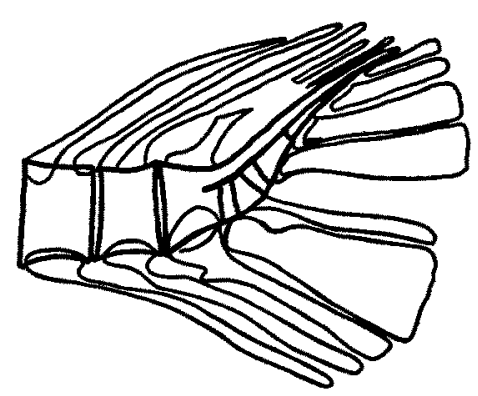

c)
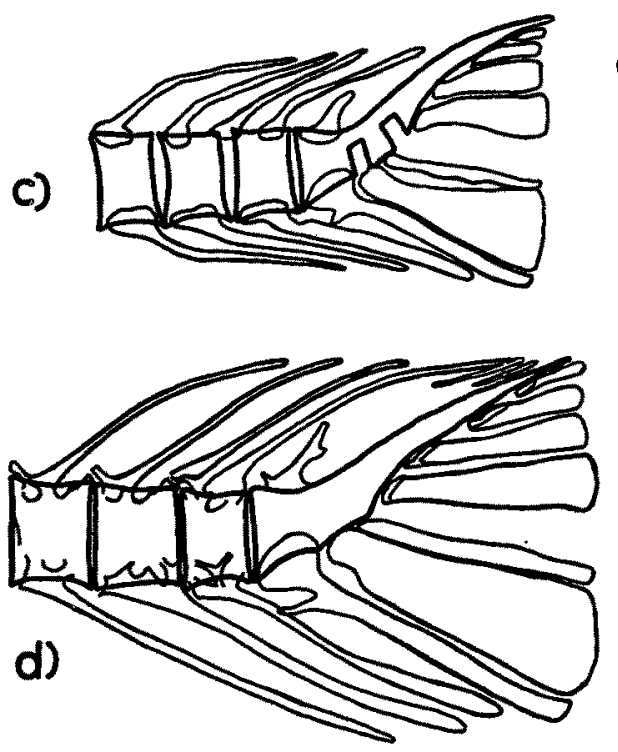

$\theta)$

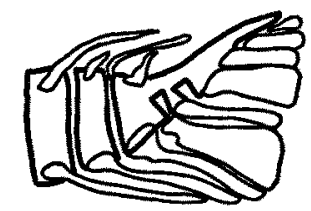

f)

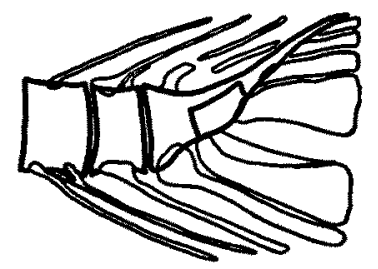

g)

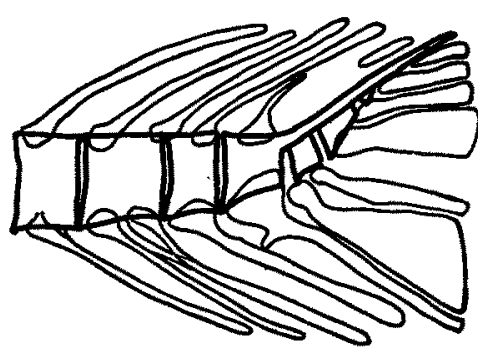

h)

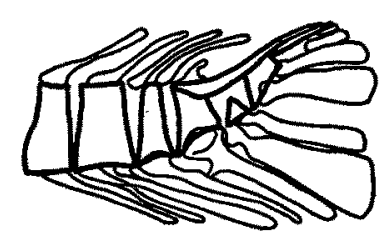

i)

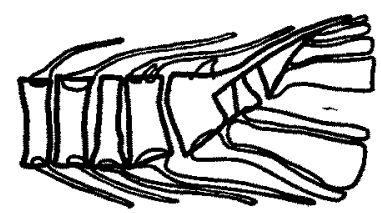

Abb. 2. Komplexbildungen im Schwanzteil der Wirbelsäule bei Heringslarven. a-e dorsalkomplexe Individuen: $a: d(n-1)$ b: $d(n-2)$ c und $d: \operatorname{di}(n-1)(n-2)$ e: $\operatorname{di}(n)(n-1) ; f-h$ amphikomplexe Individuen: $\because \mathrm{v}(\mathrm{n}-2) \mathrm{d}(\mathrm{n}-1) \mathrm{g}: \mathrm{v}(\mathrm{n}-\mathrm{z}) \mathrm{d}(\mathrm{n}-1)(\mathrm{n}-2) \mathrm{h} \mathrm{v}(1-2)$ di $(\mathrm{n})(\mathrm{n}-1)(\mathrm{n}-2 ; \mathrm{i}$ abnormes Individuum, $(\mathrm{n}-2)$ shne Spinalfortsatz, $(\mathrm{n}-\mathrm{l})$ mit zwei distal verschmolzenen Fortsätzen. 
Der überzählige Spinalfortsą $s a ß$ am häufigsten an dem Wirbel vor dem Urostyl. Hierfür wird das Symbol d $(n-1)$ verwendet. Vergl. Abb. 2 a. Selten nur fand sich der Fortsat auf dem vorhergehenden Wirbel $=d(n-2) \quad(A b b .2 b)$. In einem beträchtlichen Teil der Fälle aber saß der Fortsat nicht auf einem der Wirbelkörper auf, sondern auf der Grenze, bei noch nicht völlig verknöcherten Wirbeln geradezu auf dem Zwischenraum zwischen den beiden Wirbelkörpern $=\operatorname{di}(n-1)(n-2)(A b b .2 c$ u. d). Hin und wieder saß der Fortsatz auch zwischen dem Urostyl und dem letten Wirbel auf $=\operatorname{di}(n)(n-1)(A b b .2 e)$. Weiter gab es auch einige Fälle, wo die beiden leţten Fortsätze nicht mit dem Körper des Wirbels $(n-1)$ in Verbindung standen, sondern einer zwischen diesem und dem Urostyl, der andere zwischen ihm und dem vorhergehenden Wirbel aufsaßen $=\operatorname{di}(n)(n-1)(n-2)$.

War sowohl dorsal wie ventral ein überzähliger Fortsatz vorhanden - amphikomplexe Individuen - , so befand sich der ventrale fast ausnahmslos am $z$ we ite $n$ Wirbel vor dem Urostyl $=\mathrm{v}(\mathrm{n}-2)$. Nur bei zwei Individuen fand sich die Ausprägung $\mathrm{v}(\mathrm{n}-1)$, bei zweien $v(n-3)$ und bei einem vi $(n-2)(n-3)$. Der legtgenannte war der einzige Fall, wo ein Haemalbogen intervertebral ansegte.

Die überzähligen Spinalbögen setzten bei den amphikomplexen Individuen auf alle Arten an, die bei den dorsalkomplexen aufgezählt worden sind, am häufigsten aber ist die Form di $(n-1)(n-2)$ v (n-2) (Abb. 2g). Die Ausprägung di $(n)(n-1)(n-2)$ v $(n-2)$ ist als ein weiteres Beispiel in $\mathrm{Abb} .2 \mathrm{~h}$ dargestellt.

Die kleine Gruppe der haemal-komplexen Individuen, die nur ventral einen überzähligen Fortsał haben, umfaßt nur fünf Stück in der Gestalt v (n-2). entnehmen.

Die Häufigkeit der einzelnen Komplexformen im einzelnen ist der Zahlentafel $8 \mathrm{zu}$

$$
Z \text { ahlentafel } 8 \text {. }
$$

Häufigkeit der einzelnen Komplexformen unter 1278 Heringslarven mit Komplexbildungen an der Wirbelsäule.

I. Dorsalkomplex (nur dorsal ein überzähliger Fortsatz): 1033 Stück $=80.6 \%$,

$$
\begin{aligned}
& \text { davon } d(n-1) \quad 626 \text { Stück }=488 \% \\
& \mathrm{~d}(\mathrm{n}-2) \quad 25 \%=20 \% \\
& \operatorname{di}(n-1)(n-2) \quad 303 \quad,=23.6 \% \\
& \operatorname{di}(\mathrm{n})(\mathrm{n}-1) \quad 64 "=5.0 \% \\
& \text { di }(n)(n-1)(n-2) \quad 15 \%=1.2 \%
\end{aligned}
$$

II. A mphikomplex (dorsal und ventral je ein überzähliger Fortsatz): 240 Stück $=18,9 \%$,

$$
\begin{aligned}
& \text { davon } \mathrm{v}(\mathrm{n}-2) \mathrm{d}(\mathrm{n}-1) \quad 38 \text { Stück }=3.0 \% \\
& v(n-2) d(n-2) \quad 69 \%=54 \% \\
& v(n-2) \text { di }(n-1)(n-2) \quad 120 \quad "=9.4 \% \\
& v(n-2) \mathrm{di}(n)(n-1) \quad 4 \quad=0.3 \% \\
& v(n-2) \operatorname{di}(n)(n-1)(n-2) \quad+\quad=0.3 \% \\
& \mathrm{v}(\mathrm{n}-1) \mathrm{d}(\mathrm{n}-1) \quad 1 \quad \overline{1}=0.1 \% \\
& \mathrm{v}(\mathrm{n}-1) \mathrm{di}(\mathrm{n}-1)(\mathrm{n}-2) \quad 1 \quad \mathrm{n}=01 \% \\
& v(n-3) \mathrm{di}(n-1)(n-2) \quad 1 \quad "=0.1 \% \\
& v(n-3) d(n-3) \\
& \text { vi }(n-2)(n-3) d(n-2) \\
& =0.1 \% \\
& 1 "=0.1 \% \text {. }
\end{aligned}
$$

III. H a e m a l k o m plex (nur ventral ein überzähliger Fortsatz): 5 Stück $=0,4 \%$,

$$
v(n-2) \quad 5 \text { Stück }=0.4 \% \text {. }
$$

Eine Anzahl von Bildungen kommen so selten vor, daß sie nur wie andere Anomalien gewertet werden können. Unregelmäßigkeiten an der Gestalt der Wirbel geben weitere Stützen für diese Annahme, z. B. bei den amphikomplexen Individuen mit v(n-1). Einige andere seltenere Formen sind nur Sonderfälle der häufigen Bildungen, oder sie gehen im Laufe der Entwicklung in solche über.

Bei den haemalkomplexen Individuen z. B. zeigt die nähere Untersuchung, daß anscheinend der Spinalfortsat von ( $\mathrm{n}-1)$ doppelt angelegt, aber wieder vollständig zu einem Gebi'de verschmolzen ist, so daß diese Form auf eine amphikomplexe zurückzuführen wäre. Ähnlich sind Anzeichen dafür vorhanden, daß bei einigen Dorsalkomplexen der Form $d(n-2)$ eine völlige Verschmelzung der ursprünglich doppelt angelegten Haemaldornen des Wirbels $(n-2)$ zu verzeichnen sind. Bei anderen handelt es sich offenbar nur um Grenzfälle der Ausprägung di $(n-1)(n-2)$, so bei dem in Abb. $2 b$ dargestellten Individuum.

Die Formen di $(n)(n-1)$ und di $(n)(n-1)(n-2)$ kommen nur bei ganz kleinen dorsalkomplexen und amphikomplexen Individuen vor, bei denen noch breite unverknöcherte Zonen vorhanden sind. Es scheint daher, daß bei fortschreitender Verknöcherung der hintere Spinalfortsał stets mit dem Wirbelkörper $(\mathrm{n}-1)$ verschmilzt. Dagegen kommt der intervertebrale 
Ansaty des zweitletten, di $(n-1)(n-2)$, auch noch bei großen Iarven vor. Offenbar bildet sich bei diesen Individuen der Zustand aus, den Ford 1933 als C und D in seiner Fig. 4 abbildet. Unsere Abb. 2d zeigt den Übergang der Entwicklung vom intervertebral angelegten Fortsat5 der Larve zum "autonomen“ Fortsats des metamorphosierten Herings.

Es kommen bei den Komplexbildungen übrigens mancherlei Unregelmäßigkeiten vor. Der überzählige Spinalfortsaz kann mit dem bənachbarten proximal oder distal verschmo' 7 en sein, wie auch Ford das darstellt. Bei einem abnormen Individuum war der zweite Spinalfortsaty auf einer Körperseite mit dem leţten, auf der anderen mit dem drittletzten verschmolzen.

Wichtig aber ist es, daß bei fast allen amphikomplexen Individuen die beiden $\mathrm{H} \times$ emalfortsätze des Wirbels $(n-2)$ irgendwelche Verschmelzungen zeigten, entweder an den Bogenbasen oder distal, dann häufig nur an einer Körperseite, wie Abb. $2 \mathrm{~g}$ es zeigt. In den übrigen Fällen lagen die beiden Fortsätze doch wenigstens sehr dicht beisammen, während die Spinalfortsäţe in sehr vielen Fällen ziemlich gleichmä3ige Abstände aufwiesen. Bei zwei amphikomplexen Individuen. bei denen die beiden Haemalfortsäge des Wirbels $(n-2)$ nicht verschmolzen waren, bot das Aussehen des Wirbelkörpers Anzeichen dafür, daß er aus 2 Anlagen verschmolzen war.

Endlich ist noch ein Einzelfall abnormer Bildung zu erwähnen, der nicht eigentlich als Komplexbildung zu bezeichnen ist: Bei einer Larve trug der Wirbelkörper $(n-1)$ zwei Dorsalfortsätze, dafür fehlte aber dem Wirbel (n-2) der Fortsatg. Die Zahl der Fortsätge stimmte also mit der der Wirbel überein, nur der Ansatspunkt des einen war verschoben.

Die genauere Untersuchung der Komplexbildungen läßt eine Reihe von Tatsachen hervortreten, die für die Deutung der Erscheinung von Wichtigkeit sind.

1. Nicht weniger als $80 \%$ der Komplexbildungen hat nur dorsal einen überzähligen Fortsat5. Die wenigen haemalkomplexen Individuen sind wahrscheinlich amphikomplexe mit zwei völlig verschmolzenen Neuraldornen.

2. Von den drei Spinalfortsätten, die bei den komplexen Individuen über den beiden letzten Wirbeln stehen, kann der mittlere entweder auf dem Wirbel $(\mathbf{n}-1)$ oder auf dem Wirbel ( $n-2)$ oder zwischen beiden ansetzen. Einige abnorme Fälle bestätigen die Tatsache, daß der Ansaţpunkt der leţten Spinalfortsätge im Verhältnis zu den Wirbelkörpern variabel ist.

3. Uberzählige Haemalfortsätye seţen praktisch stets auf dem Wirbel (n-2) an, n:cht auf $(n-1)$, der am häufigsten den überzähligen Spinalfortsats trägt. Intervertebraler Ansaţ des Haemal torns ist als Abnormität zu werten.

4. Während Verschmelzungen von überzähligen Spinalfortsätgen mit dem benachbarten vorkommen, sind sie bei überzähligen Haemalfortsätzen fast die Regel.

Diese Eigentümlichkeiten sind nicht gut mit der Annahme vereinbar, daß die Komplexbildung die Realisierung des Bruchteils einer Wirbelanlage oder die Verbindung eines normalen Wirbels mit einer weiteren. unvollkommen abgegliederten Restanlage sei. Einen so'chen Rest würde man am Ende der Wirbelsäule erwarten, d. h., da das Urostyl frühzeitig angeległ wird. bei dem letzten normalen Wirbel. In der Tat erscheint aber der zweite Fortsat vor dem Urostyl als der überzählige: Ventral erfolgt die Verdop velung stets am Wirbel $(n-2)$ und dorsal ist es gleichfalls der zweite Fortsaty, der durch die Variabilität seines Ansatzes eine Ausnahmestellung einnimmt. Es ist auch schwer zu verstehen, weshalb ein solcher Wirbelrest in ${ }^{4 / 5}$ der Fälle nur aus einem Spinalfortsaty bestehen sollte.

Auch die Längenverhä'tnisse der leţ'en Wirbelkörper bei Heringslarven mit Komplexbildungen, die im Folgenden besprochen werden sollen, sprechen nicht für die Auffassungen KäNDLERS und FoRDS.

d). Die Längenverhältnisseder letzten Wirbel.

KäNDLER hat nachgewiesen, daß der Körper komplexer Wirbel bei den Schollen länger ist als der eines normalen Wirbels in gleicher Lage. Bei den Heringslarven lehrte der Augen-. schein ohne weiteres, daß der Wirbelkörper $(n-2)$ bei amphikomplexen Individuen merk'ich verlängert war. Es wurden nun einige Messungen an Wirbelkörpern von Individuen mit und ohne Komplexbildungen vorgenommen. Die Länge des dritten Wirbels vor dem Urostyl wurde dabei als Vergleichsmaßstab benuzt und gleich 1 gesetgt. Die Ergebnisse der Messungen finden sich in Zahlentafel 9. 
$Z$ ahlentafel 9.

Längenverhältnis der letztendrei Wirbelkörper vordem Urostyl.

\begin{tabular}{l|c|c|c|c|c}
\hline \multicolumn{1}{c|}{ Ausbildung } & \multicolumn{3}{|c|}{ Relative Länge der Wirbel } & Zahl der \\
& $(\mathrm{n}-3)$ & $(\mathrm{n}-2)$ & $(\mathrm{n}-1)$ & Messungen \\
\hline Normal & 1.00 & 1.00 & 1.03 & 104 \\
Dorsalkomplex & 1.00 & 1.04 & 1.06 & 27 \\
d (n-1) & 1.00 & 1.08 & 0.99 & 18 & \\
di (n-1) (n-2) & 1.00 & 1.17 & 0.97 & 28 \\
Amphikomplex & 1.00 & 1.17 & 0.91 & 22 \\
v (n-2) di (n-1) (n-2) & & & \\
v (n-2)d (n-2) & &
\end{tabular}

Bei Larven ohne Komplexbildung sind die drei Wirbelkörper nahezu gleich lang, der Wirbel $(n-1)$ übertrifft die beiden anderen um nur $3 \%$.

Bei dorsalkomplexen Individuen zeigen sich kleine Abweichungen. Trägt der lette Wirbel zwei Fortsäłze, so sind be ide lebten Wirbel ein wenig verlängert und zwar um 4 bezw. $3 \%$. Wenn aber der überzählige Dornfortsatz intervertebral ansetzt, so ist der Wirbel $(\mathrm{n}-2)$ um $8 \%$ länger, der leţte Wirbel dageg en um $4 \%$ kürzer als bei normalen Tieren.

Bei amphikomplexen Individuen ist stets der Wirbel (n-2), der zwei Haemalfortsäge trägt, erheblich verlängert (17\%), der lefte Wirbel aber verkürzt, in geringem Maße, wenn der Spinalfortsaty intervertebral ansetgt, stark dagegen (um $12 \%$ ), wenn er auf dem zweiten Wirbel vor dem Urostyl ansegt.

KäNDLER wertet die Verlängerung der komplexen Wirbel bei den Schollen als weiteres Indizium dafür, daß sie die Summe eines normalen Wirbels und eines unvollkommen abgegliederten Restes darstellen. Die bei den Heringslarven festgestellten Verhältnisse lassen sich nicht ohne weiteres so deuten. $Z_{w a r}$ ist der Wirbel $(n-2)$ verlängert, wenn er 2 Haemalfortsäţe trägt; dagegen ist eine adaequate Verlängerung des Wirbels, der den überzähligen Spinalfortsats trägt, nicht nachzuweisen.

e) Beobachtungen über die Entwicklungdes Schwanzskeletts.

Die wesentlichen Züge der Entwicklung der Heringslarven, insbesondere ihres Skeletts, dürfen als bekannt vorausgesetzt werden. Es sei hier insbesondere auf die Arbeit von SchnakenBECK (1930) verwiesen.

Während die Wirbelkörper auf ziemlich späten Stadien unmittelbar auf der Grundlage des perichordalen Bindegewebes verknöchern, werden die oberen und unteren Bögen knorplig präformiert. Das gleiche gilt für die Hypuralia und Enuralia. Bei den Hypuraljen und den leţten Spinal- und Haemalfortsätzen tritt die Knorpelbildung sehr frühzeitig ein. Man erzielt eine differente Färbung mit Toluidinblau teilweise schon bei Larven von $15 \mathrm{~mm}$ Länge.

Bei dem Individuum dieser Länge, desien Schwanzskelett in Abb. 3 a dargestellt ist, ist der Endabschnitt der Chorda, die Urostylan'age, noch nicht vollständig dorsalwärts aufgebogen. Knorplig ausgebildet sind das viscera'e Kopfskelett, die Scapula und teilweise die Träger der Rückenflosse. Im Schwanz sind die Hypuralia 2 bis 6 als Knorpelskelett zu erkennen. Das oberste Hypurale fehlt noch. Vorhanden ist ferner das Skelettelement, das Scrnakenbeck als Hypurale 7 bezeichnet. Es sizt später dem vorderen, wirbelähnlichen Teil des Urostyls an und zeigt basal noch die Reste eines Haemalkanals. Deshalb wird es hier als Haemalfortsat ( $n$ ) bezeichnet. Außerdem aber, und das ist bezeichnend, ist auch der Haemalfortsat $(n-1)$ schon voll mit ausgebildet und in das System der hypuraien Schwanzplatte einbezogen. Der cranialwärts folgende Haemalfortsaţ ist viel kürzer und schwächer und steht nicht in Verbindung mit der Schwanzplatte.

Schon etwas weiter in der Entwicklung fortgeschritten ist ein Individuum von $16 \mathrm{~mm}$. (Abb. 3b.) Das Chordaende ist stärker aufwärts gebogen, die Schwanzplatte wird langsam mehr senkrecht gestellt, der oberste Hypura'knorpel ist erschienen. Der Haemalfortsat3 (n-1) ist sehr stark entwickelt und ganz eng in die Schwanzplatte einbezogen. Hinter ihm sind drei Haemalfortsäţe entwickelt, die in gleichmäßigen Abständen parallel zu ihm verlaufen, aber wesentl' ch schwächer sind und nicht in die Schwanzplatte einbezogen. Dorsal sind noch keine knorp.igen Fortsätze erschienen.

In der Folge erscheinen weitere Haemalfortsäge und nun auch. kleiner und schwächer, die Spinalfortsätze des Schwanzstiels. Bei dem Stadium von $19 \mathrm{~mm}$ (Abb. 3c) ist die Aufbiegung des Chordaendes im wesentlichen abgeschlossen. Im Schwanzstiel sind, den n-Fortsats eingerechnet, 6 Haemalfortsätze entwickelt, von denen $(n)$ und $(n-1)$ wiederum deutlich in die 


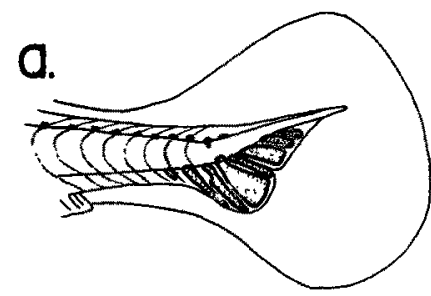

\section{$75 \mathrm{~mm}$}

b.
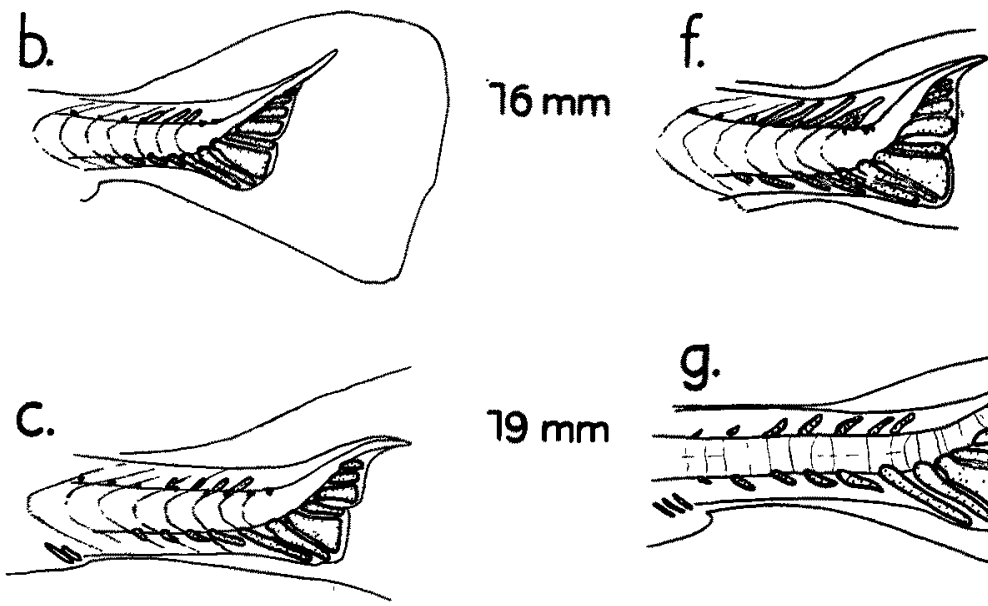

$19 \mathrm{~mm}$
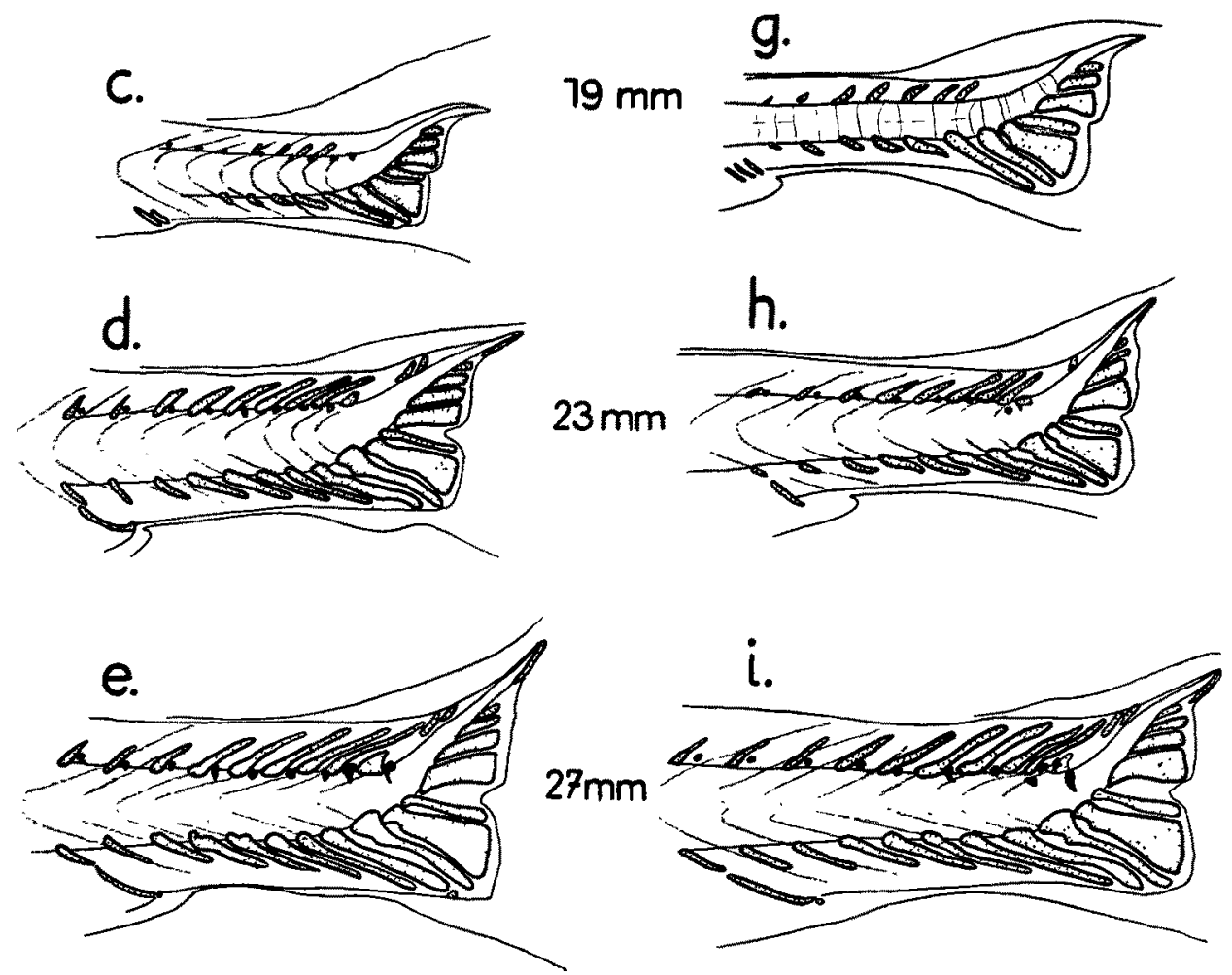

Abb. 3. Entwicklung des knorpligen Schwanzskeletts. Knorpel punktiert. Myosepten und Spinalganglien eingezeichnet; $a-e$ Individuen ohne Kompl xbildung. $\mathrm{f}-\mathrm{i}$ dorsalkomplexe Individuen. Erkärung im Text.

nun schon ziemlich senkrecht gestellte Schwanzplatte einbezogen sind. Die folgenden schwächeren Haemalfortsätze schließen sich parallel zu ihnen an. Dorsal sind 4 Spinalfortsätze entwickelt, schwächer als die Haemalfortsätze. Auffällig ist eine Lücke im Dorsalskelett zwischen dem leţten Spinalfortsat und dem aufgebogenen Chordaende.

In dieser Lücke erscheinen auf den folgenden Stadien am dorsalen Körperende zwei kleine Epuralknorpel und die oberen Bögen des cranialen, wirbelähnlichen Teils des Urostyls [die Spinalbögen von $(\mathrm{n})$ ], die aber im Knorpelstadium kurz bleiben, dorsal nicht verschmelzen und keinen Dornfortsaty bilden. Trotsdem bleibt die Lücke im Dorsalskelett zwischen der Urostylanlage und dem letten Spinalfortsaty noch auf dem in Abb. 3d dargestellten, $23 \mathrm{~mm}$ langen Stadium deutlich erkennbar. Im übrigen aber sind die Spinal- und Haemalfortsäts? im Schwanzstiel mächtige Knorpelgebilde geworden, die bis an die Körperränder reichen und im optischen Schnitt einen großen Teil der Fläche einnehmen. Im auffallenden Gegensaţ dazu 
haben sich im Rumpf nur kleine unscheinbare Knorpelstümpfe der oberen und unteren Bögen entwickelt.

Bei einer Länge von ca. $27 \mathrm{~mm}$ ist der Höhepunkt der Ausbildung des Knorpelskeletts im Schwanz, erreicht. Alle Fortsätze sind breit und mächtig entwickelt (Âbb. 3c). Der leţte Spinalfortsats $(n-1)$, ist weit caudalwärts ausgewachsen und erstreckt sich über den Neuralbogen von $(\mathrm{n})$, ja sogar über den vord ren der beiden Epuralknorpel hinweg, so die oben beschriebene Lücke im Dorsalskelett schließend.

Individuen mit Komplexbildungen kann man in den weitaus meisten Fällen bereits auf frühen Stadien der Knorpelbildung als solche erkennen. Bei allen dorsalkomplexen Individuen stehen dem Haemalfortsaţ (n-1) zwei Spinalfortsäzze gegenüber, und dies ist bereits nach Ausbildung weniger knorpliger Fortsätze festzustellen.

Abb. 3f zeigt das Schwanzskelett eines dorsalkomplexen Individuums von ca. $16 \mathrm{~mm}$ Länge, das allerdings in der Entwicklung verhältnismäßig weit fortgeschritten ist. Das Chordaende ist weit aufgebogen, einschließlich des Fortsatyes von (n) sind 5 Haemalfortsätge ausgebildet, und außerdem sind 4 Spinalfortsätse vorhanden (noch nicht völlig verknorpelt), von denen die leţten beiden distal verschmolzen sind. Sie stehen beide dem Haemalfortsats $(n-1)$ gegenüber und werden aller Voraussicht nach später dem Wirbel (n-1) aufsitzen.

Abb. 3g stellt ein dorsalkomplexes Individuum von $19 \mathrm{~mm}$ vor, bei dem die beiden leţen Spinalfortsäţe nicht verschmolzen sind. Hier fällt besonders stark die große Lücke auf, die im Dorsalskelett zwischen dem letten Spinalfortsats und dem aufgebogenen Chordaende besteht. Sie würde noch größer und empfindlicher sein, wenn kein überzähliger Fortsats vorhanden wäre.

Auch bei dem $23 \mathrm{~mm}$ langen, dorsalkomplexen Individuum (ohne Verschmelzung der Spinalfortsätze), das in Abb. 3a wiedergegeben ist, ist dic Lücke ebenso erkennbar wie bei der danebenstehen. den, gleichlangen normalen Larve Abb. 3d, und sie würde ohne den überzähligen Fortsaţ wiederum noch größer sein.

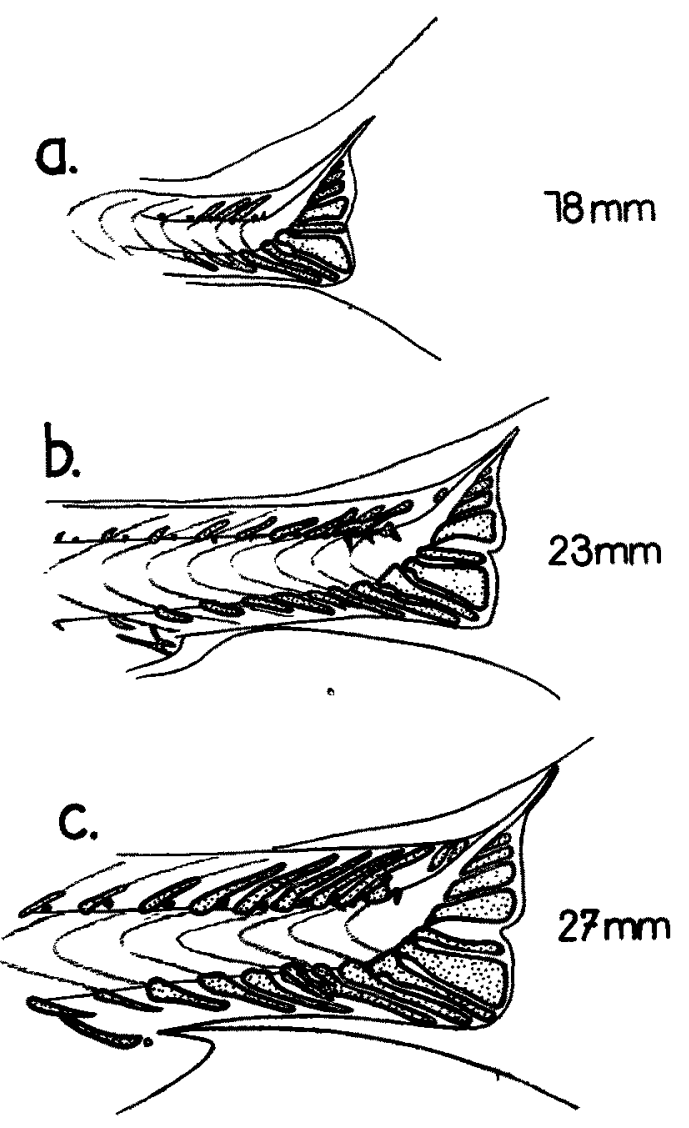

Abb. 4. Entwicklung des knorpeligen Schwanzskeletts. a bis $c$ amphikomplexe Individuen. Erklärung im Text.

Bei der $27 \mathrm{~mm}$ langen dorsalkomplexen Larve in Abb. 3i endlich ist die Lücke in derselben Weise wie bei der normalen Abb. 3e dadurch überbrückt, daß der letgte Spinalfortsats caudalwärts ausgewachsen ist.

Auch amphikomplexe Individuen kann man auf früheren Stadien erkennen; wenn die beiden Haemalfortsätge miteinander verschmolzen sind, wie das in der Mehrzahl der Fälle zutrifft. Amphikomplexe Bildungen der Stad:en von 18, 23 und $27 \mathrm{~mm}$ sind in Abb. 4 wiedergegeben. Bei der $23 \mathrm{~mm}$ langen Larve (Abb. 4 b) sind nicht nur die beiden Haemalfortsäze auf der rechten Körperseite miteinander verschmolzen, sondern auch die beiden letten Spinalfortsäze vor (n) und zwar auf der linken Körperseite. Die Lücke im Dorsalskelett ist in Abb. 4a und $\mathrm{b}$ wieder deutlich, bei dem $27 \mathrm{~mm}$ langen Individuum (Abb. 4c) ist sie wiederum geschlossen. Bei diesem sind die beiden Ha-malfortsätye rechtsseitig verschmolzen. - Wesentlich ist insbesondere die Feststellung, daß die Entscheidung über die Komplexbildung auch hier schon auf sehr frühe Stadien fällt.

Von Bedeutung sind für uns weiterhin die Vorgänge bei der Verknöcherung des Schwanzskeletts, deren Verlauf nunmehr in den großen Zügen geschildert werden soll.

Die ersten Anzeichen der Verknöcherung sind schon auf dem Stadium von $23 \mathrm{~mm}$ in dem Schwanzskelett festzustellen. Abgesehen von den knöchernen Flossenstrah'en verknöchert zuerst das.Urostyl, vor allem eine dorsale Leiste über dem Chordaende. Knochen ist ferner nachweisbar in den Hypuralien. Im übrigen Körper erscheinen die Clavicularia und die Kieferknochen. 
Bei $25 \mathrm{~mm}$ (Abb. 5a) sind Urostyl, Hypuralien und die Haemalfortsätze (n) und $(\mathrm{n}-1)$ bereits stark verknöchert. Auf diesem Stadium beginnt im mittleren Körperabschnitt die Bıldung der knöchernen Wirbel. Sie erscheinen als ganz schmale Knochenringe, zwischen denen zunächst breite intervertebrale Räume bleiben. In diesen stellt die Chorda allein die axiale Stütze. Ein solches Stadium ist in Abb. 5a dargestellt. Ubrigens ist auch dieses Individuum amphikomplex. Die beiden verschmolzenen Haemalfortsätze sind aber noch nicht verknöchert.

In der Folge nimmt die Breite der Knochenringe zu, bis nur noch schmale intervertebrale Zonen übrigbleiben, und gleichzeitig schreitet $d_{e} e$ Wirbelbildung cranial- und caudalwärts fort. Auf Stadien von 27-30 mm Länge (Abb. 5b) beginnt die Verknöcherung des Schwanzstielskeletts. Bei den starken Fortsäzen dieser Region beginnt die Verknöcherung im mittler en Teil, etwa an der Verschmelzungsstelle der Bögen. An der Bogenbasis und distal bleibt Knorpel lange erhalten, ebenso übrigens in der Schwanzplatte. Mit der Verknöcherung wird die Fo:m der Fortsäbe schlanker: der festere Knochen vollbringt die geforderte mechanische Leistung mit geringerer Masse als der Knorpel.

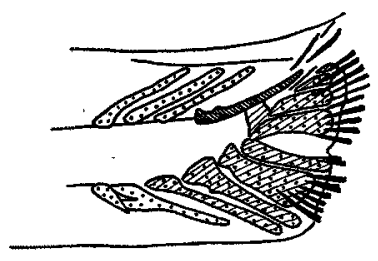

$25 \mathrm{~mm}$

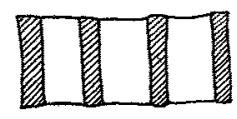

a

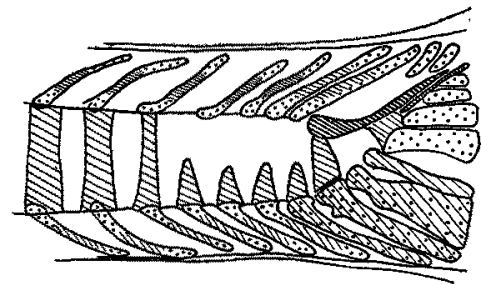

$27 \mathrm{~mm}$
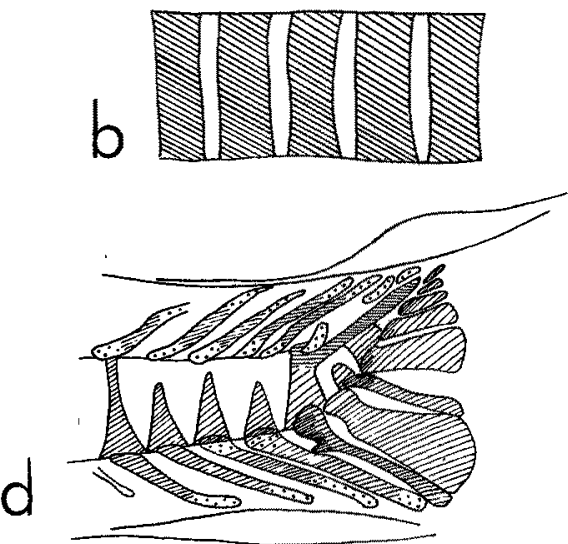

$32 \mathrm{~mm}$

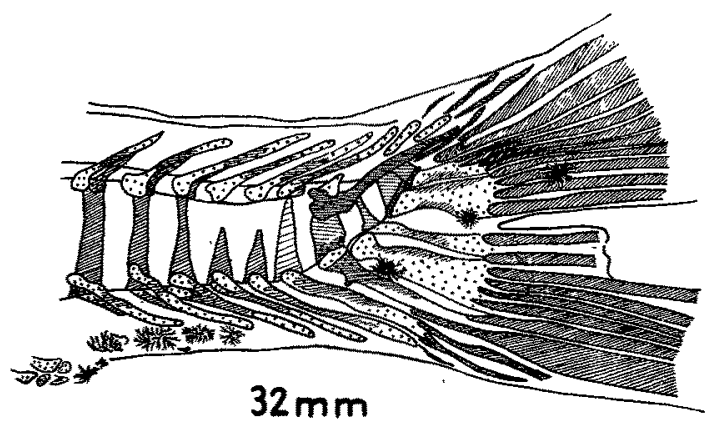

C

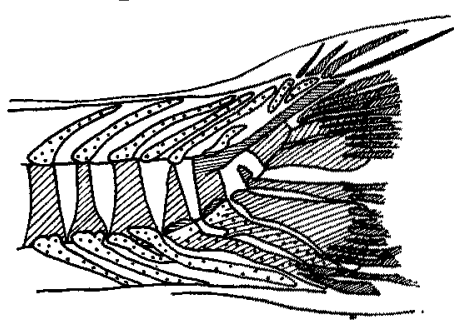

$29 \mathrm{~mm}$

Abb. 5. Entwicklung des knöchernen Schwanzskeletts und Wirbelbildung. Knorpel punktiert, Knochen schraffiert. Bei $a$ und $b$ unten die Gestalt der Wirbel im mittleren Abschnitt der Wirbelsäule. Erklärung im Text.

Die Bildung der knöchernen Wirbel im Schwanzstiel erfolgt in anderer Weise als in den anderen Körperabschnitten. Wie die Ausbildung des knorpligen Schwanzskeletts ventral beginnt, so beginnt auch die Bildung der Wirbelkörper von der Ventralseite her. Sie stellt zunächst an der Ansaţstelle der Haemalbögen eine breite Zone dar, die sich dorsalwärts verschmälert und anfangs vor Erreichen des dorsalen Chordarandes auskeilt. So entsteht im optischen Schnitt das Bild einer dreieckigen Verknöcherungszone, wie Abb. 5b sie bei einem normalen Individuum an den 4 letsten Wirbeln vor dem Urostyl zeigt. Auch wenn bei weiterer Entwicklung die Verknöcherung den dorsalen Chordarand erreicht, wie bei dem Wirbel $(n-5)$, so bleibt die Zone dorsal zunächst noch schmäler als ventral.

Den Fortgang der Verknöcherung bei einem normalen Individuum zeigt Abb. 5c. Die Wirbelanlagen (n-2) und $(n-3)$ haben noch auskeilende Verknöcherungszonen, $(n-1)$ und $(\mathrm{n}-4)$ aber schon ringförmige, wenn auch dorsal noch schmale. Die Verknöcherungszone erreicht den Dorsalrand der Chorda hier gerade unter den zugehörigen Spinalfortsätzen.

Bezeichnend ist nun das entsprechende Entwicklungsstadium bei komplexen Individuen. Abb. 5d zeigt ein dorsalkomplexes Individuum von $32 \mathrm{~mm}$. 3 Wirbelzonen sind noch keilförmig. Die beiden cranialen werden dorsal auf die Ansatgstellen der oberen Bogen stoßen. Die Anlage des Wirbels $(n-1)$ aber trifft mitten zwischen die Ansatspunkte der beiden leten. Eine 
Zeitlang wird die Bildung die Form di $(n)(n-1)(n-2)$ haben. Mit zunehmender Breite der Verknöcherungszone aber wird mindestens einer, wahrscheinlich werden in diesem Falle be de Spinalfortsäłge mit dem Wirbelkörper $(\mathrm{n}-1)$ verschmelzen. $\mathrm{Ob}$ der vordere der beiden Spinalfortsätze auf dem Wirbel $(n-1)$, intervertebral oder auf dem Wirbel (n-2) ansetzt, muß ersichtlich von den Lagebeziehungen, der Lage der Ansätye und der Breite der Wirbelkörper, abhängen.

Abb. 5e zeigt schließlich ein frühes Verknöcherungsstadium eines amphikomplexen Individuums. Die beiden Haemalfortsäţe des Wirbels ( $n-2)$ sind rechtsseitig verschmolzen, die Basen berühren einander, und von dieser Stelle aus ist eine Verknöcherungszone entstanden, die sich deutlich durch größere Breite von den benachbarten auszeichnet. Die noch keilförmige Verknöcherungszone des Wirbels $(n-1)$ wird etwa auf den Ansatpunkt des letten Spinalfortsates vor dem Urostyl treffen. Bei der weiteren Ausbreitung der Knochenringe wird der zweitletzte Spinalfortsaty voraussichtlich intervertebral ansezen. Bei etwas anderen Lagebeziehungen ist selbstverständlich die Entstehung der anderen vorkommenden Ausprägungen durchaus möglich.

Bei einer Länge von ca. $35 \mathrm{~mm}$ haben alle Wirbel des Schwanzstiels eine gleichmäßige Ringform erreicht, und die intervertebralen Zonen sind schmal geworden. Die Verschmelzung der Spinalfortsätze mit den Wirbelkörpern ist erfolgt. - Die endgültige Gestalt der Wirbelkörper und ihrer Fortsätze, die Fond im einzelren beschrieben hat, z. B. der doppelte Ansaţ der Haemalbögen bei den Schwanzwirbeln, bildet sich erst bei Längen über $40 \mathrm{~mm}$ aus. Dieser Teil der Entwicklung ist aber für die hier erörterte Frage nicht weiter von Bedeutung.

Die geschilderte Entwicklung des Schwanzskeletts ist offenbar weitgehend geprägt durch den Leistungsbedarf des Larvenkörpors. Anfangs stellt die unverknorpelte Anlag o der Hypuralia nur eine das Ruder verbreitende Bildung ventral von der durchlaufenden Chorda dar. Vorausseţung für die Steigerung der Beweglichkeit der Larve ist aber die Ausbildung der Schwanzplatte. Gleichzeitig mit der Aufbiegung des Chordaendes erfolgt die Ausbildung der mächtigen hypuralen Knorpelplatten. Um die Verbindung mit dem axialen Teil der Chorda auch ventral sicher zu stellen, gleichsam als ventrales Gegenstück zur Urostylanlage, wird auch der Haemalfortsat $(n-1)$ sogleich in die Schwanzplatte einbezogen. Die ventrale Hälfte des Schwanzes bleibt aber beweglicher. Es ist bekannt, daß die ausgiebigeren Bewegungen der ventralen Schwanzflossenfahne eine große Bedeutung für die Ruder- und Steuerfunktion haben. Dies braucht hier nicht näher erörtert zu werden: die Beobachtung jedes langsam schwimmenden Knochenfisches lehrt es.

Der nächste Schritt für die Verstärkung der Ruderwirkung des Schwanzes ist die Ausbildung von Stützen im Schwanzstiel. Sie wird bewirkt durch die mächtige Entwicklung der knorpligen Bögen und Fortsätze dieses Körperabschnittes. Im allgemeinen bleibt ja die Knorpelentwicklung bei den Knochenfischen gering. bei manchen Gruppen ist sie fast ganz unterdrückt. In großem Umfang erfolgt jedenfalls die Knorpelbildung nur da, wo sie im Larvenleben eine Funktion erfüllt. So der Knorpel des Visceralskeletts, der Flossenstrahlenträger, so auch der der Fortsäţe im Schwanzstiel. Der Unterschied in der Ausbildung derselben und der kleinen, praktisch funktionslosen Bogenstümpfe im Rumpfabschnitt beweist die funktionelle Bedeutung des Schwanzskeletts zur Genüge.

Die ventrale Hälfte des knorpligen Schwanzstielskeletts entwickelt sich eher, bleibtt stärker und zunächst geschlossener als die dorsale. Dies ist darauf zurückzuführen, daß dic Haemalfortsätze einmal ventral die Stützfunktion für die Schwanzflosse übernehmen müssen, die dorsal der durchlaufenden Chorda zukommt (Sonderstellung des Haemalfortsatyes $(\mathbf{n}-\mathbf{1})$ ), zum anderen aber ein festes Widerlager für die ausgiebigeren Bewegungen der Schwanzflossenfahne bilden. So entsteht ventral eine lückenlose, eng geschlossene Reihe von Skele!telementen, während dorsal zunächst die mehrfach erwähnte Lücke zwischen leţtem Spinalfortsatz und Urostylanlage entsteht, die erst verhältnismäßig spät geschlossen wird.

Die Reihenfolge der Verknöcherung im Schwanz läßt gleichfalls die funktionelle Bedeutung zuerst der Schwanzplatte mit ihrer dorsalen und ventralen Stüţe, Urostyl und Haemalfortsats (n) und ( $n-1)$, erkennen. Zweifellos ist es die stärkere mechanische Beanspruchung der Haemalfortsäłze, die es bewirkt, daß abweichend von dem Modus in den anderen Körperabschnitten die Wirbelbildung vom Ansaty der Haemalbögen her erfolgt. bildungen?

Was ergibt sich nun unter diesen Gesichtspunkten für die Entstehung der Komplex- 
1. Die Lücke im dorsalen Skelett zwischen dem Fortsaty (n-1) und dem Chordaende bietet Raum für die Einfügung eines überzähligen Fortsatzes. Wahrscheinlich ist der überzählige Spinalfortsaty sogar erforderlich, um die Leistung, die vom Schwanzstiel gefordert wird, zu ermöglichen. Es ist nämlich zu berücksichtigen, daß der Fortsatz als erster gebi'det wird, nicht etwa als Rest aus einer im übrigen aufgegliederten Masse. Die Frage, ob gleichwohl für den überzähligen Fortsats eine ursprüngliche Segmentanlage vorhanden ist, wird an anderer Stelle noch näher beleuchtet werden. Jedenfalls erklärt die Tatsache, daß dorsal Raum und Bedarf für einen überzähligen Fortsał ist, ventral aber kein Raum, das häufige Vorkommen der nur dorsalkomplexen Bildungen.

2. Die Bildung der knöchernen Wirbel erfolgt von der Ansatzstelle der unteren Bögen aus. Die oberen Bögen üben im Schwanzstiel keinen Einfluß auf die Wirbelbildung aus. Bei komplexen Individuen stehen 3 Spinalfortsäte über 2 sich bildenden Wirbeln. Die Folge muß zwangsläufig sein, daß der Ansabpunkt der Spinalfortsätze variabel wird und abhängig einmal von ihrem Abstand voneinander, zum andeı en von der Breite der sich bildenden Wirbelkörper. Sind die Wirbelkörper oben noch schmal, so wird häufig die Bildung di $(n)(n-1)$ oder di $(n-1)$ $(n-2)$ entstehen, mit der Verbreitung der Verkü̈cherungszone aber verschwinden. Ist der letzte Wirbel relativ lang, so ist die Bildung $\mathrm{d}(\mathrm{n}-\mathrm{l})$ wahrscheinlich, weil die beiden letz en Fortsätze häufig etwas näher beieinander stehen (wie denn überhaupt der Abstand bei den leţten Fortsäţen schwanzwärts abnimmt). Ist der Wirbel (n-2) verhältnismäßig lang, so wird der intervertebrale Ansats des mittleren der drei Spinalfortsätse wahrscheinlich, ja er kann sogar auf den Wirbel (n-2) vorrücken. Da der Wirbel (n-2) bei den amphikomplexen Individuen stets bedeutend verlängert ist, ist der Ansat $d(n-2)$ oder di $(n-1)(n-2)$ bei diesen wesentlich häufiger als bei den nur dorsalkomp'exen. Es leuchtet ein, daß3 unter diesen Umständen die Länge des letgten Wirbels $(n-1)$ entscheidend dafür ist, welche von den beiden Ansatgformen sich er-. gibt. Auch die abnorme Bildung, daß ein Wirbel zwei, der andere dafür gar keinen Spinal-fortsaţ trägt, ist so leicht zu erklären.

3. Wenn die knöchernen Wirbelkörper von der Ansałstelle der unteren Bögen her entstehen, so müßte ihre Zahl stets der der Haemalfortsätge entsprechen. Es ist aber dargelegt worden, daß bei amphikomplexen Individuen fast stets irgendwelche Verschmelzungen der benachbarten Fortsäłze vorkommen. Liegt eine solche an der Basis, so kann selbstversłändl'ch nur eine Verknöcherungszone angelegt werden. Besteht sie distal, so ist jedenfalls die Biegung der Skelettachse zwischen beiden Basen behindert, und die Voraussetzung für das Bestehenbleiben ciner Wirbelgrenze nicht gegeben. Wenn endlich die Basen unverschmolzener Fortsäze sehr dicht nebeneinander liegen, so kann man sich leicht vorstellen, daß die Verknöcherungszonen zusammenfließen. In der Tat wurden ja in einigen derartigen Fällen Verschmelzungsspuren an den Wirbelkörpern festgestellt.

Das Auftreten von Verschmelzungen und das allzunahe Zusammenrücken von Fortsätzen wird durch die enge Lagerung und breite Ausbildung der Haemalfortsätge begünstigl. Wir stellen Verschmelzungen $\mathrm{ja}$ auch hin und wieder bei Spinalfortsätgen fest, wenn durch Einfügung eines überzähligen Fortsatzes der Abstand derselben vermindert wird. Es ist nicht verwunderlich, wenn die Erscheinung auch bei den stets eng gelagerten Haemalfortsätzen gelegentlich vorkommt. Dann bedingt sie die Ausbildung des amphikomplexen Typs. Die größere Länge des Wirbelkörpers $(n-2)$ bei diesem Typ ist eine selbstverständliche Folge der Entstehungsweise.

4. Daß diese Verschmelzung praktisch niemals bei dém Wirbel $(n-1)$ auftritt, wird völlig durch die Sonderfunktion und frühzeitige Entwicklung des Haemalfortsaţes (n-1) erklärt.

\section{f) Die Wirbelzahl von Heringslarven mit und ohne Komplexbildung.}

Es ist bereits eingangs darauf hingewiesen, daß nach KäNDLERs Feststellungen die Schollen mit komplexem letten Wirbel im Durchschnitt eine um 1/2 Wirbel geringere Wirbelzahl haben als die mit normalen Wirbeln. Das gleiche ergab sich für Fords Heringe und für eine Anzahl weitere von ForD hierauf untersuchte Arten. Allerdings betrug der Unterschied nicht immer gènau $1 / 2$ Wirbel.

Die hier untersuchten Heringslarven mit Komplexbildungen haben ebenfalls nahezu einen halben Wirbel weniger als die ohne so'che. Das ist in Zahlentafel 10 belegt. 


\begin{tabular}{|c|c|c|c|c|}
\hline $\begin{array}{c}\text { Durchschnittliche Wirb } \\
\text { Längengruppe }\end{array}$ & $\begin{array}{r}Z \text { ah } \\
\text { hl von H } \\
30-35 \mathrm{~mm}\end{array}$ & $\begin{array}{l}\text { e } 110 . \\
\text { s I a r v en } \\
35-40 \mathrm{~mm}\end{array}$ & $\begin{array}{l}\text { d ohne } \\
40 \mathrm{~mm}+\end{array}$ & $\begin{array}{l}\text { lexbild } \\
\text { Zusammen }\end{array}$ \\
\hline $\begin{array}{l}\text { Normale, Vert. S. } \\
\text { Komplexe, Vert. S. }\end{array}$ & $\begin{array}{l}56,493 \\
56,067\end{array}$ & $\begin{array}{l}56,575 \\
56,080\end{array}$ & $\begin{array}{l}56,612 \\
56,133\end{array}$ & $\begin{array}{l}56,557 \\
56,088\end{array}$ \\
\hline $\begin{array}{l}\text { Differenz } \\
\text { F (Diff.) }\end{array}$ & $\begin{array}{r}0.426 \\
\pm 0,031\end{array}$ & $\begin{array}{r}0,495 \\
\pm 0,023\end{array}$ & $\begin{array}{r}0,479 \\
\pm 0,031\end{array}$ & $\begin{array}{r}0,469 \\
\pm 0,016\end{array}$ \\
\hline
\end{tabular}

Die amphikomplexen Larven unterscheiden sich in der mittleren Wirbelzahl nicht von den dorsalkomplexen. Der Durchschnitt beträgt bei ihnen 56,084 Wirbel.

KÄNDLER wertet den festgestellten Unterschied als Indicium dafür, daß die Komplexbildung die Anlage von mehr als einem, nämlich einem und einem halben Wirbel repräsentiert. Diese Folgerung ist durchaus einleuchtend. Auf Grund des oben Festgestellten müßte man sie dahin ergänzen, daß amphikomplexe Bildungen nicht etwa einen größeren Bruchteil repräsentieren würden als dorsalkomplexe.

Es schien von Interesse, zu untersuchen, ob sich bei komplexen Individuen neben den überzähligen Fortsätgen auch sonst noch Anzeichen dafür finden, daß ursprünglich ein Körpersegment mehr vorhanden war, als d e Zahl der Wirbel beträgt. Solche Anzeichen konn'en in der Zahl der Myomeren und der Spina'gang ien in der Tat gefunden werden. Aber auch bei diesen Gebilden ist die Metamerie im Schwanzabschnitt gestört. Das Ergebnis ist nicht eindeutig, sondern liefert nur Indizien. Um die Un'ersudhung technisch nicht allzu schwierig werden zu lassen, wurde bei Larven zwischen 20 und $30 \mathrm{~mm}$ Länge nach Toluidinblaufärbung nur die Zahl der Myosepten ermittelt, die hinter dem 6. Haemalfortsat vor dem Urostyl liegen. Die Zahl variiert zwischen 6 und 7 . Bei dorsalkomplexen Individuen ist die Durchschnittszahl etwas größer: 6,7 gegen 6,4 .

$\begin{array}{ccc}\text { Zahl der Myosepten } & \text { Larven normal } & \text { Larven dorsalkomplex } \\ 6 & 28 & 7 \\ 7 & 10 & 15\end{array}$

Ahnliches ergibt sich für die Spinalganglien. Es können deren drei Paare hinter dem Spinalbogen von $(n-1)$ liegen. Dann gehen die Nerven zu den beiden cranialen zwischen den Bögen $(n-1)$ und $(n)$ hindurch, der letgte caudalwärts des Bogens von $(n)$. Dies wurde durch Schnittuntersuchungen bestätigt. Häufiger findet man nur zwei Ganglienpaare. Diese können entweder beide $z$ wischen den Bögen von $(n-1)$ und $(n)$ liegen, oder das caudale liegt hinter dem Bogen von $(n)$. Bisweilen findet sich auch nur ein Ganglion hinter dem Bogen von $(n-1)$.

Bei den dorsalkomplexen Larven liegt stets ein Spinalganglion zwischen den beiden letsten Spinalbögen. Wäre nun die Zahl der Spinalganglien bei diesen Tieren nicht größer als bei den normalen, so müßte die Zahl der hinter dem letzten Spinalbogen vor dem Urostyl liegenden um eins niedriger sein als bei den normalen.

Es liegen hinter dem letzten Spinalbogen vor dem Urostyl

bei normalen

3 Spinalganglien in 6 Fällen,

2 Spinalganglien in 34 Fällen,

1 Spinalganglion in 7 Fällen.

0 Spinalganglion in 0 Fällen, bei dorsalkomplexen Individuen

$$
\begin{aligned}
& \text { in } 0 \text { Fällen } \\
& \text { in } 10 \text { Fällen } \\
& \text { in } 14 \text { Fällen } \\
& \text { in } 1 \text { Fall }
\end{aligned}
$$

Bei normalen beträgt der Durchschnitt etwa 2 Ganglien, bei dorsalkomplexen etwa 1,4 , der Unterschied beträgt nur 0,6 statt 1 . Jedenfalls aber haben die dorsalkomplexen im Mittel mehr Spinalganglien als die normalen.

Diese Beobachtungen sprechen für die Annahme, daß zumindest bei den dorsalkomplexen Tieren teilweise - aber nur teilweise - ein Körpersegment mehr angelegt wird, als Wirbel zur Ausbildung gelangen. Unbedingt beweisend ist aber die Feststellung nicht, denn die Vermehrung der Myosepten und Spinalganglien kann auch in gleicher Weise wie die Bildung des überzähligen Fortsatges funktions- und raumbedingt sein und mit derselben parallel laufen. Auch ist nicht bewiesen, daß das überzählige Segment bei normalen Tieren von vornherein gefehlt hat.

Für die bisher behandelte Fragestellung macht es übrigens wenig Unterschied, ob bei komplexen Individuèn eine Segmentanlage ohne Wirbelkörperbildung angenommen werden muß oder nicht. Ist sie vorhanden, so lautet die Frage, warum die Bildung des Haemalfortsatzes und anschließend die des Wirbelkörpers unterblieb, ist sie nicht vorhanden, so lautet die Frage. 
warum die Bildung des Dorsalfortsages erfolgte. Beide Fragen werden in gleicher Weise aus den Unterschieden der Funktion und der Platzverhältnisse beantwortet.

Kann man aber den Unterschied in der durchschnittlichen Wirbelzahl der komplexen und der nicht komplexen Individuen auch ohne die Annahme einer Segmentanlage ohne Wirbelkörper erklären? Das ist durchaus möglich: Die Notwendigkeit, dorsal eine zusäţliche Stü̈ze des Schwanzstiels einzufügen, wird sich selbstverständlich am häufigsten bei solchen Individuen ergeben, die wenige Wirbel haben. Die geringe Wirbelzahl kann geradezu als eine der Ursachen angesehen werden, weshalb es zur Komplexbildung kommt. - Es werden aber nicht schematisch alle Individuen mit geringer Wirbelzahl komplex, weil ja auch die Körperlänge und die Verteilung der Wirbel auf die einzelnen Körperabschnitte unabhängig - oder doch teilweise unabhängig - von der Wirbelzahl variiert, und diese Faktoren bestimmen mit, ob die Zahl der Stützen im dorsalen Schwanzskelett ausreicht oder nicht.

Etwas anders liegt die Sache bei den amphikomplexen Tieren. Hier ist ja die Zahl der Wirbel nachträglich durch das Zusammenfließen zweier Verknöcherungszonen herabgesetgt. Es ist also ganz selbstverständlich, daß die Wirbelzahl dieser Individuen geringer ist als die der normalen. Nur sollte man zunächst erwarten, daß sie nicht um einen halben, sondern um einen ganzen Wirbel geringer sei. Die Erklärung ergibt sich aus folgender Überlegung:

Amphikomplexe Bildungen entstehen, wenn Haemalfortsäte partiell miteinander verschmelzen oder doch allzu dicht zusammengedrängt sind. Die Vorbedingung hierfür ist ein gewisser Platmangel, wie er am ehesten bei Individuen mit einer großen Zahl von Haemalfortsägen eintreten kann. Amphikomplexe Individuen werden also im Mittel eine höhere Zahl von Haemalfortsätzen haben als normale Individuen. Die Wirbelzahl der Amphikomplexen ist um eine ganze Einheit geringer als die der Haemalfortsätze, kann aber nach dem Gesagten nicht um eine ganze Einheit geringer sein als die Wirbelzahl der normalen Individuen, die ja bei diesen mit der Zahl der Haemalfortsäze übereinstimmt.

Wir haben also die Entstehung der dorsalkomplexen und der amphikomplexen Bildungen auf das gleiche Prinzip - Raum- und Funktionsverhältnisse - zurückgeführt, jedoch auf antagonistische Wirkungen des gleichen Prinzips: die dorsalkomplexen auf Raumüberschuß, die amphikomplexen auf Raummangel. Würde man ein Individuum finden, das haemalkomplex ist und außerdem einen Spinalfortsaţ mehr hätte als Haemalfortsäţe, so würde diese Auffassung unmöglich werden, denn es kann nicht bei dem gleichen Individuum Platgmangel und Platzüberschuß vorhanden sein. Ein solches Individuum ist aber in unserem immerhin beträchtlichen Material, das zahlreiche Varianten der Komplexbildungen aufwies, nicht gefunden worden.

Wenn Funktions- und Raumverhältnisse hier als das regelnde Prinzip der Komplexbildungen dargestellt wurden, so schließt das das Vorhandensein einer erblichen Anlage natür-lich keineswegs aus. Ererbte Eigenschaften bestimmen ja sowohl Raumverhältnisse wie Funktion der Körperteile. Die eingehende Darstellung der Verhältnisse des Schwanzskeletts bei den Heringslarven aber erschien insofern lohnend, als sie einen Einblick in die Bildungsvorgänge gewährt, bei denen Erbanlage und Umwelteinfluß miteinander in Beziehung treten.

\section{Die Variation der Zahl der Wirbelkörper.}

Die 34 Proben von Heringslarven, deren Wirbel gezählt wurden, sind in Zahlentafel 11 aufgeführt. Sie enthält die Probenummer, das Datum des Fanges, Fangort bzw. Fanggebiet, die Zahl der untersudten Larven (n), die mittlere Wirbelzahl der ganzen Probe(A), den Standardfehler des Mittels F (A) und die Standardabweichung (s). Bezeichnung und Berechnungsweise bei BüCKMANN 1929, S. 54-60.

Schon aus der genaueren Betrachtung der Zahlentafel 11 ergibt sich, daß die durchschnittliche Wirbelzahl der gefangenen Larven in keinem einzigen Jahr gegen Ende der Beobachtungszeit eine einwandfrei feststellbare Zunahme zeigt. Noch deutlicher ergibt sich das aus Zahlentafel 12. Wo überhaupt zwischen den Monaten März/April/Mai eine Zunahme zu verzeichnen ist, ist sie ganz unerheblich im Vergleich zu den Fehlern der Mittelwerte.

Ebensowenig haben zur gleichen Zeit weiter seewärts gefangene Larven höhere Wirbelzahl als die, die näher an der Küste gefangen und daher vermutlich früher zugewandert sind. Am 29. März 1930 hatten die Larven bei Elbe II $56,52 \pm 0,069$ Wirbel, auf den Innenstationen bei Elbe IV und Neufeld 56,49 $\pm 0,030$ Wirbel. Am 12. April 1931 betrugen die Mittelwerte bei Elbe I $56,39 \pm 0,038$, bei Elbe II und III $56,43 \pm 0,040$, bei Elbe IV $56,42 \pm 0,052$, am 13. April 1932 bei Helgoland $56,34 \pm 0,036$, bei Elbe IV 56,45 $\pm 0,037$, am 26. März 1933 bei Elbe I bis III $56,40 \pm 0,042$, bei Elbe IV $56,44 \pm 0,035$. 
Zahlentafell1.

Verzeichnis der auf die Wirbelzahl untersuchten Proben von Heringslarven.

\begin{tabular}{|c|c|c|c|c|c|c|c|}
\hline Jahr & Probe $\mathrm{Nr}$. & Datum & Fangort & $\mathrm{n}$ & A & $F(A)$ & s \\
\hline \multirow[t]{2}{*}{1929} & $I$ & 3. Mai & Amrum Bank Durdhfahrt & 389 & 56,52 & $\pm 0,033$ & $\pm 0,64$ \\
\hline & II & 10. Mai & Emsmündung (Dukegat) & 596 & 56,47 & $\pm 0,027$ & $\pm 0,66$ \\
\hline \multirow[t]{8}{*}{1930} & III & 21. Jan.-10. Febr. & Helgoland, Elbe, Jade & 112 & 56,51 & $\pm 0,058$ & $\pm 0,61$ \\
\hline & IV & 7. März & Jade & 432 & 56,48 & $\pm 0,031$ & $\pm 0,65$ \\
\hline & V & 25. März & Außenjade-Geniusbank & 545 & 56,50 & $\pm 0,028$ & $\pm 0,65$ \\
\hline & VI & 29. März & Elbe IV-Neufeld & 463 & 56,49 & $\pm 0,030$ & $\pm 0,64$ \\
\hline & VII & 29. März & Elbe II & 107 & 56,52 & $\pm 0,069$ & $\pm 0,71$ \\
\hline & VIII & 23. April & Elbe IV & 295 & 56,57 & $\pm 0,038$ & $\pm 0,65$ \\
\hline & IX & 25. April & Elbe IV & 371 & 56,46 & $\pm 0,034$ & $\pm 0,65$ \\
\hline & $\mathbf{X}$ & 20. Mai & Elbe IV & 218 & 56,49 & $\pm 0,043$ & $\pm 0,68$ \\
\hline \multirow[t]{7}{*}{1931} & $\mathrm{XI}$ & 26. März & Elbe III-IV & 587 & 56,47 & $\pm 0,026$ & $\pm 0,62$ \\
\hline & $\mathrm{XII}$ & 31. März & Helgoland & 115 & 56,48 & $\pm 0,069$ & $\pm 0,75$ \\
\hline & XIII & 12. April & Elbe IV & 164 & 56,42 & $\pm 0,052$ & $\pm 0,67$ \\
\hline & XIV & 12. April & Elbe II-III & 265 & 56.43 & $\pm 0,040$ & $\pm 0,68$ \\
\hline & $\mathrm{XV}$ & 12. April & Elbe I & 283 & 56,39 & $\pm 0,038$ & $\pm 0,68$ \\
\hline & $\mathrm{XVI}$ & 24. April & Gr. Vogelsand & 446 & 56,43 & $\pm 0,029$ & $\pm 0,61$ \\
\hline & XVII & 25. April & Elbe III-Elbe Tonne A & 381 & 56,46 & $\pm 0,033$ & $\pm 0,60$ \\
\hline \multirow[t]{7}{*}{1932} & XVIII & 20. Jan.-18. Febr. & Helgoland-Elbe III & 88 & 56,42 & $\pm 0,064$ & $\pm 0,60$ \\
\hline & XIX & 4.-26. März & Helgoland, Außenjade, Eider FS. & 104 & 56,47 & $\pm 0,069$ & $\pm 0,70$ \\
\hline & $\mathrm{XX}$ & 6. April & Neufeld & 514 & 56,39 & $\pm 0,028$ & $\pm 0,68$ \\
\hline & XXI & 13. April & Helgoland & 342 & 56,34 & $\pm 0,036$ & $\pm 0,67$ \\
\hline & XXII & 13. April & Elbe IV & 298 & 56,45 & $\pm 0,037$ & $\pm 0,64$ \\
\hline & XXIII & 17.-26. April & Elbe-Amrum & 567 & 56,43 & $\pm 0,027$ & $\pm 0,65$ \\
\hline & XXIV & 20.-30. April & Oster- und Westerems & 328 & 56,44 & $\pm 0,034$ & $\pm 0,62$ \\
\hline \multirow[t]{6}{*}{1933} & $X X V$ & 26. Jan. & Jade-Wesermündung & 65 & 56,38 & $\pm 0,089$ & $\pm 0,72$ \\
\hline & XXVI & 7.-9. März & Elbe IV & 265 & $.56,56$ & $\pm 0,042$ & $\pm 0,68$ \\
\hline & XXVII & 26. März & Elbe I-III & 229 & 56,40 & $\pm 0,042$ & $\pm 0,64$ \\
\hline & XXVIII & 26. März & Elbe IV & 367 & 56,44 & $\pm 0,035$ & $\pm 0,68$ \\
\hline & XXIX & 20. April & Elbe II-IV & 527 & 56,42 & $\pm 0,029$ & $\pm 0,67$ \\
\hline & $\mathrm{XXX}$ & 5. Mai & Neufeld & 200 & 56,40 & $\pm 0,049$ & $\pm 0,69$ \\
\hline \multirow[t]{3}{*}{1934} & $\mathrm{XXXI}$ & 28. Febr.-1. März & Helgoland-Elbe & 23 & 56,43 & $\pm 0,103$ & $\pm 0,50$ \\
\hline & XXXII & 24. März-5. April & Helgoland-Elbe & 532 & 56,59 & $\pm 0,030$ & $\pm 0,69$ \\
\hline & XXXIII & 4. Mai & Elbe IV-Neufeld & 370 & 56,62 & $\pm 0,036$ & $\pm 0,69$ \\
\hline 1935 & XXXIV & 7.-12. März & Deutsche Bucht & 372 & 56,43 & $\pm 0,033$ & $\pm 0,63$ \\
\hline
\end{tabular}

Zahlentafel 12.

Variationderdurchschnittlichen Wirbelzahl der Heringslarven mit der Jahreszeit

\begin{tabular}{lccccc}
\hline Jahr & 1930 & 1931 & 1932 & 1933 & 1934 \\
\hline Monat & & & & & \\
Januar-Februar & 56,51 & 56,42 & 56,42 & 56,38 & 56,43 \\
März & $\pm 0,058$ & - & $\pm 0,064$ & $\pm 0,089$ & $\pm 0,106$ \\
& 56,49 & 56,47 & 56,52 & 56,46 & 56,59 \\
April & $\pm 0,017$ & $\pm 0,025$ & $\pm 0,065$ & $\pm 0,023$ & $\pm 0,030$ \\
Mai & 56,51 & 56,43 & 56,41 & 56,42 & \pm \\
& $\pm 0,025$ & $\pm 0,017$ & $\pm 0,014$ & $\pm 0,029$ & \pm \\
& 56,37 & - & - & 56,40 & 56,62 \\
& $\pm 0,055$ & - & - & $\pm 0,042$ & $\pm 0,036$ \\
\hline
\end{tabular}

Es ist also auch hier kein Anzeichen dafür vorhanden, daß die später eintreffenden Larven höhere Wirbelzahl hätten.

Endlich zeigt ein Vergleich der Proben I und II vom Mai 1929 (bei Amrum Bank $56,52 \pm 0,033$, in der Emsmündung 56,47 $\pm 0,027)$ und der Proben XXIII und XXIV von der Poseidonfahrt April 1932 (vor der nordfriesischen Küste 56,43 \pm 0,027, in der Ems 56,44 $\pm 0,034$ ), daß auch zwischen etwa gleichzeitig im Osten und im Westen der Deutschen Bucht gefangenen Heringslarven keine bezeichnenden Unterschiede in der Wirbelzahl bestehen. 


\section{$\mathrm{Zahlentafel} 13$.}

Vergleich der Differenzder Mittelwertedereinzelnen Proben jedes Jahres mit dem Standardfehlerder Differenzen.

1. Die Differenz liegt innerhalb der Grenzen des einfachen Standardfehlers,

2. Die Differenz liegt innerhalb der Grenzen des doppelten Standardfehlers,

3. Die Differenz liegt innerhalb der Grenzen des dreifachen Standardfehlers,

4. Die Differenz ist größer als der dreifache Standardfehler.

Jahr 1929 .

$\begin{array}{ll}\text { Probe Nr. II } & \text { I } \\ \text { II } & \text { N }\end{array}$

Jahr 1931 .

Probe Nr.

XII

XIII

$\mathrm{XIV}$

XVI

XVII

Jahr 1932.

Probe Nr.

XIX

$X X$

XXI

XXII

XXIII

XXIV

Jahr 1933.

Probe $\mathrm{Nr}$.

XXVI

XXVII

XXVIII

XXIX

XXX

Jabr 1934 .

Probe Nr.

XXXII

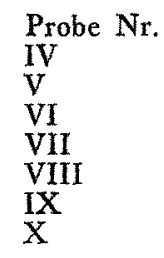

$\mathrm{XI}$
1
1
1
2
2
1

XII XII

XII XIII XIV xV xVr

Jahr 1930 .

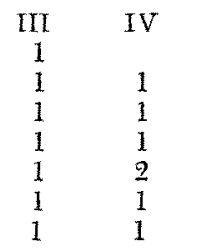

V VI

VI VII VIII IX

1

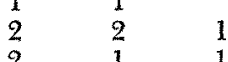

$\begin{array}{lllll}1 & 1 & 1 & 2 & 1\end{array}$

$\begin{array}{lllll}1 & 1 & & & \\ 2 & 1 & 1 & & \\ 1 & 1 & 1 & 1 & \\ 1 & 1 & 1 & 2 & 1\end{array}$

$\begin{array}{cccccc}\text { XVIU } & \text { XIX } & \text { XX } & \text { XXI } & \text { XXII } & \text { XXII } \\ 1 & 2 & & & & \\ 1 & 2 & 2 & & & \\ 2 & 2 & 2 & 3 & & \\ 1 & 1 & 2 & 2 & 1 & \\ 1 & 1 & 2 & 3 & 1 & 1 \\ 1 & 1 & 2 & & & \end{array}$

$\begin{array}{ccccc}\text { XXV } & \text { XXVI } & \text { XXVII } & \text { XXVIII } & \text { XXIS } \\ 2 & 3 & & & \\ 1 & 3 & 1 & & \\ 1 & 3 & 1 & 1 & \\ 1 & 3 & 1 & 1 & 1 \\ 1 & & \end{array}$

$\begin{array}{cc}\mathrm{XXXI} & \mathrm{XXXII} \\ 2 & 1\end{array}$

Uberhaupt sind die Unterschiede der Proben eines Jahres gering und statistisch bede!1tungslos. Das ist in Zahlentafel 13 nachgewiesen. In dieser ist angegeben, ob die Differenz der Mittelwerte von je zwei Proben eines Jahres kleiner ist als ihr einfacher Standar (fehler - dann findet sich in der Zahlentafel eine $1-$, ob sie kleiner ist als der doppelte (2) oder dreifache Standardfehler (3) oder ob sie größer ist als der dreifache Standardfehler. In diesem Falle würde eine 4 in die Tafel eingesetzt worden sein. Aber so große Abweichungen kommen in keinem Jahr vor. In der Summe aller Fälle hält sich die Differenz der Probenmittel 62mal innerhalb der Grenzen des einfachen Standardfehlers, 21mal innerhalb des doppelten, $7 \mathrm{mal}$ innerhalb des dreifachen Standardfehlers. Bei wahllosen Proben aus einheitlichem Bestande hat man 62, 25 und drei Fälle zu erwarten. Die beobachteten Abweichungen stimmen hiermit überraschend gut überein. Hieraus ergibt sich, daß den Abweichungen der Probenmittel eines Jahres voneinander keine Bedeutung zukommt. Das Material jedes einzelnen Jahres kann als einheitlich angetprochen werden.

Andererseits bestehen teilweise erhebliche Unterschiede zwischen dem Material der einzelnen Jahre. In Zahlentafèl 13 sind die Zählungen jahrweise zusammengefaßt. Für die sieben Variationsreihen 1929 bis 1935 sind die Durchschnittswerte mit ihren Standardfehlern sowie die Standardabweichung angegeben. Man sieht, daß das Jahresmittel für 1934 mit 56,6 auffallend hoch ist. Rund 56,5 betrugen die Mittelwerte für 1929 und 1930. Dann folgten die Mittel für 1931 und 1933 mit 56,44, für 1935 mit 56,43, und den niedrigsten Mittelwert hatte das Jahr 1932 mit 56,41 . 
$\mathrm{Zahlentafel} 14$.

Variation and Mittelwerteder Wirbelsummebei den Heringslarven a us verschiedenen Jahren.

\begin{tabular}{|c|c|c|c|c|c|c|c|c|}
\hline Jahr & 1929 & 1930 & 1931 & 1932 & 1983 & 1934 & 1935 & Zusammen \\
\hline $\begin{array}{l}\text { Vert. S. } \\
53\end{array}$ & 1 & 1 & - & - & - & - & - & - \\
\hline 54 & - & i & 2 & 1 & 5 & 1 & 一 & 10 \\
\hline 55 & 40 & 77 & 81 & 12.3 & 80 & 28 & 19 & 448 \\
\hline 56 & 456 & 1236 & 1135 & 1138 & 824 & 386 & 182 & 5357 \\
\hline 57 & 449 & 1109 & 898 & 914 & 680 & 441 & 162 & 4653 \\
\hline 58 & 38 & 114 & 73 & 63 & 58 & 65 & 9 & 420 \\
\hline 59 & 1 & 5 & 1 & 1 & 5 & 4 & - & 17 \\
\hline 60 & - & - & 1 & 1 & 1 & - & - & 3 \\
\hline $\mathrm{Nn}=$ & 985 & 2543 & 2191 & 2241 & 1653 & 925 & 372 & 10910 \\
\hline$A=$ & 56,492 & 56,499 & 56,441 & 56,411 & 56,439 & 56,598 & 56,433 & 56,466 \\
\hline$F(A)=$ & $\pm 0,021$ & $\pm 0,013$ & $\pm 0,013$ & $\pm 0,014$ & $\pm 0,017$ & $\pm 0,023$ & $\pm 0,033$ & $\pm 0,006$ \\
\hline$s=$ & $\pm 0,653$ & $\pm 0,648$ & $\pm 0,632$ & $\pm 0,647$ & $\pm 0,676$ & $\pm 0,688$ & $\pm 0,629$ & $\pm 0,654$ \\
\hline
\end{tabular}

Um zu prüfen, ob diesen Unterschieden statistisch Bedeutung zuzumessen ist, wurden die Differenzen zwischen den Jahresmitteln und die Standardfehler der Differenzen berechnet. Sie sind in Zahlentafel 15 aufgeführt. Durch die beigefügten großen Zahlen ist wiederum gekennzeichnet, ob sich die Differenzen innerhalb des einfachen, doppelten oder dreifachen Fehlers halten oder den dreifachen Fehler überschreiten. Innerhalb des einfachen Fehlers liegen von 21 Differenzen 5, innerhalb des doppelten 5, innerhalb des dreifachen 2, außerhalb des dreifachen Fehlers 9 Differenzen. Es ist also durchaus unwahrscheinlich, daß die Heringslarven sich in den verschiedenen Jahren bezüglich der Wirbelzahl gleich verhalten. Insbesondere unterscheidet sich das Material von 1934 von allen anderen Jahren. Außerdem bestehen statistisch gesicherte Unterschiede zwischen den Mittelwerten von 1930 und 1931 sowie zwischen dem von 1932 und denen von 1929 und 1930.

Zahlentafel 15.

Differenzen der Mittelwerteder Wirbelsummeder verschiedenen Jahrgänge der Herings larven.

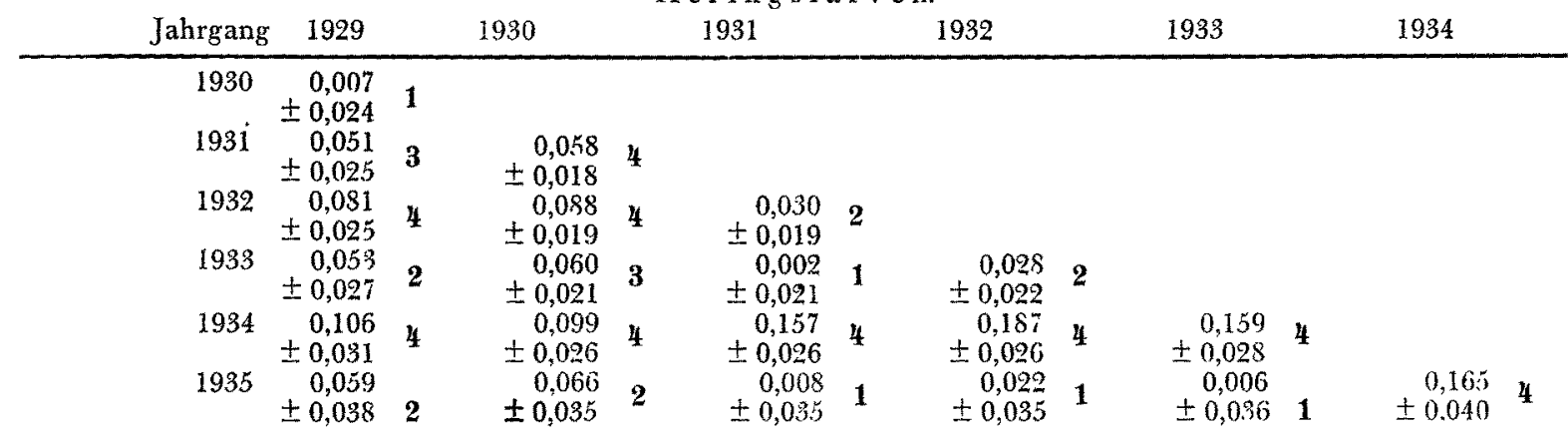

Damit erhebt sich wiederum die Frage, ob in den Jahren mit hoher mittlerer Wirbelzahl, wie 1930 und 1934, den Larven des Nordsee-Bankherings solche des Kanaltyps in merklicher Anzahl beigemischt sind. An und für sich würde man dann allerdings erwarten, daß sich die Wirbelzahl erst gegen Ende der Untersuchungszeit heben würde, weil die Larven aus der Flämischen Bucht erst dann das Stadium der Wirbelbildung erreichen. Es ist bereits nachgewiesen, daß das nicht der Fall ist.

Eine weitere Möglichkeit, die Frage zu entscheiden, ob die Proben mit hoher Wirbelzahl eine Rassenmischung darstellen, ist der Vergleich der Standardabweichung der Proben. Eine Probe, die ein Gemisch zweier, in der mittleren Wirbelzahl verschiedener Rassen vorstellt, muß für diesen Charakter eine größere Standardabweichung haben als ein einheitliches Material. In dem vorliegenden Material sind aber die Proben mit hoher mittlerer Wirbelzahl nicht durch große Streuung ausgezeichnet. Berechnet man auf Grund von Zahlentafel 9 den Korrelationskoeffizienten für mittlere Wirbelzahl und Standardabweichung, so erhält man einen sehr kleinen und statistisch nicht gesicherten Wert.

$$
\varrho=+0,17 \pm 0,11
$$

Es wäre also auch unter diesem Gesichtspunkt nicht wahrscheinlich, daß die hohen Wirbelzahlen auf eine Beimischung von Heringen des Kanaltyps zurückzuführen wäre. 
Indessen ist diese Beweisführung nicht schlüssig. Voraussegung dafür wäre es, daß die Variationsreihen der Wirbelzahl der beiden reinen Rassen nicht wesentlich von der Normalverteilung nach dem Fehlergesets abweichen. Berechnet man aber aus Mittelwert und Standardabweichung der beobachteten Variationsreihen die Normalverteilung und vergleicht sie mit den empirischen Werten, so weichen diese fast ausnahmslos erheblich ab: sie sind stark übergipflig. Wenn man Probe 31, die nur zwei Varianten aufweist, unberücksichtigt läßt, so ist die Variante 56 mit einer einzigen Ausnahme zu stark vertreten, in der Mehrzahl der Fälle auch die Variante 57. Die Varianten 55 und 58 sind immer zu selten, die extremen Varianten, 54 oder 53 und 59 oder 60, wieder zu häufig. Berechnet man nach dem z. B. bei KäNDíER 1935, S. 401, beschriebenen Verfahren von ELDERTON $\chi^{2}$ und $\mathrm{P}$, so wird die mangelhafte Übereinstimmung der Proben mit der Fehlerkurve deutlich. Sie ist im allgemeinen um so schlechter, je mehr Varianten vorhanden sind, d.h. wenn die extremen Varianten 53,54,59,60 vorkommen, weicht die Verteilung am stärksten von der Fehlerkurve ab. Dies ist in Zahlentafel 16 nachgewiesen.

$$
Z \text { ahlentafel } 16 .
$$

Wahrscheinlichkeit P, daß die Variantenverteilung in den Proben nurzufällig vonder Fehlerkurve abweicht.

\begin{tabular}{|c|c|c|c|c|c|c|}
\hline$P=$ & & $\geq 0,5$ & $0,5-0,1$ & $0,1-0,05$ & $0,05-0,01$ & $\because 0,01$ \\
\hline
\end{tabular}

Unglüdklicherweise hat der Verf. bei diesen 'Berechnungen nicht berücksichtigt, daß die Erwartungswerte der extremen Varianten unter 5 lagen, so daß die $\chi^{2}$-Methode in diesen Fällen keine zuverläsigen Werte liefern kann. - Da die Unterlagen über die Variation in den einzelnen Proben verloren gegangen sind, bleibt nichts anderes übrig, als die Frage später an einem neu gesammelten Material von Heringslarven wieder zu prüfen. Versuchsweise wurde auch SHEPPARDS Korrektion, die den Einfluß der Gruppierung in wenige Klassen ausgleichen soll, sowie auch FISHERS Methode fortschreitender Annäherung, wie von BUCHANAN-WOLLASTON 1933 .S. 19-21 dargestellt, angewandt. Es ergab sich aber auch dann keine befriedigende UUbereinstimmung. Genaueres läßt sich indessen darüber nicht sagen, da auch diese Unterlagen verloren gingen.

W. JOHANSEN weist darauf hin, daß die Übergipfligkeit gerade bei genetisch einheitlichen Proben nicht selten ist. Es wäre denkbar, obwohl nach unseren sonstigen Feststellungen nicht wahrsheinlich, daß unsere Proben ein solches genetisch verhältnismäßig einheitliches Material darstellten. Dann würde die Übergipfligkeit also bei der Zusammenfasung eines größeren Materials verschwinden. Faßt man das Material der einzelnen Jahrgänge zusammen, wie es in Zahlentafel 14 geschehen ist, so zeigt sich, daß auch jetzt noch die Extremwerte zu häufig sind, und daß die Erwartungswerte für sie erheblich unter 5 liegen, so daß der $\chi^{2}$-Test nicht ohne weiteres brauchbar ist. Die genauere Prüfung wird auch in diesem Falle zurückgestellt. Aus der Zahlentafel 17, deren absolute Werte aus rem angeführten Grunde keine Berücksichtigung finden dürfen, geht hervor, daß die Ơbereinstimmung. für die Größengruppe von mehr als $40 \mathrm{~mm}$ im allgemeinen etwas höher sind als für die kleineren Larven. Hier ergibt übrigens die Approximationsberechnung nach WOLLASTON, für die über $40 \mathrm{~mm}$ langen Larven des Jahrgangs 1930 durchgeführt, mit $\mathrm{P}=0,05$ schon eine erträgliche Ưbereinstimmung mit der Normalverteilung.

Zahlentafel 17

Wahrscheinlichkeit P der Übereinstimmungmit derFehlerkurvefürdie einzelnen Jahrgänge und Größengruppender Heringslarven.

\begin{tabular}{l|l|l|l|l|l|l|l}
\hline Jahrgang & 1929 & 1930 & 1931 & 1932 & 1933 & 1934 & 1935 \\
\hline Größ3engruppe & 0,11 & 0,000 & 0000 & 0000 & 0,001 & 0.4 & - \\
$30.35 \mathrm{~mm}$ & 0.20 & 0,000 & 0000 & 0.000 & 0,000 & 0,04 & - \\
$35.40 \mathrm{~mm}$ & 0,22 & 0,003 & 0,39 & 0,006 & 0,06 & 0,07 & - \\
$40 \mathrm{~mm}+$ & 0,005 & 0,000 & 0.000 & 0,000 & 0,000 & 0,004 & 0,12 \\
\hline Zusammen &
\end{tabular}

Da Proben erwachsener Heringe aus der Nordsee, wie von Buchanan-Woliaston gezeigt worden ist, zumeist eine gute Ubereinstimmung der Wirbelvariation mit dem Fehlergesetz aufweisen, ist es wahrscheinlich, daß die Variation der Wirbelzahl der Heringe sich im Laufe 
der Entwicklung und Metamorphose noch ändert. Dies kann natürlich nur durch Ausmerzung eines Teils der Varianten erfolgen. Es liegt zunächst durchaus im Bereich des Möglichen, daß die extremen Varianten aus irgendeinem Grunde, der mit der Wirbelzahl vielleicht nur sehr mittelbar verknüpft ist, nicht lebensfähig sind. Fallen die extremen Varianten im wesentlichen weg, so würde sich die Übereinstimmung mit der Fehlerkurve bei verkleinerter Standardabweichung wesentlich verbessern.

Es muß hier auf eine Erscheinung hingewiesen werden, die zunächst völlig unerklärlich war, die aber sofort begreiflich wird, wenn man annehmen darf, daß ein Teil der Varianten mit niederer Wirbelzahl im Daseinskampf irgendwie schlechter gestellt ist und vorzugsweise ausgemerzt wird.

Es zeigt sich nämlich, daß die größeren Larven im Durchschnitt eine höhere Wirbelzahl haben als die kleineren. Vereinigt man zunächst die Larven jeder der drei unterschiedenen Größengruppen ohne Rücksicht auf die Zeit des Fanges, so findet man folgende Zahlen:

\begin{tabular}{|c|c|c|c|}
\hline Längengruppe & A & $\circlearrowleft A$ & $\therefore A$ \\
\hline $30-35$ & 56,422 & & $0,047 \pm 0,015$ \\
\hline $\begin{array}{c}35-40 \\
40+\end{array}$ & $\begin{array}{l}56,469 \\
56,512\end{array}$ & $0,090 \pm 0,017$ & $0,043 \pm 0.015$ \\
\hline
\end{tabular}

Die größeren Larven haben eine um soviel höhere Wirbelzahl, daß die Unterschiede statistisch gesichert sind. Untersucht man weiter die Mittelwerte der Größengruppen in den einzelnen Proben, so findet man hier natürlich eine große Streuung der Werte. Berechnet man aber den Koeffizienten der Korrelation zwischen Größe und mittlerer Wirbelzahl nach Bravais für die 91 Teilproben, so ergibt sich

$$
\varrho=0,423 \pm 0,086
$$

Es besteht also auch hier eine Beziehung zwischen Größe und Wirbelzahl. Die Unterlagen für die Berechnung sind in Zahlentafel 18 gegeben.

$$
Z \text { ahlentaf el } 18 .
$$

\begin{tabular}{|c|c|c|c|c|c|c|c|c|c|c|c|c|}
\hline \multicolumn{2}{|c|}{ Wirbelzahl 56} & 25.29 & $30-34$ & 35-39 & $40-44$ & $\begin{array}{c}45-49 \\
\text { Vox }\end{array}$ & & & 60.64 & 65.69 & 70.74 & zus. \\
\hline $\begin{array}{c}\text { Länge } \\
\text { mm } \\
30.35 \\
35.40 \\
40+\end{array}$ & $\begin{array}{l}\text { Gruppe } \\
1 \\
2 \text { Voy } \\
3\end{array}$ & $\begin{array}{l}2 \\
1 \\
0\end{array}$ & $\begin{array}{l}1 \\
2 \\
0\end{array}$ & $\begin{array}{l}8 \\
6 \\
1\end{array}$ & $\begin{array}{l}7 \\
5 \\
6\end{array}$ & $\begin{array}{l}9 \\
8 \\
4\end{array}$ & $\begin{array}{r}1 \\
7 \\
10\end{array}$ & $\begin{array}{l}0 \\
2 \\
2\end{array}$ & $\begin{array}{l}2 \\
1 \\
1\end{array}$ & $\begin{array}{l}0 \\
0 \\
3\end{array}$ & $\begin{array}{l}0 \\
0 \\
2\end{array}$ & $\begin{array}{l}30 \\
32 \\
29\end{array}$ \\
\hline$Z \mathrm{us}$ & & 3 & $\begin{array}{c}3 \\
{ }^{\mathrm{a}} 1_{\mathrm{x}}= \\
{ }_{\mathrm{s}}=\end{array}$ & $\begin{array}{r}-0,10 \\
\pm 1,88\end{array}$ & $\begin{array}{c}18 \\
{ }^{a_{1}}= \\
\mathrm{s}_{\mathrm{y}}=\end{array}$ & $\begin{array}{l}21 \\
-0,01 \\
\pm 0,80\end{array}$ & 18 & $\begin{array}{c}4 \\
\rho= \\
(p)= \pm\end{array}$ & $\begin{array}{c}4 \\
0,423 \\
-0,086\end{array}$ & 3 & 2 & 91 \\
\hline
\end{tabular}

Korrelation zwischen Wirbelzahlund Längebcideneinzelnen Proben

Eine solche Beziehung ist auch von anderen Fischarten bekannt. Dannevig (1933) beobachtete, daß die größeren Individuen des Köhlers eine höhere Wirbelzahl haben als die kleinen. Ebenso fand KäNDLER in mehreren Fällen bei Ostseeschollen bei den größeren Individuen höhere Wirbelzahlen. Für Schollen der O-Gruppe von Island stellte TẢNING umgekehrt fest, daß die Wirbelzahl der kleinen Individuen höher war.

Als Erklärungsmöglichkeit für die Unterschiede kommt es nach allen drei Autoren in Frage, daß die großen und kleinen Individuen eines Jahrganges sich unter verschiedenen Bedingungen des Lebensraumes entwickelt haben, insbesondere, daß die Gruppe mit der höheren Wirbelzahl während der Entwicklung einer geringeren Temperatur ausgesetgt war. Es ist ja eine weit verbreitete Erscheinung, daß die mittlere Wirbelzahl von Fischbevölkerungen in kälteren Gebieten größer ist als in wärmeren.

Diese Erklärung aber kann für die Heringslarven nicht in Anspruch genommen werden.. Es sind nämlich während des ganzen Verlaufes der Untersuchungsperiode die Wirbelzahlen der 
größeren Larven höher als die der kleineren. In Zahlentafel 19 sind die Mittelwerte für Januar und Februar, für die Halbmonate des März und April und für den Mai aufgeführt. Mit einer einzigen Ausnahme (in der ersten Aprilhälfte ist die Wirbelzahl der Gruppe 30-35 mm höher als die der Gruppe $35-40 \mathrm{~mm}$ ) haben stets die größeren Larven die höhere Wirbelzahl. Es ist aber unmöglich, daß während der ganzen Zeit von Februar bis Mai stets die größeren Larven die geringere Entwicklungstemperatur gehabt haben, oder wäre das der Fall, so müßte die durchschnittliche Wirbelzahl im Laufe der Saison fortgesetzt sinken.

Diejenigen Larven, die zu Beginn der Untersuchungsperiode der Längengruppe 30 bis $35 \mathrm{~mm}$ angehört haben und eine verhältnismäßig geringe Wirbelzahl aufweisen, müssen späterhin in die Längengruppe $35-40 \mathrm{~mm}$ und $40 \mathrm{~mm}+$ aufrücken und müßten hier den Durchschnittswert herunterdrücken. Wenn trołdem auch nun wieder die kleineren Larven eine geringere durchschnittliche Wirbelzahl haben, so müßte die Wirbelzahl der neu in die kleinste Gruppe eintretenden Larven im Laufe der Jahreszeit immer mehr abnehmen. In Zah'entafel 19 ist noch einmal belegt, daß das nicht der Fall ist. Der Unterschied in der Wirbelzahl großer und kleiner Larven kann daher nicht durch die Annahme erklärt werden, daß sie sich unter verschiedenen Umweltbedingungen entwickelt hätten.

Z a h l entafel 19.

Mittlere Wirbelzahl der Heringslarven der drei Größengruppen im Laufe
der Untersuchungsperiode.

\begin{tabular}{c|rrr|rrr|rrr}
\hline $\begin{array}{c}\text { Längengruppe } \\
\text { mm }\end{array}$ & \multicolumn{3}{|c|}{ Januar-Februar } & \multicolumn{2}{|c|}{ März, 1. Hälfte } & \multicolumn{3}{|c}{ März, 2. Hälfte } \\
& $\mathrm{n}$ & $\mathrm{A}$ & $\mathrm{F}(\mathrm{A})$ & $\mathrm{n}$ & $\mathrm{A}$ & $\mathrm{F}(\mathrm{A})$ & $\mathrm{n}$ & $\mathrm{A}$ & $\mathrm{F}(\mathrm{A})$ \\
\hline $30-35$ & 121 & 56,413 & $\pm 0,058$ & 407 & 56,440 & $\pm 0,032$ & 792 & 56,400 & $\pm 0,024$ \\
$35-40$ & 112 & 56,464 & $\pm 0,053$ & 533 & 56,503 & $\pm 0,029$ & 1547 & 56,511 & $\pm 0,017$ \\
$40+$ & 55 & 56,491 & $\pm 0,096$ & 180 & 56,556 & $\pm 0,045$ & 895 & 56,545 & $\pm 0,021$
\end{tabular}

\begin{tabular}{c|ccc|ccc|ccc}
\hline $\begin{array}{c}\text { Längengruppe } \\
\text { mm }\end{array}$ & \multicolumn{3}{|c|}{ April. 1. Hälfte } & \multicolumn{3}{|c|}{ April, 2. Hälfte } & \multicolumn{3}{c}{ Mai } \\
n & A & F (A) & n & A & F (A) & n & A & F (A) \\
\hline $30-35$ & 412 & 56,415 & $\pm 0,031$ & 868 & 56,402 & $\pm 0,022$ & 449 & 56,494 & $\pm 0,030$ \\
$35-40$ & 808 & 56,354 & $\pm 0,023$ & 1314 & 56,457 & $\pm 0,018$ & 701 & 56,509 & $\pm 0,026$ \\
$40+$ & 482 & 56,444 & $\pm 0,029$ & 682 & 56,499 & $\pm 0,025$ & 544 & 56,526 & $\pm 0,029$ \\
\hline
\end{tabular}

DANNEVIG und KäNDLER erörtern noch eine weitere Erklärungsmöglichkeit: Aus größeren Eiern schlüpfen größere Lạven. Es ist sehr wahrscheinlich, daß diese Plusvarianten der Größe im weiteren Verlauf ihren Vorsprung vor den anderen halten oder gar vermehren. Bei einem Fisch mit so kurzer Laichzeit wie der Köhler es ist, stammen daher die größten Individuen des Jahrgangs wahrscheinlich vorzugsweise aus den größten Eiern, zumal nach HEINGKE und EHreNBAUM die durchschnittlich größten Eier zu Beginn der Laichzeit erzeugt werden. Möglicherweise bedingt nun einfach die größere Substanzmenge, der größere Körper des Embryos, daß mehr Wirbel angelegt werden. Daraus ergäbe sich dann eine höhere Durchschnittswirbelzahl für die größeren Individuen. Bei den Heringslarven steht einer solchen Deutungsmöglichkeit wiederum die Überlegung entgegen, daß die grôßere Längengruppe nicht zu jeder Zeit vorwiegend Plusvarianten der Größe und des Wachstums enthalten kann. Auch die Minusvarianten älterer Bruten rücken ja mit der Zeit in die größeren Gruppen auf.

Man könnte annehmen, daß bei den kleinen Larven mehr Beobachtungsfehler gemacht, d. h. mehr Wirbel übersehen worden wären als bei den großen. Bei der Sorgfalt, die auf die Zählungen verwandt wurde, und der zumeist vorgenommenen Kontrollzählung durch eine andere Person können aber die systematischen Beobachtungsfehler keineswegs solchen Umfang angenommen haben, um die Differenz (zwischen Gruppe $30-35 \mathrm{~mm}$ und Gruppe $40 \mathrm{~mm}+$ fast 0,1 Wirbel) zu erklären.

Weiter bestände die Möglichkeit, daß bei einem Teil der kleinsten Larven die Anlage eines Wirbelkörpers noch nicht verknöchert war und aus diesem Grunde nicht mitgezählt wurde. Auf frühen Stadien der Verknöcherung sind am Kopfende der Wirbelsäule die Zwischenräume 
zwischen den Knochenringen in der Tat so weit, dafs sich dort allenfalls eine weitere Wirbelanlage dazwischenschieben könnte. Aber dann müßte man auf den etwas fortgeschritteneren Stadien dort zwei besonders kurze Wirbel antreffen, und das ist niemals beobachtet worden. Der Unterschied der Wirbelzahl der Gruppen 35-40 $\mathrm{mm}$ und $40 \mathrm{~mm}+$ aber könnte auf diese Weise gar nicht geklärt werden, denn bei $35 \mathrm{~mm}$ ist die Reihe der Wirbel stets schon fest geschlossen.

Wir haben nun wahrscheinlich gemacht, daß die Form der Variation der Wirbelzahl der jungen Larven von der der metamorphosierten Heringe unterschieden ist, und mußten deshalb annehmen, daß gewisse extreme Varianten im Verlauf der Entwicklung und Metamorphose selektiv eliminiert werden. Es ist daher eine einleuchtende Annahme, daß auch die Lage des arithmetischen Mittels der Wirbelzahl während dieser Zeit durch solche selektive Eliminierung verschoben wird. Wenn ein verhältnismäßis großer Teil der Minusvarianten der Wirbelzahl während der Entwicklung zugrunde geht, so würd: das die beobachtete Zunahme der durchschnittlichen Wirbelzahl erklären. Es gibt freilich keinen un-

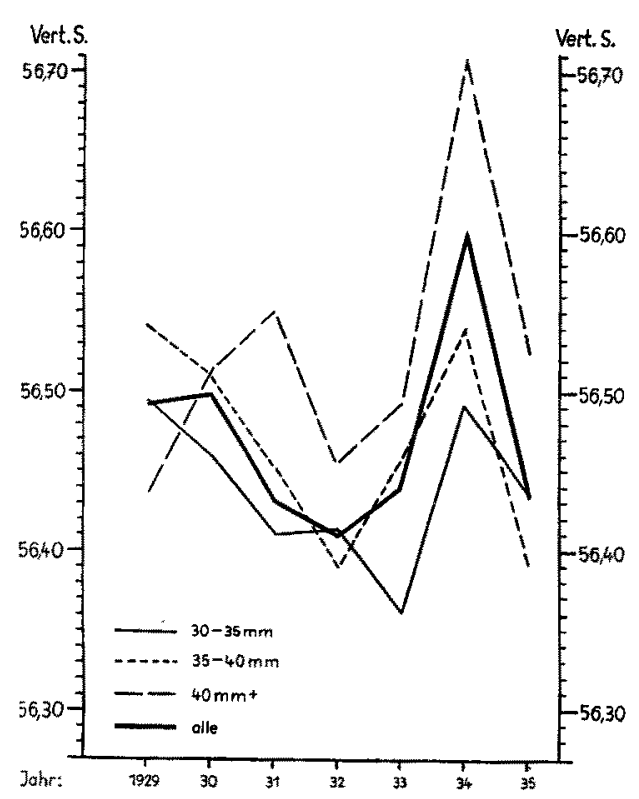

Abb. 6. Variation der Wirbelzahl bei den einzelnen Größengruppen der Heringslarven 1929 bis 1935 mittelbaren Beweis für diese Annahme, und man kann auch nichts darüber aussagen, wie der negative Selektionswert geringer 'Wirbelzahl zuitande kommen könnte. Es ist aber nicht einzusehen, wie die beobachteten Tatsachen anders erklärt werden sollten.

$\mathrm{Da}$ oben ein Unterschied in der durchschnittlichen Wirbelzahl größerer und kleinerer Larven festgestellt worden ist, war zu prüfen, ob etwa die Unterschiede in den Durchschnittswerten der Jahrgänge lediglich auf die Unterschiede der Größenzusammensetzung der Proben zurückzuführen seien. Es zeigt sich aber, daß die Schwankungen der mittleren Wirbelzahl bei den einzelnen Größengruppen, die in Abb. 6 wiedergegeben sind, im wesentlichen gleichsinnig verlaufen. Nur für 1929 und 1931 zeigt der Verlauf der Kurve für die Gruppe $40 \mathrm{~mm}+$ größere Abweichungen von den beiden anderen, 1933 der der Kurve für die Gruppe $30-35 \mathrm{~mm}$. Wir haben es also mit wirklichen Unterschieden in der Wirbelzahl der einzelnen Jahrgänge zu tun.

\section{Die Ursachen der Unterschiede in der Wirbelzahl der Jahrgänge}

Die vorstehenden Untersuchungen haben mit hinlänglicher Sicherheit dargetan, daß die Unterschiede in der durchschnittlichen Wirbelzahl der einzelnen Jahrgänge nicht daher rühren. daß zwei in dieser Hinsicht verschiedene Rassen in wechselndem Verhältnis miteinander vermischt auftreten. Es ist daher wahrscheinlich, daß es sich um die Wirkung von irgendwelchen Einflüssen des Lebensraumes auf die Brut während der Entwicklungszeit handelt. Manche Tatsachen sprechen dafür, daß die Temperatur einen Einfluß auf die Wirbelzahl auszuüben vermag:

Beim Pazifischen Hering (Clupea pallasii) hat TESTER eine negative Korrelation zwischen der mittleren Wirbelzahl der Heringe und der Wassertemperatur nachgewiesen, während eine solche mit der Lufttemperatur schon früher von ROUNSEFELL und DAHLGREEN testgestellt worden war. Beziehungen zwischen der ortlichen Wassertemperatur und der Wirbelzahl des norwegischen Herings hat RUNNSTROM 1933 auf gedeckt.

'Bei vielen Fischen ist bekanntlich die Wirbelzahl in nördlichen Gebieten höher als in südlichen. Insbesondere gelangt JOH. SCHMIDT (1930) zu dem Ergebnis, daß beim Kabeljau des Nordatlantischen Ozeans eine Beziehung zwischen der Wassertemperatur und der Wirbelzahl der Kabeljaubevölkerung des betr. Mecresgebiets besteht. KANDLER findet Beziehungen zwischen der Wassertemperatur verschiedener Mecresteile und der Zahl der Analflossenstrahlen der dort heimischen Schollenbestände. Einen Einfluß der Temperatur auf die Zahl der Analflossenstrahlen der Schollen nimmt auch TANING für das Gebiet um Island an. Bemerkenswert ist es, daß JENSEN gleichfalls eine Korrelation zwischen der Wassertemperatur zur Zeit der Larvenentwicklung der Schollen des Hornsriffgebiets und der Durchschnittszahl der Analflossenstrahlen bei den Jahrgängen nachweist. Diese Korrelation ist aber positiv: Hier geht die höhere Temperatur mit der höheren Zahl des meristischen Merkmals Hand in Hand, während sonst die höhere Temperatur mit der geringeren Wirbel- und Strahlenzahl verknüpft war.

Das vorliegende Material von Wirbelzählungen eignet sich nur wenig für eine Korrelationsberechnung. Es sind nur 7 Jahrgänge untersucht worden. Von 1935 ist nur eine ganz kleine Probe vorhanden. Auch ist die Herkunft der Proben in den cinzelnen Jahren nicht ganz gleichmäßig. Unter diesen Umständen wird man ein brauchbares Ergebnis der rechnerischen Analyse nicht von vornherein erwarten dürfen. Ja, man wird Bedenken tragen, dem tatsählich sich einstellenden 'Befund allzu große Bedeutung zuzumessen, obwohl er völlig mit den Erwartungen übereinstimmt. 
Zunächst wurde die durchschnittliche W irbelzahl eines jeden Jahrgangs mit den Temperaturen des Oberflächenwassers bei Helgoland verglichen, für die die Monatsmittel von GOEDECKE (1939) veröffentlicht worden sind. Es ergeben sich bei diesem Vergleich die folgenden Korrelationskoeffizienten:

$$
Z \text { ahlentaf el } 20 \text {. }
$$

Korrelation zwischen den Monatsmitteln der Oberflächentemperaturbei Helgoland und der durchschnittlichen Wirbelzahl der Heringslarven-Jahrgänge.

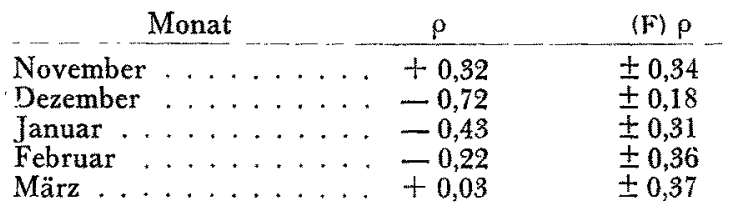

Eine merkwürdig gute Übereinstimmung der Variation ist hiernach für den Dezember festzustellen: je kälter das Wasser im Dezember. desto höher die Wirbelzahl. - Die gleichfalls negative Korrelation für die Januartemperatur en ist schon sehr zweifelhaft, für die November-, Februar- und Märztemperaturen ist keine Covariation nachzuweisen.

Indessen befinden sich die Larven, um deren Wirbelzahl es sich hier handelt, im Dezember und Januar noch gar nicht in der Deutschen Bucht. Die. festgestellte Covariation kann also höchstens darauf hindeuten, daß die Temperaturverhältnisse, die etwa die Wirbelzahl des Jahrgangs beeinflußt haben, im Wasser der Deutschen Bucht ähnlich zu spüren waren wie in den Gebieten, wo die Larven zur gegebenen Zeit an zutreffen waren.

Es wurde daher weiter der Versuch gemacht, die Temperatur der jeweiligen Aufenthaltsgebiete der Larven zum Vergleich heranzuziehen. Als Material dienten die im Bulletin hydrographique veröffentlichten Oberflächentemperaturen. Für die Flämische Bucht wurden monatsweise verschiedene Gradfelder gewählt, entsprechend dem normalen, nordostwärts gerichteten Transport der Larven. Für November und Dezember wurden die Temperaturen in dem Gradfeld $51^{\circ} \mathrm{N}$ und $2^{\circ} \mathrm{O}$, für Januar $52^{\circ} \mathrm{N}$ und $3^{\circ} \mathrm{O}$, für Februar $53^{\circ} \mathrm{N}$ und $4^{\circ} \mathrm{O}$ herangezogen. Die Berechnung ergab folgende Korrelationskoeffizienten:

$Z$ ahlent af el 21 .

Korrelation zwischender Oberflächentemperatur in der Flämischen Bucht und der durchschnittlichen Wirbelzahlder Heringslarven-Jahrgänge.

\begin{tabular}{|c|c|c|}
\hline Monat & $\rho$ & (F) $\rho$ \\
\hline $\begin{array}{l}\text { November } \ldots \ldots \ldots \\
\text { Dezember } \ldots \ldots \\
\text { Januar } \ldots \ldots\end{array}$ & $\begin{array}{l}+0,20 \\
-0,57 \\
-0,55 \\
-0,38\end{array}$ & $\begin{array}{l} \pm 0,38 \\
\pm 0,25 \\
\pm 0,26 \\
\pm 0,32\end{array}$ \\
\hline
\end{tabular}

Wir finden also für Dezember und Januar auch hier eine Korrelation, deren Koeffizient immerhin mehr als doppelt so groß ist wie der zugehörige Standardfehler. Allerdings ist die Korrelation nicht so scharf wie die im. Dezember für die Deutsche Bucht festgestellte. Das deutet darauf hin, daß die Temperaturverhältnisse in der Flämischen Bucht nicht von ganz ausschlaggebendem Einfluß auf die Wirbelzahl der Bevölkerung ist, die später in der Deutschen Bucht vorhanden ist.

Das Gebiet, in dem sich die Larven der mittleren Nordsee in den einzelnen Wintermonaten aufhalten, kann nicht so genau umschrieben werden, und die Temperaturangaben sind auch sehr spärlich. Es wurden deshalb für den Vergleich in allen Monaten die Temperaturen in den Gradfeldern $53^{\circ}$ und $54^{\circ} \mathrm{N}$ und $2^{\circ}$ bis $4^{\circ} \mathrm{O}$ herangezogen. Hier findet man folgende Korrelationskoeffizienten:

$$
Z \text { ahlentafel } 22 \text {. }
$$

Korrelation zisischen der Temperatur in dermittleren Nordsee und der durch-

\begin{tabular}{|c|c|c|}
\hline Monat & $p$ & (F) $p$ \\
\hline $\begin{array}{l}\text { November } \\
\text { Dezember }\end{array}$ & $\begin{array}{l}+0,28 \\
-0,80\end{array}$ & $\begin{array}{l} \pm 0,35 \\
\pm 0,14\end{array}$ \\
\hline Januar ... & $-0,36$ & $\pm 0,33$ \\
\hline
\end{tabular}
schnittlichen Wirbelzahl der Heringslarven-Jahrgänge.

Für das Gebiet der mittleren Nordsee, in dem die Doggerbanklarven sich um die Jahreswende aufhalten, ergibt sich hiernach für den Dezember eine sehr scharfe negative Korrelation der Wirbelzahl mit der Wassertemperatur (Abb. 7$)$. 


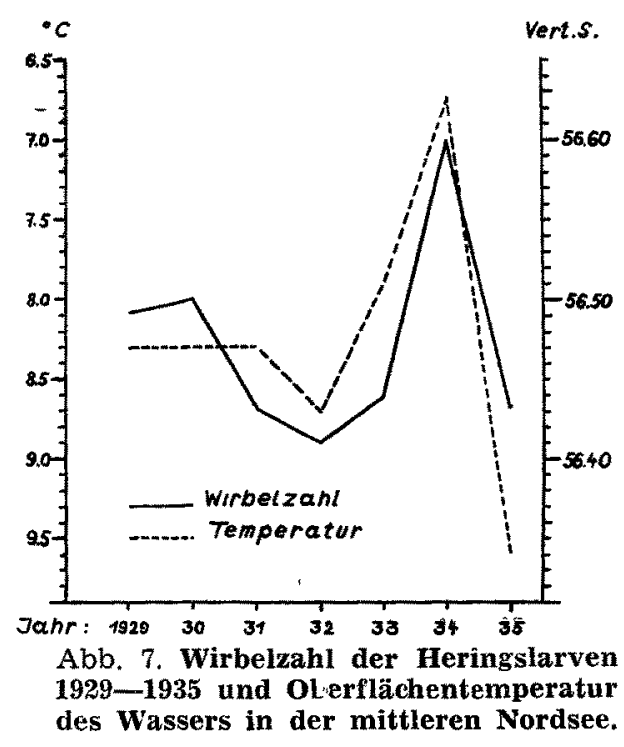

Es wäre bedenklich, wollte man diese Analyse noch weitertreiben und noch weitergehende Schlüsse daraus ziehen. Immerhin besteht unzweifelhaft eine gewisse Wahrscheinlichkeit dafür, daß die Wirbelzahl mit der Wassertemperatur, der die Larven während einer gewissen Zeit ihrer Entwicklung ausgesetzt waren, in Beziehung steht. Vielleicht wird sie unmittelbar durch die 'Temperatur beeinflußst. Die Korrelation ist nachzuweisen für die mittlere Nordsee im Dezember, für die Flämische Bucht im Dezember und Januar. Zu dieser Zeit hat bei der großen Masse der Larven die Knochenbildung noch nicht eingesetyt, vielmehr befinden sie sich noch auf dem Stadium der Knorpelbildung. Da nach den obigen Angaben über die Entwicklung des Skeletts dic Wirbelbildung von den Ansatgstellen der knorplig präformierten Haemalbögen aus erfolgt, war etwas Derartiges zu erwarten. Allerdings hätte man für die Larven der mittleren Nordsee vielleicht eine bessere Covariation bereits im November erwartet, zu der Zeit, wo bei ihnen die Knorpelbildung beginnen dürfte. Für diesen Monat bestehen aber während der 7 Untersuchungsjahre überhaupt nur sehr geringe Temperaturdifferenzen. Erst mit der schnelleren Abkühlung im Dezember wird der thermische Charakter des Herbstes festgelegt.

Um die hier nur mit Vorbehalt vorgetragenen Folgerungen auf ihre Stichhaltigkeit zu prüfen, empfiehlt es sich, einen Versuch über die Abhängigkeit der Wirbelzahl des Herings von der Wassertemperatur während der Entwicklung durch Aufzucht einheitlichen Materials bei verschiedener Temperatur zu machen. Dadurch wird die Frage exakt entschieden werden können. Statistische Untersuchungen über die Wirbelzahl von in See gefangenen Larven müßten, um weiter zu führen, in sehr großem Umfange und lange Zeit hindurch fortgeführt werden. Für andere, praktisch wichtige Fragen würden sie dagegen von geringer Bedeutung sein. So würde man dadurch, wie gezeigt, keinen Aufschluß über die Herkunft der Larven erhalten. Auch würden sie zu den Zählungen an den erwachsenen Heringen aus den befischten Schwärmen nur mit großem Vorbehalt in Beziehung gesetzt werden können, da mit einer Veränderung der Variation durch selektive Zehrung gerechnet werden muß.

Es schien nicht ratsam, die Schwankungen der Wirbelzahl der Jahrgänge noch mit denen anderer Faktoren des Lebensraumes zu vergleichen, um gegebenenfalls weitere Beziehungen aufzudecken. Beim Salzgehalt z. B. sind die vorkommenden Differenzen allzu gering. Eine Korrelationsberechnung würde infolgedessen ein noch weniger verläßliches Bild ergeben, als wir es bei der Temperatur erhielten.

\section{Zusammenfassung}

Der vorliegende zweite Teil der Untersuchungen über die Ökologie der Heringsbrut befaßt sich mit den Fängen von Heringslarven, die in dem Gebiet von Helgoland und der Elbeund Jademündung in den Monaten November bis Mai der Jahre 1926/27 bis 1933/34 gemacht worden sind. Diese Fänge sollten Auskunft über Zeit und Art des Eintreffens der Heringslarven an der Küste 'sowie über Menge und Größe der Larven geben. In der Absicht, Aufschlüsse über die Herkunft der Larven zu erhalten, wurden Wirbelzählungen an einem Teil des Materials und an ergänzenden Proben von Forschungsfahrten des "Poseidon" vorgenommen. Die Ergebnisse sind folgende:

1. Einzelne Heringslarven erscheinen schon im Herbst (November) an den Küsten der inneren Deutschen Bucht. In größerer Zahl aber sind sie bei Helgoland erst von Februar, näher an der Küste erst von Anfang März und in den inneren Teilen des Wattenmeeres erst von Ende März an zu fangen.

2. Die Tatsache, daß eine Beziehung zwischen den hydrographischen Verhältnissen und dem Auftreten (Menge und Tiefenverbreitung) der Heringslarven bei Helgoland nicht beste'it, läßt erkennen, daß es sich bei dem Aufcuchen der Küste nicht mehr um passiven Transport der Heringslarven durch die Strömung, sondern um eine aktive Wanderung handelt.

3. Bei dieser Wanderung bevorzugen die Heringslarven die oberen Wasserschichten (Tagfänge!), wenn sie auch die Tiefe nicht meiden, und dringen dabei schnell in das salkärmere Küsten- und Brackwasser (bis unter 10\%) ein.

4. Bei der Küstenwanderung gehen die größten Individuen voran, so daß sich eine Größenstaffelung von Helgoland nach der Küste zu ausbildet. Die Unterscheidung der Herkunft 
der Heringslarven nach ihrer Größe, wie sie in der offenen See bis zum März möglich ist, ist daher im Küstengebiet unmöglich.

5. In den inneren Teilen des Wattenmeeres sammeln sich die vor der Metamorphose stehenden Heringslarven in großer Zahl an. Große Ungleichmäßigkeiten in der Fangmenge lassen erkennen, daß die Tendenz zur Schwarmbildung einsetzt. Jungheringe nach der Metamorphose werden vom Knüppelneţ nur selten und mehr zufällig gefangen.

6. Die Larvenfänge waren in den Jahren $1927 / 28,1929 / 30$ und 1930/31 verhältnismäßig groß, 1931/32 und vor allem 1933/34 besonders gering, 1926/27, 1928/29 und 1932/33 mittelmäßig.

7. Im Jahre 1927/28 waren die Larven besonders klein, 1931/32 besonders groß. Auch 1932/33 und 1933/34 waren sie über Durchschnitt groß. Die Wahrscheinlichkeit spricht dafür, daß häufiges Vorkommen von Larven aus der Flämischen Bucht die Durchschnittslänge der Larven in der inneren Deutschen Bucht herabseţt, Mangel an diesen Larven sie dagegen erhöht. Dann wären außer dem Winter 1933 auch die von 1932 und 1934 arm an Larven aus der Flämischen Bucht gewesen.

8. Die Larvenfänge im Küstengebiet sind wenig geeignet, ein zuverlässiges Bild von der Larvenversorgung der. Deutschen Bucht in den einzelnen Jahren zu geben.

9. Bei den Wirbelzählungen an Heringslarven bestätigte sich die ursprüngliche Erwartung nicht, daß die kleinsten und am spätesten eintreffenden, mithin jüngsten Larven des Jahres durch höhere Wirbelzahl eine Beimischung von Heringen des Kanaltyps erkennen lassen würden.

10. Während das Material der, einzelnen Jahre sich hinsichtlich der Wirbelzahl als ziemlich éinheitlich erwies, bestanden bezeichnende Unterschiede zwischen den einzelnen Jahrgängen.

11. Die Variation in der Zahl der Wirbelkörper bei den Proben der Heringslarven wich erheblich von der Variantenverteilung des Fehlergesetzes ab: sie war stark übergipflig. Diese Abweichung nimmt mit der Größe der Larven etwas ab. Bei metamorphosierten Heringen ist nach BuChaNAN-WOLLASTON die Übereinstimmung mit der Fehlerkurve befriedigend.

12. Während der ganzen Untersuchungszeit haben stets die größeren Larven im Durchschnitt höhere Wirbelzahl.

13. Die unter 11. und 12. festgestellten Erscheinungen lassen sich kaum anders als durch die Annahme erklären, daß im Laufe der Entwicklung und Metamorphose ein Teil der extremen Varianten, und zwar vorzugsweise der Minusvarianten, selektiv ausgemerzt wird.

14. Zwischen der durchschnittlichen Wirbelzahl der Larvenjahrgänge und der Wassertemperatur im Verbreitungsgebiet der Larven um die Jahreswende (Dezember, bzw. Døzember und Januar) besteht eine teilweise recht scharfe Covariation. Die Vermutung, daß die. Wassertemperatur während der Entwicklungszeit einen Einfluß auf die Wirbelzahl ausübt, wird dadurch nahegelegt. Eine experimentelle Prüfung ist erwünscht.

15. Komplexbildungen, bei denen die Zahl der Spinal- bzw. Haemalfortsätze größer ist als die der Wirbelkörper, kamen bei $20 \%$ der Heringslarven vor. In mehr als $80 \%$ dieser Fälle ist nur dorsal ein überzähliger. Fortsatz vorhanden, in $19 \%$ sowohl Spinal- als Haemalfortsatz, sehr selten ist nur der Haemalfortsatz überzählig; dann ist ein überzähliger Spinalfortsatz mit dem normalen verschmolzen.

16. Der überzählige Spinalfortsatz kann aut dem letzten Wirbel vor dem Urostyl oder auf dem vorletzten oder zwischen beiden ansetzen. Der überzählige Haemalfortsatz setzt fast ausnahmslos an dem vorletzten Wirbel vor dem Urustyl an.

17. Ist ein überzähliger Haemalfortsatz vorhanden, so ist er fast stets mit dem benachbarten verschmolzen oder ihm ganz dicht angelagert.

18. Bei Individuen mit überzähligem Haemalfortsatz ist der vorletzte Wirbel vor dem Urostyl stets beträchtlich verlängert. Der Ansatzpunkt des überzähligen Spinalfortsatzes dagegen scheint seinerseits abhängig von den Längenverhältnissen der letzten Wirbel zu sein.

19. Die Entwicklung des Schwanzskeletts wird geschildert. Im Schwanzstiel werden dic knorpligen Spinal- und Haemalbögen und -fortsätze im Gegensatz zum Rumpfabschnitt mächtig entwickelt. Offenbar haben sie eine erhabliche funktionelle Bedeutung. Nach den Hypuralknorpeln erscheinen zuerst die caudalen Haemalfortsätze, von denen der letzte in enge Beziehung zur Schwanzplatte tritt. Die Vorhergehenden schließen sich lückenlos parallel an. Wenig später erscheinen die caudalen Spinalfortsätze. Komplexbildungen kann man zum allergrößten Teil schon auf diesen frühen Stadien erkennen. Man kann sie daher nicht gut als den bei der Wirbelbildung übrigbleibenden, unvollkommen angegliederten Rest der Anlage auffassen. 
20. Zwischen dem aufgebogenen Ende des Urostyls und dem letzten Spinalfortsatz besteht anfangs eine Lücke, die erst bei der etwa $27 \mathrm{~mm}$ langen Larve durch Auswachsen des Fortsatzes nach hinten bis über die Epuralia geschlossen wird. Wahrscheinlich erfordert die Beanspruchung des Schwanzstielskeletts, daß in gewissen Fällen hier ein überzähliger Fortsatz eingeschoben wird, damit die Lücke nicht zu groß wird. Ob der überzählige Spinalfortsatz einer ursprünglich vorhandenen Segmentanlage entspricht oder nicht, konnte auch bei Berücksichtigung anderer metamerer Anlagen, der Myosepten und Spinalganglien, nicht einwandfrei entschieden werden.

21. Während im Rumpf die erste Knochenanlage der Wirbelkörper ringförmig ist, beginnt die Verknöcherung der Schwanzstielwirbel offenbar von der Ansatzstelle der Haemalbögen her. Die Verknöcherungszone erreicht erst mit der Zeit anfangs nur in geringer Breite den oberen Rand der Chorda. Da die Ansatzpunkte der oberen Bögen somit keinen Einfluß auf die Bildung der Wirbelkörper haben, wird die Veränderlichkeit des Ansatzpunktes der überzähligen Spinalfortsätze begreiflich.

22. Die Zahl der Wirbelkörper im. Schwanzabschnitt ist hiernach von der Zahl der Haemalbögen abhängig. Sind aber benachbarte Haemalbögen miteinander verschmolzen, was nicht sehr selten der Fall ist, oder sind sie doch allzu nahe aneinander gelagert, so kann eine Wirbelgrenze zwischen ihren Ansatzpunkten nicht entstehen. Es wird dann ein verlängerter Wirbel körper mit zwei Haemalfortsätzen gebildet. Daß dies im allgemeinen nicht den letzten Haemalfortsatz betrifft. ist darauf zurückzuführen. daß dieser frühzeitig ausgebildet wird und eine besondere Stützfunktion für die Schwanzplatte hat.

23. Daß die Individuen mit überzähligem Spinalfortsatz im Durchschnitt eine geringere Wirbelzahl als die normalen Individuen haben, wird wie folgt erklärt: Die Ausbildung eines überzähligen Fortsatzes ist funktionell bedingt und wird bei solchen Individuen notwendig, wo während der Entwicklung eine zu große Lücke zwischen dem Urostylende und den Spinalfortsätzen besteht. Dies ist vorwiegend bei Individuen mit geringer Zahl von Haemalfortsätzen und in der Folge auch von Wirbelkörpern - der. Fall.

24. Daß die Individuen mit überzähligen Spinal- und Haemalfortsätzen im Durchschnitt eine geringere Wirbelzahl als die normalen Individuen haben, ist die Folge davon, daß hier zwei Haemalbögen nur einem Wirbelkörper Entstehung geben. Die dichte Lagerung bzw. Ver schmelzung der benachbarten Haemalbögen tritt aber vorzugsweise bei Individuen mit hoher Zahl von Haemalbögen ein. Deshalb wird die durchschnittliche Zahl der Wirbelkörper dieser Individuen nicht um einen ganzen Wirbel geringer als die normalen, sondern nur etwa um einen halben. 


\section{Schriftenverzeichnis}

(Vergleiche außerdem das Schriftenverzeichnis im I. Teil diẹser Arbeit, diese Zs., Seite 56/57)

BUCHANAN-WOLLASTON, H. J., 1933. Some Modern Statistical Methods: their Application to the Solution of Herring Race Problems. J. Conseil int. Expl. Mer. Vol. VIII No. 1. 1933.

BÜCKMANN, A., 1929. Die Methodik fischereibiologischer Untersuchungen an Meeresfischen. In: Handb. Biol. Arbeitsmeth. herausgeg. v. E. Abderhalden. Abt. IX. Teil 6. S. 1-194. 1929

Bulletin hydrographique pour les années 1929-1935. Conseil Internat. pour l'Expl. de la Mer. Kopenhagen.

DANNEVIG, ALF,, 1933. The number of vertebrae in Gadus virens L. from the Norwegian Skagerrak coast. J. Conseil int. Expl. Mer. Vol. VIII No. 3. 1933.

FORD, E., 1933. The "Number of Vertebrae“ in the Herring and its Variation. J. Conseil int. Expl. Mer. Vol. VIII. S. 211. 1933 .

FORD, E., 1937. Vertebral Variation in Teleostean Fishes. J. Mar. Biol. Assoc. U. K. Vol. XXII. 1937.

GOEDECKE, E., 1939a. Beitrag zur Hydrographie der Helgoland umgebenden Gewässer- I. Die Oberllächen verhältnisse bei Helgoland Reede. Ann. Hydr. Mar. Meteorol. 1939. S. 161.

GOEDECKE, E., 1939b. Beitrag zur Hydrographie der Helgoland umgebenden Gewässer II. Die mittleren hydrographischen Verhältnisse bei den Helgoländer Terminstationen. Ann. Hydrogr. Mar. Meteorol. 1939 H. V. S. 224.

JENSEN, AAGE J. C. 1939. Fluctuations in the Rac ial Characters of the Plaice and the Dab. J. Conseil int. Expl. Mer, Vol. XIV. No. 3. 1939.

JOHANNSEN, W. Elemente der exakten Erblichkeitslehre. 3. Aufl. Jena 1926.

KANDLER, R., 1932. Unsicherheiten bei der Bestimmung der Wirbelzahl infolge Verwachsungserscheinungen. J. Conseil int. Exp1. Mer. Vol. VII. S. 373-38.5. 1932.

KANDLER, R., 1935. Rassenkundliche Untersuchungen an Plattfischen I. Variabilitätsstudien an den Flossenstrahlen- und Wirbelzahlen der Ostseeschollen. Ber. Dtsch. wiss. Kornı. Meeresforsch. N. F. Bd. VII. Heft 4. 1935. S. 381-493.

KOTTHAUS, A, 1936. Rassenuntersuchungen an Heringslarven aus der Deutschen Bucht. M. S.

KOTTHAUS, A., 1939. Zuchtversuche mit Heringslarven (Clupea harengus L). Helgol. wiss. Meeresunters Bd. I. H. 3. S. 349-358. 1939.

POULSEN, E. M., 1932. On the spawning-places of the Herring in certain parts of the North Sea, the Skagerrak and the Kattegat in the Autumn of 1930 and some earlier Years. Meddel. fra Komm. for Danm. Fiskeri- og Havunders. Ser. Fisk. 9; 4 .

ROUNSEFELL, G. A., 1932, and DAHLGREN, E. H. Fluctuations in the supply of herring, Clupea pallasii, in Prince William Sound, Alaska. U. S. Bur. Fisheries 47, Bull. No. 9. 1932.

RUNNSTROM, S., 1933. Uber die Rassenverhältnisse beim Norwegischen Frühjahrshering mit́ besonderer Berücksichtigung der Konstanz der Rassenmerkmale. J. Conseil int. Expl. Mer. VIII, 2, 235-249. 1933.

SCHACH, H., 1939. Die künstliche Aufzucht von Clupea hareng. Helgoländer Wiss. Meeresunters. Bd. I. H. 3. 1939.

SCHAUINSLAND, H. Die Entstehung der Wirbelsäule nebst Rippen und Brustbein. In: Handbuch der vergleichenden und experimentellen Entwicklungslehre der Wirbeltiere von Oskar Hertwig. 3. Band. 2. Teil.

SCHMIDT, JOHS., 1930. The Atlantic Cod (Gadus callarias L. and Local Races of the same. Compt. Rend. d. Trav. du Labor. Carlsberg Bd. 18.

SCHNACKENBECK, W., 1930. Entwicklungsgeschichtliche und morphologische Untersuchungen am Hering. Be: Deutsch. wiss. Komm. f. Meeresforschung. N. F. Bd. V. H. 2.

TESTER, TA. L., 1938. Variation in the Mean Vertebral Count of Herring (Clupea palasii) with Water Temperature. J. Conseil int. Expl. Mer. Vol. XIII, 1, 71-75. 1938. 